\title{
Connectedness in times of ecological overshoot
}

\author{
Citation for published version (APA):
}

Figge, L. S. (2017). Connectedness in times of ecological overshoot: a quantitative analysis of the sustainability of globalization. [Doctoral Thesis, Maastricht University]. Datawyse / Universitaire Pers Maastricht. https://doi.org/10.26481/dis.20170929lf

\section{Document status and date:}

Published: 01/01/2017

DOI:

10.26481/dis.20170929lf

Document Version:

Publisher's PDF, also known as Version of record

\section{Please check the document version of this publication:}

- A submitted manuscript is the version of the article upon submission and before peer-review. There can be important differences between the submitted version and the official published version of record.

People interested in the research are advised to contact the author for the final version of the publication, or visit the DOI to the publisher's website.

- The final author version and the galley proof are versions of the publication after peer review.

- The final published version features the final layout of the paper including the volume, issue and page numbers.

Link to publication

\footnotetext{
General rights rights.

- You may freely distribute the URL identifying the publication in the public portal. please follow below link for the End User Agreement:

www.umlib.nl/taverne-license

Take down policy

If you believe that this document breaches copyright please contact us at:

repository@maastrichtuniversity.nl

providing details and we will investigate your claim.
}

Copyright and moral rights for the publications made accessible in the public portal are retained by the authors and/or other copyright owners and it is a condition of accessing publications that users recognise and abide by the legal requirements associated with these

- Users may download and print one copy of any publication from the public portal for the purpose of private study or research.

- You may not further distribute the material or use it for any profit-making activity or commercial gain

If the publication is distributed under the terms of Article $25 \mathrm{fa}$ of the Dutch Copyright Act, indicated by the "Taverne" license above, 


\title{
Connectedness in times of Ecological Overshoot:
}

\author{
A quantitative analysis of the \\ sustainability of globalization
}

Lukas Figge 
(C) copyright Lukas Figge, Maastricht 2017

All rights reserved. No part of this publication may be reproduced, stored in a retrieval system or transmitted in any form, or by any means, electronic, mechanical, photocopying, recording or otherwise, without the prior permission in writing from the author.

Printing: Datawyse | Universitaire Pers Maastricht

ISBN 9789461597458

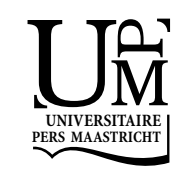




\title{
Connectedness in times of Ecological Overshoot:
}

\section{A quantitative analysis of the sustainability of globalization}

\author{
DISSERTATION \\ to obtain the degree of Doctor at Maastricht University, \\ on the authority of the Rector Magnificus, Prof. Dr. Rianne M. Letschert \\ in accordance with the decision of the Board of Deans, \\ to be defended in public \\ on Friday, 29 September 2017, at 10.00 hours
}

by

Lukas Simeon Figge 


\section{Supervisor}

Prof. dr. Pim Martens

\section{Co-supervisor}

Dr. Astrid Offermans

\section{Assessment Committee}

Prof. dr. Marc Davidson (Maastricht University, Chair)

Prof. dr. Harro van Lente (Maastricht University)

Prof. dr. Noel Gaston (Adelaide, South Australia)

Dr. Axel Marx (KU Leuven) 



\section{CONTENTS}

$\begin{array}{lll}\text { Chapter } 1 & \text { Introduction } & 1\end{array}$

1 Sustainable globalization 3

1.1 Background and context 5

1.2 Research aims, objectives and research questions 10

1.3 Research strategy and key methodologies 11

$\begin{array}{ll}1.4 \text { Outline of the thesis } & 12\end{array}$

Chapter $2 \quad$ New directions in globalization indices 15

2 Introduction 17

2.1 Globalization and its measurement 18

2.2 Concepts to be measured 19

2.3 Dimensions of measurement 22

2.4 Unit of measurement 24

2.5 A way forward $\quad 27$

Chapter 3 Globalization continues: The Maastricht Globalization 29 Index revisited and updated

3 Introduction $\quad 31$

3.1 Components of the MGI 32

3.2 Calculation of the MGI 37

3.3 Results 41

3.4 Discussion and conclusions $\quad 48$

$\begin{array}{lll}\text { Chapter } 4 & \text { The effects of globalization on Ecological Footprints: an } \quad 49\end{array}$ empirical analysis using the Maastricht Globalization Index

4 Introduction 51

4.1 Literature review $\quad 52$

4.2 Method and data $\quad 55$

4.3 Results and discussion $\quad 59$

4.4 Conclusions 64

Appendix $4 \quad 65$ 
5 Introduction

5.1 Literature review and hypotheses $\quad 73$

5.2 Methods $\quad 77$

5.3 Results 83

5.4 Discussion and conclusions 88

$\begin{array}{ll}\text { Appendix } 5 & 91\end{array}$

$\begin{array}{lll}\text { Chapter } 6 & \text { The sustainability of globalization: } & 97\end{array}$

Including the 'social robustness criterion'

6 Introduction: sustainable globalization? 99

6.1 The social robustness criterion and Cultural Theory $\quad 100$

6.2 Methods $\quad 104$

6.3 Results 109

6.4. Discussion and conclusions 113

$\begin{array}{ll}\text { Appendix } 6 & 115\end{array}$

$\begin{array}{lll}\text { Chapter } 7 & \text { Conclusion, Discussion \& Epilogue } & 117\end{array}$

7.1 Conclusion: What have we learned? 119

7.2 Discussion 124

$\begin{array}{ll}7.3 \text { Epilogue } & 128\end{array}$

$\begin{array}{ll}\text { References } & 129\end{array}$

$\begin{array}{ll}\text { Summary } & 137\end{array}$

Valorization addendum $\quad 140$

$\begin{array}{ll}\text { Acknowledgements } & 144\end{array}$

$\begin{array}{ll}\text { About the author } & 146\end{array}$ 
"Science of the past is a description, for the future a belief; it is not and has never been, an explanation, if by this word is meant that science shows the necessity of any sequence of perceptions"

Karl Pearson, mathematician and statistician 
CHAPTER 1

\section{Introduction}


"The trends that are shaping the twenty-first-century world embody both promise and peril. Globalization, for example, has lifted hundreds of millions of people out of poverty while contributing to social fragmentation and a massive increase in inequality, not to mention serious environmental damage."

Klaus Schwab, founder and executive chairman of the World Economic Forum 


\section{Sustainable globalization}

Sustainable Development which is defined as "development that meets the needs of the present while safeguarding Earth's life support system, on which the welfare of current and future generations depends" (Griggs et al., 2013), remains one of the greatest challenges for humanity in the $21^{\text {st }}$ century. According to the Ecological Footprint Atlas (Ewing et al., 2010), we have lived in a state of ecological overshoot since the 1970s, which means that human demands have exceeded the Earth's biocapacity (WWF (2014) and Fig 1.1). ${ }^{1}$ Human demands alter ecosystems by creating ecological pressures such as land-use changes, resource extraction and depletion (such as deforestation and overfishing), emissions of waste and pollution and the modification and movement of organisms (Steffen et al., 2005; UNEP, 2012a). The resulting environmental impacts on Earth's life support system include, but are not limited to, climate change, land degradation, loss of biodiversity, and pollution. Consequences on humans affect primarily the very poor and vulnerable populations in developing countries through, for instance, famine, water shortages, and competition over resources (Field et al., 2014).

The same period has experienced increasing globalization (See figure 1.1). Since the 1950s, economic exchange, institutional change, political affairs and the global environment have become increasingly inter-twined across various dimensions of human relations. Increased global economic integration is manifesting itself in greater international movement of goods and services, financial capital, information and people. Advances in communication, transportation and mobility technologies result in greater international cultural exchanges, and promote cultural diversity both within and between countries. Migration, both legal and illegal, and tourism further contribute to the $21^{\text {st }}$ century socio-cultural melting pot. New and enhanced forms of governance, legal systems and institutions come into existence, which often transcend nation-states, connecting people in novel ways.

According to Jones (2010), there is agreement among key thinkers that contemporary globalization is the continuation of long-term developments of increasing societal integration at the global level while also exhibiting features that are qualitatively different from previous times. In the broadest sense, globalization is defined as "the growing interconnectedness and inter-relatedness of all aspects of society" (Jones, 2010). Add-

\footnotetext{
${ }^{1}$ In 2013 the total global Ecological Footprint was 20 billion gha, with an EF per capita of 2.87 gha and biocapacity only 12 billion gha or 1.71 gha per capita, data available at http://data.footprintnetwork.org/ Empirically, the overshoot is the carbon dioxide that is not taken up by land and hence contributes to athmospheric degradation and climate change. In 2017, Earth Overshoot Day was on 02 August.
} 
ing trans-dimensionality and trans-scalarity, we define contemporary globalization as "the intensification of cross-national interactions that promote the establishment of trans-national structures and the global integration of cultural, economic, ecological, political, technological and social processes on global, supra-national, national, regional and local levels" (Rennen \& Martens, 2003).

Figure 1.1: global trends in Globalization and Ecological Footprint for the 1961 - 2013 period

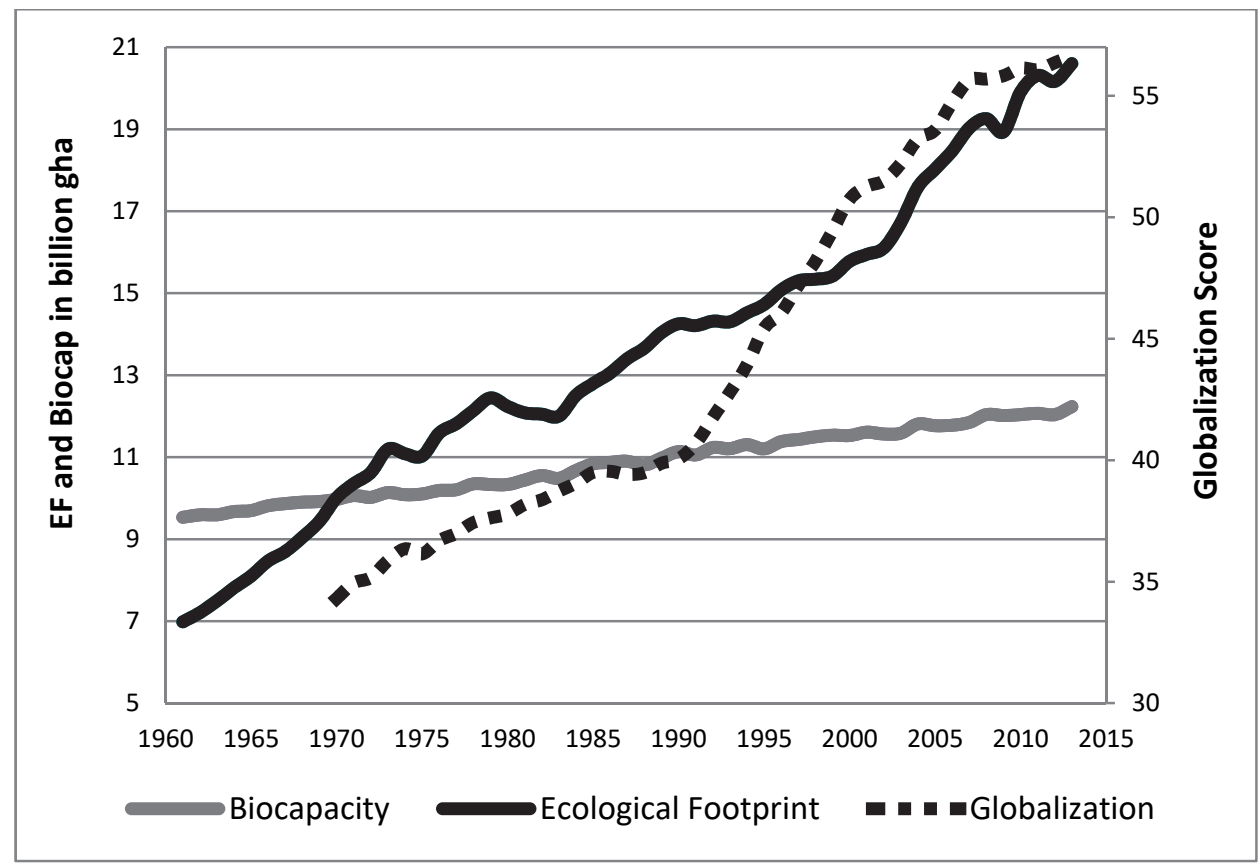

Note: global EF and biocapacity measured in gha (billion), difference between EF and biocapacity is the ecological overshoot; Globalization is the global average score as measured by the KOF index, the scales of the axis are adjusted; Data from data.footprintnetwork.org and globalization.kof.ethz.ch respectively

This "trans-" approach enables us to perceive globalization as a phenomenon, or process in which many different processes simultaneously operate across, beyond and through many domains and scale levels ${ }^{2}$ (Martens \& Rotmans, 2005, 2002). Hence, processes and structures at different scales, i.e. the global, international, regional, national and sub-national and in different dimensions, i.e. the economic, social, cultural, ecological, political and technological are seen to be interconnected and co-evolving. Nevertheless, researchers have often boiled the phenomenon down to singular dimen-

${ }^{2}$ Sometimes the prefix 'multi-' will be used and sometimes 'trans-'. 'Multi-' means many, or consisting of more than one, whereas 'trans-' goes further and implies that these many (domains or scales) are also (causally) inter-related. Multi-dimensional and mutli-scalar approaches are often the best first step towards trans- approaches. 
sions, thereby negating trans-dimensionality. For instance, globalization has been described as the growing integration of markets and nation-states and the spread of technological advancements (Friedman, 1999), receding geographical constraints on social and cultural arrangements (Waters, 1995), the increased dissemination of ideas and technologies (Albrow, 1996), the threat to national sovereignty by trans-national actors (Beck, 2004), or the transformation of the economic, political and cultural foundations of societies (Mittelman, 2000).

Discussing the relationship of globalization and ecological sustainability, many scholars have no doubt about the degrading impact of globalization on the global environment. This is highlighted by Borghesi and Vercelli (2003, p. 82), who state that "A long-term correlation between the recent processes of globalization of international markets and environmental degradation is quite evident [... and ...] so uncontroversial that, for the sake of brevity, we do not need to document it here." At the same time, competing claims exist that "globalization is in fact good for the environment" (Stern, 2004, p. 1428). Employing trans-dimensional approaches of globalization and human demands provides the possibility of systematically assessing this complex relationship without risking problems of multicollinearity and omitted variable bias in empirical work (Dreher et al., 2008).

\subsection{Background and context}

Trans-scalarity and trans-dimensionality make globalization, and more specifically the quantitative assessment thereof, a challenging endeavor. This is for three main reasons: first, there are many (other) competing definitions and conceptualizations. Second, it is difficult to measure and to operationalize. Third, the topic is very normative - a diversity of cultural perspectives causing polarization and disagreement. We now turn to discuss the issues in more depth and show how they are inter-related.

Measurement and quantitative assessment of globalization and its consequences on sustainability is important to provide empirical facts for a debate that is ridden by conceptual ambiguity, and ambivalent causal claims. One powerful tool to measure, illustrate, monitor and communicate the complexity and trans-dimensionality inherent to globalization are Globalization Indices (GI). Gls allow for a relative ranking or comparison of country performance (OECD, 2008) with respect to globalization trends and processes, on the basis of indicators. However, Gls are clearly not free of controversies. Given the considerable stakes involved in the use (and potential misuse) of Gls, it is vital to place their measurements under careful critical examination. Invariably, all of these measures face contentious methodological questions and choices. Some of the more positivist authors claim that objective measurement is possible/realistic (e.g. 
Ghemawat \& Altman, 2016; Potrafke, 2014), while others acknowledge the constructivist nature of composing any such index. Nevertheless, core issues for Gls include the specific concept of globalization adopted, the selection of dimensions and the units (countries or other entities) whose globalization is being assessed. To continue this discussion (De Lombaerde \& lapadre, 2008; Dreher, Gaston, \& Martens, 2008; Dreher, Gaston, Martens, \& Van Boxem, 2010), which addresses those limitations in more depth, presents the first knowledge gap.

Two scientifically validated indices that have been used to assess the consequences of multi-dimensional globalization are the Maastricht Globalization Index (MGI) (Martens \& Raza, 2009; Martens \& Zywietz, 2006c) and the KOF index of globalization (the latter index was developed at the KOF Swiss Economic institute and KOF is the acronym for the German word 'Konjunkturforschungsstelle' which means business cycle research institute) (Dreher, 2006; Dreher et al., 2008) (see Table 1.1 for a comparison of the MGI and KOF index). While the KOF Index is available for up to 207 countries over the period 1970 - 2013, the MGI has been available only for 117 countries and two points in time: 2000 and 2008. Missing recent data, especially for the MGI beyond 2008 presents a second knowledge gap. Other globalization indices have been developed, but are not further considered at this moment, as they do not fulfill the following criteria: a) recently updated, b) published in peer-reviewed journals, c) available for more than one year and more than 100 countries and/or d) used to assess the consequences of globalization. Some of them will be mentioned later in the thesis. For a recent overview of nine GIs (including the MGI and KOF index) we refer to Guo and Schwarz (2016).

Previous indices usually praised those countries which have been most globalized, implying that being more globalized is a desirable outcome, since it contributes to socioeconomic development (Dreher, et al., 2008). However, being more globalized does not necessarily imply positive outcomes as illustrated by the Maastricht Globalization Index (MGI) which, for example, includes the Ecological Footprint as a measure of ecological globalization (Martens \& Raza, 2009; Martens \& Zywietz, 2006c). This means that a more globalized country puts larger pressures on ecosystems, at home or elsewhere, which is undesirable from a sustainability perspective. Therefore, the most globalized countries are not necessarily the most sustainable countries. Gls by themselves do not say anything about the effects or consequences of globalization and are unable to conclude whether globalization is sustainable or not; other approaches are needed.

Sustainable development is often seen as having three 'pillars': the economic, social and environmental/ ecological (Kemp \& Martens, 2007; Martens, 2006). The social dimension includes health, justice, equity, equality and education. The economic dimension includes affluence, income, employment and wealth. Finally, the ecological dimension requires that socio-economic development does not threaten the integrity 
of ecological systems (Griggs et al., 2013). If globalization has decisive impacts on each of the three dimensions of sustainable development (in the sense of improving - making more sustainable) then it could be considered sustainable, while if it has negative consequences for one or more dimensions it may be considered unsustainable. This three pillar approach can be thought of as one criterion for judging the sustainability of globalization (Giddings, Hopwood, \& O'brien, 2002). What is the current evidence on globalization's consequences on sustainability?

In general we found that previous empirical work on the relationship between globalization and environmental pressures in many cases assesses only the economic dimension of globalization, such as the level of trade openness, or on single environmental pollutants (for the ecological pillar of sustainability) (Antweiler, Copeland, \& Taylor, 2001; Cole, 2004; Dreher et al., 2008; Lamla, 2009; York, Rosa, \& Dietz, 2003a). To our knowledge, there has been no peer-reviewed study that systematically analyzes the ecological consequences of globalization over time, addressing endogeneity concerns, which presents a third knowledge gap.

Two studies using the MGI have suggested that more globalized countries are also more sustainable (using various sustainability indices), and in general also healthier (Martens, Akin, Huynen, \& Raza, 2010b; Martens \& Raza, 2010). In addition, the more widely used KOF index has been applied in over one hundred empirical studies (Potrafke, 2014). The results of this review have suggested inter alia that contemporary globalization has exerted positive effects on economic growth and human rights, but negative effects on in-country inequality (Dreher et al., 2008; Potrafke, 2014). The overview by Potrafke (2014) reveals that the effects of globalization on human demands (ecological footprints) have been mostly neglected in the peer-reviewed KOF literature (not a single study is mentioned in this review that looks at ecological issues - our third knowledge gap). In their book on the consequences of globalization Dreher et al. (2008) show that in the long-term (taking a 30 year average) globalization has increasing effects on water pollution and round-wood production. They found no significant effects on carbon dioxide, sulfur dioxide and the environmental sustainability index. Further, they suggest that these results are mostly driven by economic globalization. Lamla (2009) investigates robust determinants of pollution (carbon dioxide, sulfur dioxide and biochemical oxygen demand) and considers, among other factors, overall globalization as an explanatory variable. He finds differing correlations for different pollutants in the long-run: positive (increasing) for carbon dioxide and negative for sulfur dioxide and biochemical oxygen demand (Lamla, 2009). Dreher et al. (2008, p. 167) conclude that "our answers to this most controversial of issues are suggestive and certainly not the last word on the matter. On the other hand, our results do not vindicate painting globalization as the bogeyman for the environment. Of course this conclusion awaits further scrutiny by other researchers". 
Table 1.1: Comparison of MGI and KOF index

\begin{tabular}{|c|c|c|}
\hline & $\begin{array}{l}\text { Maastricht Globalization Index } \\
\text { (before this thesis) }\end{array}$ & KOF Index of Globalization \\
\hline References & $\begin{array}{l}\text { a) Martens \& Zywietz, } 2006 \\
\text { b) Martens \& Raza, } 2009\end{array}$ & $\begin{array}{l}\text { a) Dreher, } 2006 \\
\text { b) Dreher et al., } 2008\end{array}$ \\
\hline $\begin{array}{l}\text { Data Coverage } \\
\text { Years } \\
\text { Countries } \\
\text { Indicators (total) }\end{array}$ & $\begin{array}{l}2000 \& 2008 \\
117 \\
11\end{array}$ & $\begin{array}{l}1970-2013 \\
207 \\
23\end{array}$ \\
\hline $\begin{array}{l}\text { Dimensions } \\
\text { (Indicators) }\end{array}$ & $\begin{array}{l}\text { Economic (3) } \\
\text { Socio-Cultural (2) } \\
\text { Technological (2) } \\
\text { Political (3) } \\
\text { Ecological (1) }\end{array}$ & $\begin{array}{l}\text { Economic (8) } \\
\text { Actual Flows (4) } \\
\text { Restrictions (4) } \\
\text { Social (11) } \\
\text { Personal Contact (5) } \\
\text { Information flows (3) } \\
\text { Cultural Proximity (3) } \\
\text { Political (4) }\end{array}$ \\
\hline Google citations & $\begin{array}{l}\text { a) } 81 \\
\text { b) } 23\end{array}$ & $\begin{array}{l}\text { a) } 1488 \\
\text { b) } 865\end{array}$ \\
\hline Applications & 7 & 153 \\
\hline Webpage & $\mathrm{N} / \mathrm{A}$ & http://globalization.kof.ethz.ch/ \\
\hline
\end{tabular}

Status: 14 January 2017

The results of empirical studies suggest that the trends and processes towards sustainable globalization are not uniform. Further, the quantitative assessment of the sustainability of globalization, even when composite indices are applied for analysis, is fraught with difficulties for the following reasons: complexities of the relationships involved, the lack of suitable data and methods, and the political nature of the subject matter (Borghesi \& Vercelli, 2003). The resulting empirical and methodological uncertainty means it is possible for proponents and opponents to argue for conflicting views whilst backing those views up with sound evidence. We argue that conflicting perspectives over the sustainability of globalization will continue to exist and shape the future of the process, despite more empirical evidence and greater perceived certainty about the impacts of globalization. As Sarewitz (2004) argues, sustainability controversies exist not because of a lack of knowledge necessarily but rather because of conflict over (cultural) values and interests. Sustainability remains inherently subjective and political (Banerjee, 2003; Castro, 2004; Robinson, 2004). Thus, in any sustainability issue, and even more so for globalization, people's perceptions of, and hence their cultural perspectives on the positive or negative nature of observed trends will differ (Martens \& Rotmans, 2002).

It has been argued that culture is the most visible manifestation of globalization (Nederveen-Pieterse, 2004). Yet, apart from using proxies, such as the number of 
McDonalds restaurants, tourists and migrants (Dreher et al., 2008) no adequate solution has been put forward so far on how to integrate culture in the quantitative assessment of globalization. The deeper complex layers and patterns of culture such as values and worldviews that shape the social, cultural, political and even environmental context for and direction of the global system (Erez \& Gati, 2004; Keesing, 1974; Schuerkens, 2003) remain overlooked, which raises concerns from a sustainability perspective.

Based on evolutionary theory of socio-ecological resilience and adaptation (Anton, 1995; Gunderson \& Holling, 2002), we argue, that a diversity of cultural perspectives is crucial for a sustainable globalization in two ways: first, societal support for strategies that strengthen globalization processes and sustainability developments is determined by the level of cultural inclusiveness; second, the socio-cultural adaptive capacity to deal with global environmental, economic and societal changes and other anticipated and unanticipated events depends on a diversity of values and strategies. This sustainability dimension of globalization can be assessed by analysing its 'social robustness'. We argue that in order to be considered sustainable and socially robust, a policy, trend or process should be acceptable to a broad range of people in society (Offermans, 2012). Current empirical methods measuring the sustainability impact of globalization do not take the diversity of perspectives into account. For a more insightful debate in the globalization arena it is therefore imperative to gain a better understanding of the underlying cultural perspectives of relevant policy discourses. This presents a fourth crucial knowledge gap.

Figure 1.2: 'The wheel of globalization'

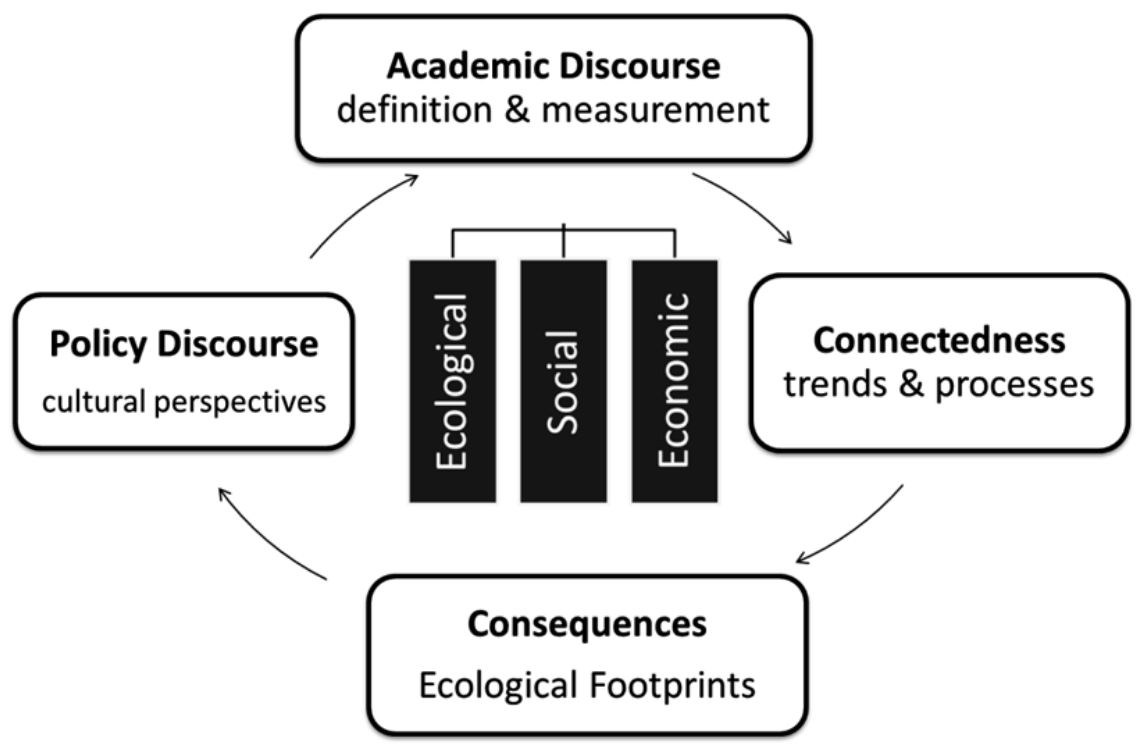


To summarize, we define sustainable globalization as a form of globalization that is socially robust and contributes (positively) to the three pillars of sustainable development: the economic, social and ecological. As a structuring tool for this thesis we put forward 'the wheel of globalization' (figure 1.2). We found four knowledge gaps. The first one regarding the definition and measurement of globalization through Gls is to be found in the academic discourse. The second one regarding the missing data beyond 2008 for the MGI belongs to trends and processes in connectedness. The third one regarding the ecological consequences of globalization (over time) is placed at the interface between trends in connectedness and (ecological) consequences. The fourth deals with the social robustness of cultural perspectives within the policy discourse.

\subsection{Research aims, objectives and research questions}

The main research question of this study is: to what extent is globalization as a process and policy discourse sustainable?

In order to find answers to this question, this study pursued the following research aims, objectives and questions:

\subsubsection{Aims - where the research will go}

- To assess the contributions and, in particular, the limitations of globalization indices to the understanding of globalization.

- To advance the scientific understanding and measurement of globalization.

- To contribute to and complement the empirical evidence on the ecological consequences of globalization.

- To conduct a quantitative assessment of the sustainability of globalization, covering as many countries and years as possible.

- To explore the sustainability of globalization by analyzing its 'social robustness'.

\subsubsection{Objectives - what the research will do}

- Critically review the practice and use of globalization indices - by subjecting their ontology, epistemology and methodologies to critical scrutiny.

- Further develop the calculation method of, update and extend the Maastricht Globalization Index for the 2012 edition.

- $\quad$ Link the MGI and KOF index of globalization to Ecological Footprints in order to quantitatively assess the ecological consequences of globalization.

- Identify statistically robust determinants of the Ecological Footprint. 
- Make explicit the underlying values and assumptions that shape global policy in the domains of the global economy (economic globalization), climate change (ecological globalization) and human well-being (social globalization)

\subsubsection{Research Questions}

1. To what extent can globalization be better understood by measuring it andwhat are the limitations of existing indices?

2. What are the recent states and trends in globalization between 2000 and 2012?

3. To what extent does globalization and its different domains affect Ecological Footprints and/or contribute to ecologically sustainable development?

4. What are robust determinants of Ecological Footprints?

5. How socially robust is the policy discourse on globalization?

\subsection{Research strategy and key methodologies}

This research is placed within the emerging field of Sustainability Science, which seeks to produce trans-disciplinary knowledge on the interactions between nature and society, at different temporal and spatial scales (Kemp \& Martens, 2007). Sustainable Development research at ICIS (International Centre for Integrated assessment and Sustainable development, Maastricht University) highlights three interrelated knowledge domains: Assessment, innovation and governance for SD. Together these yield scientific theories and methods in order to address societal challenges (Cörvers, de Kraker, Kemp, Martens, \& van Lente, 2016)

While this research is not trans-disciplinary in its nature (i.e. working with practitioners, policy makers, stakeholders), it is inter-disciplinary, crossing different scientific disciplines, including contributions from the political, social \& cultural sciences; economics \& econometrics; and ecology \& health. Further, it makes the normative concept of sustainability operational in the context of globalization (see Spangenberg, 2011), and aims to advance our understanding of coupled socio-ecological systems, with a specific interest in the driving forces and consequences of global change (see Martens, 2006). Finally, it is highly reflexive regarding the limitations of the disciplinary construction of reality by critically assessing the pros and cons of the employed tools and methods (Spangenberg, 2011).

Martens (2006) points out that one objective of Sustainability Science is to provide integrated analysis of driving forces and their consequences in order to build a scientific foundation for the concept of sustainable development. Hence, an Integrated Sustaina- 
bility Indicator and Regression Analysis (ISIRA) is put forward here, as a quantitative empirical assessment of the sustainability of globalization, which is rigorous as well as reproducible with respect to methods and data.

For this, two Globalization Indices are employed; the MGI and KOF index. As the current literature largely neglects ecological indicators, the ecological dimension of sustainable development is operationalized by using four variants of the Ecological Footprint (The EF of consumption, production, imports and exports). The panel data for the regressions cover up to 181 countries for the period 1981 to 2012, depending on the particular indices and variables used. The MGI includes up to 11 indicators, and the KOF index up to 23 , to measure globalization. In order to ensure the robustness of the findings, up to 29 control variables are tested and included.

To assess the social robustness of globalization, we put forward a discourse analysis, based on Cultural Theory and analyze eleven reports published by significant organizations in the field of global governance. Those cover themes reflected by the three pillars of sustainability: economy (read: economic globalization), climate change (read: ecological globalization), and human well-being (read: social globalization).

Globalization and its quantification lies at the core of this thesis. Understanding this concept, its measurement and how it relates to sustainable development is necessary in order to assess whether it is sustainable. This should be of interest to researchers, policy actors and institutions at the frontline of shaping the future direction of our globalization.

\subsection{Outline of the thesis}

Chapter two critically reviews the literature as well as the ontology, epistemology and methodology of Gls. The key issues discussed are (a) the focus of measurement (i.e. on activities or policies); (b) dimensions of measurement (i.e. cultural, ecological, economic, political and/or social aspects of globalization); and (c) units of measurement (i.e. local, national, regional and/or global).

Chapter three introduces the MGI in detail, elaborating on its indicators and the revised calculation method, and reports the results of the updated 2012 edition. In addition to the assessment of the current state of globalization, recent trends between 2000 and 2012 are presented for 117 countries.

Chapter four builds on chapter three and extends the data coverage of the MGI to up to 181 countries by employing imputation methods. Furthermore, this chapter reviews 
the evidence on the consequences of globalization put forward in previous studies with the MGI and KOF index. The chapter further introduces the Ecological Footprint to operationalize the ecological dimension of sustainable development and links the MGI to four variants of the Ecological Footprint, while controlling for affluence.

Chapter five extends this analysis by introducing and employing the KOF index of Globalization. This index is available for more years and countries, which allows for the scope of the analysis to be extended to the period 1981 - 2009. Theoretically, this chapter contributes by developing hypotheses on the potential ecological consequences of globalization. Furthermore, this chapter tests 29 potential determinants of human demands and identifies which of those are statistically robust.

Chapter six explores the sustainability of globalization by analyzing its 'social robustness'. A text and discourse analysis, based on Cultural Theory, demonstrates the overall dominance of the 'individualist' perspective across various organizations of global policy significance delineating sustainable futures within three core themes of global governance: climate change, the economy and well-being.

Chapter seven concludes by answering the research questions, discusses the sustainability of globalization and presents the epilogue to this research. 

CHAPTER 2

New directions in globalization indices 
"Perfect numbers like perfect men are very rare."

Rene Descartes, philosopher and scientist

\begin{abstract}
This chapter discusses the measurement of globalization with a view to advancing the construction of globalization indices. It critically analyzes the types of indices that can contribute to knowledge and policy on globalization. Three issues are particularly highlighted: (a) the focus of measurement (i.e. on activities or policies); (b) the dimensions of measurement (i.e. cultural, ecological, economic, political and/or social); and (c) the units of measurement (i.e. local, national, regional and/or global). The chapter argues that a workable forward strategy should not seek to identify a single best composite globalization index, but rather should work in an interdisciplinary mode towards a set of complementary approaches. These quantitative analyses can then be productively blended with qualitative approaches in a fuller assessment of globalization's extent and impact.
\end{abstract}

Published as:

Martens, P., Caselli, M., De Lombaerde, P., Figge, L., \& Scholte, J. A. (2015). New Directions in Globalization Indices. Globalizations, 12(2), 217-228.

This article built on Dreher, Gaston, Martens and Van Boxem (2010) and previous work of the authors. It has benefited from discussions at the 'Measuring Globalization' workshop held at the University of Maastricht 22-23 November 2012, with the support of the Scientific Research Group (WOG) on 'Globalization, Regionalization and Socio-Economic Inequality' (GRESI), funded by the Flemish Fund for Scientific Research (FWO). 


\section{Introduction}

The assessment of the causes, contents and consequences of globalization is a key issue for contemporary research and policy. Positivist and rather 'objective' economic, social and political analyses require data, and globalization indices are a promising means for providing concrete data. Existing indices of globalization are employed to assess the state and trends in globalization as well as its consequences, including academic research (e.g. the MGI and KOF index), business analysis - by business themselves (Ghemawat \& Altman, 2016; HUAWEI, 2016) or in strategy consulting (EY, 2012; Hales, Peterson, Pena, \& Dessibourg-Freer, 2016; McKinsey Global Institute, 2016) - and public policy (Guo \& Schwarz, 2016; OECD, 2008; UNIDO, 2011). Indices are (often) used to push and promote business and economic policies and thereby specific cultural perspectives. For instance, multi-national corporations (e.g. DHL and HUAWEI) and strategy consultancies (e.g. EY, McKinsey and A.T. Kearney) have developed GIs and published reports which contain findings and their recommendations on how to further pursue and direct globalization. This may have severe implications for the social robustness and sustainability of globalization, as will become evident in chapter 6 . The key point to be made here is that (for sustainability), it is all the more important to subject their ontology, epistemology and methodologies to critical scrutiny, in order to better understand what and how is actually measured.

This chapter discusses the measurement of globalization with a view to advancing the understanding and use of globalization indices. To what extent can globalization be better understood by measuring it? What are the intellectual and political implications of existing globalization indices? The chapter discusses the contributions and, in particular, the limitations of globalization indices. It also highlights the considerable gap between the quantitative and the qualitative analysis of globalization and argues for their integration.

The discussion that follows is more concerned with the underlying assumptions of composite indices rather than statistical arguments regarding these calculations (for this see OECD (2008)). After identifying some existing globalization indices, the chapter explores three main issues: (a) the focus of measurement (i.e. on activities or policies); (b) the dimensions of measurement (i.e. cultural, ecological, economic, political and/or social aspects of globalization); and (c) the units of measurement (i.e. local, national, regional and/or global). Different starting premises on these points can yield very different quantifications of globalization, rejecting its seemingly objective nature. 


\subsection{Globalization and its measurement}

Globalization is a pre-dominant feature of contemporary society and discourse. Some sceptics have doubted the novelty, scale and sustainability of globalization (Hirst \& Thompson, 2002), and some have worried about the hegemonic deployment of 'globalization' as an ideology to bolster big capital and/or western modernity (Rosenberg, 2005). However, large swaths of academe, business, governance, media and the general public are convinced that they live in a globalizing world - and behave accordingly in their purchases, investments, travels, communications, researches, and so on. The global orientation of much contemporary thought and action emphasizes how important it is to measure globalization. Although some might downplay the exercise (Rossi, 2008), measuring globalization helps to grasp the phenomenon, assess its consequences and derive consequences for policy making. The question then is what to measure, with what indicators, against what unit(s) of analysis, and through what equations? Clearly, different answers to these questions can generate very different calculations.

Since 2000 a number of projects have sought to measure globalization with a composite index. The first initiative of this kind, the A.T. Kearney/Foreign Policy Globalization Index, was launched in 2001 and continued its calculations until 2007 (A.T. Kearney/Foreign Policy, 2001). In 2006 the KOF Index of Globalization appeared as a second major measurement exercise, which continues to this day (Dreher, 2006; Dreher et al., 2008). The Centre for the Study of Globalization and Regionalisation (CSGR) at the University of Warwick produced a globalization index covering the years 2002-4 (Lockwood \& Redoano, 2005). A Cultural Globalization Index was suggested in 2004 (Kluver \& Fu, 2004a). The Maastricht Globalization Index (MGI) emerged in 2006 (Martens \& Raza, 2009; Martens \& Zywietz, 2006c), and a New Globalization Index was proposed two years later(Vujakovic, 2010). More recently, Caselli has suggested a Person-Based Globalization Index (PBGI) (2012), the DHL Connectedness Index has been put forward (Ghemawat \& Altman, 2016) and new indices focusing on digital connectedness rather than trans-dimensional globalization came up (HUAWEI, 2016).

Globalization indices may also have evaluative and policy consequences. High ranking on a globalization measure might be taken as a meritorious quality, on the assumption that 'globalization is a good thing'. Governments, companies and other actors might advertise a high globalization ranking in attempts to attract investment, gain policy approval, assert prestige, and so on (for instance the DHL Connectedness Index by Ghemawat and Altman (2016)). Given the considerable stakes involved in such use (and potential misuse) of globalization indices, it becomes vital to place these measurements under examination. Invariably, all of these initiatives face contentious methodological questions and choices. Some rather positivist authors claim objective measurement of 
globalization (Dreher et al., 2008; Ghemawat \& Altman, 2016; Potrafke, 2014), while the authors of this chapter rather acknowledge the constructivist nature of composing an index as the construction process involves many 'subjective' choices of the researcher who puts them together. It is important to keep in mind that composite indicators are proxies of complex concepts or phenomena rather than exact measurements. Core issues include the definition of globalization adopted, the selection of domains and phenomena to be captured, and the units (countries or other entities) whose globalization is assessed. These three crucial matters in measuring globalization are now scrutinised in turn.

\subsection{Concepts to be measured}

What is the 'globalization' that is being measured in a globalization index? In addition to our trans-dimensional and trans-scalar conception, the term has attracted multiple divergent definitions, including internationalization, liberalization, universalization, westernization and deterritorialization (Scholte, 2008). Clearly the adoption of different definitional starting points results in different - potentially radically different - measurements of 'globalization'.

\subsubsection{Internationalization}

Most existing globalization indices measure internationalization. That is, their indicators relate to levels of transactions across country borders. Such data show the 'openness' of a country to contacts with other countries and its degree of integration into an overall international system. In this vein, for example, Chase-Dunn and Jorgenson have calculated average openness indicators for countries in terms of their cross-border trade and investment flows (2007).

A particular problem with calculations of globalization-as-internationalization is their usual neglect of the geographical distribution of linkages. Thus, a country might record a high 'globalization' score when its international transactions are in fact heavily concentrated with neighboring countries. For example, 88.8 per cent of Mexico's exports go to the United States (Ebenthal, 2007). To address this issue Vujakovic (2010) suggests that globalization indicators which refer to international exchanges should be weighted in relation to the distance between the countries concerned. However, Vujakovic's New Globalization Index applies this weighting to only one indicator, trade in goods, owing to the impossibility of obtaining the data necessary to effect the same weighting on other ones. 
Certainly, it is important to distinguish between a country's internationalization on a regional as opposed to a global/world/planetary scale to capture the trans-scalarity in more detail. Such a differentiation of regional and global measurements is technically possible, although it is not free of problems (De Lombaerde \& lapadre, 2008). It is further interesting to contrast work on globalization indicators with work on regionalization indicators. Whereas globalization indicators usually measure the level of globalization of a country, regionalization indicators usually measure the level of integration of the region itself (i.e. not the level of integration of a country within a region) (De Lombaerde, Flores, lapadre, \& Schulz, 2012). One index that adds the breadth dimension (rather than only assessing the depth of integration) is the DHL connectedness index (Ghemawat \& Altman, 2016) by evaluating the distribution of countries' (economic) relations.

Another problem with measures of globalization-as-internationalization is that they omit all transactions within a country. Thus, to take an extreme example, on international measures Vatican City would be highly globalized as its residents take a bus to surrounding Rome, while telephone calls across eleven time zones between Kaliningrad and Vladivostok would be counted as 'domestic' and non-global. A Miami resident's bank account in the Bahamas less than 200 kilometers away would be counted as 'global' for having crossed a border, while an investment from Guangzhou more than 3,000 kilometers to Urumqi would be excluded from the equation for being intranational. Such illustrations point to the unit-of-analysis problem, which is discussed in more detail later.

\subsubsection{Liberalization}

It is important also to distinguish between calculations of de facto globalization (e.g. as found in the measures of international transactions just discussed) and policies of globalization. Many in commercial and governmental circles have understood 'globalization' as a policy programme of economic liberalization. From this perspective a globalization index would measure the prevalence of official policies of privatization, deregulation, tight money, and fiscal constraint.

In this vein the World Economic Forum's Global Competitiveness Index does not measure transactions between countries, but the degree to which national governments adopt policies that facilitate 'productivity' and 'growth' (WEF, 2013). Similarly, the Economic Freedom of the World index emanating from think tanks such as the Cato Institute and the Fraser Institute measures adherence to neoliberal policies rather than actual transactions (Gwartney, Lawson, \& Hall, 2013). Some such policy indicators have also been reintroduced into the KOF Index of Globalization (Dreher et al., 2008). 
Confusion between de facto globalization and policies of globalization can be problematic, particularly when both measures are incorporated in the same index. Arguably a sharp distinction needs to be made in measuring globalization between inputs (including certain policies), content (i.e., relevant activities and transactions), and outputs (i.e., the consequences of those activities) (De Lombaerde \& lapadre, 2008).

\subsubsection{Universalization and Westernization}

Next to internationalization and liberalization, many have conceived of globalization as the spread of certain objects and experiences across the planet. Usually those universalized conditions are understood to be culturally 'western'. Thus, for example, formal colonialism of the late nineteenth and early twentieth century is seen as an earlier instance of globalization-as-westernization. Today the focus is more on 'Americanization' and 'McDonaldization' (Ritzer \& Stillman, 2003).

Such a conception of globalization is reflected in the KOF Index of Globalization, which inter alia includes indicators such as the worldwide spread of McDonald's restaurants and IKEA stores (rather than, say, outlets serving Chinese or Indian food). Indeed, early editions of the KOF Index were explicitly based on the assumption that cultural globalization corresponded to 'the domination of American cultural products' (Dreher, 2006). This assumption was later drastically revised, with the consequent selection of indicators better able to grasp a wider range of globalization processes.

Nevertheless, existing globalization indices remain culturally biased towards western modernity. They measure globalization mainly as enacted and experienced by wellresourced circles in urban centres of OECD countries. Thus the indices tend to measure international tourism more than undocumented migration, Hollywood more than Bollywood, transnational professional networks more than transnational spiritualist networks, and so on. Inevitably, an index cannot equally incorporate all standpoints on globalization, and data related to 'western' aspects of globalization are usually more numerous, more precise and more readily available. Still, it is well to consider that all of the major existing globalization indices reflect a limited range of positions and interests.

\subsubsection{Deterritorialization}

Some analysts have suggested that the distinctive character of contemporary globalization lies in its pronounced 'supraterritorial' qualities (Scholte, 2005). In this conception social relations are especially global when they operate with significant autonomy from territorial places, territorial distances and territorial borders. Examples of substantially deterritorialized global connections include the cyberspace of the Internet, climate 
changes, mobile phone networks, commodity prices, nonterritorial solidarities (e.g. based on caste, faith and sexuality), and a host of health challenges.

Although some commentators have called for truly supraterritorial indicators (Caselli, 2012) such data remain in short supply. For the most part statistics continue to reflect their etymological origins as 'state-istics' i.e. measures related to territorial-country circumstances. 'Globalistics' remain comparatively scarce. This relates to the unit of analysis in globalization indices, to which we return in a later section. Diverging perspectives, whether globalization is truly only about the global or whether it encompasses processes at lower scale levels seem to persist. We take another approach by stating that globalization is a trans-scalar process, encompassing processes of increasing connectedness at the local, national, regional and global level. For now, however this supraterritorialized approach remains difficult to operationalize. More consensus exists, however, on the fact that globalization is a trans-dimensional concept.

\subsection{Dimensions of measurement}

Along with the starting definition adopted, Gls can vary immensely as a result of the dimensions included and the relative weight assigned to those dimensions. In other words, different indices combine cultural, economic, ecological, political and social elements of globalization in different ways. Having been largely developed by and for economists and business analysts, globalization indices have often given most attention to indicators such as trade investment and recently ICT. Data availability has also tended to favor this economic bias. Indicators relating to other aspects of globalization - in particular cultural and ecological dimensions - have generally been harder to assemble. In this section, we discuss the difficulty regarding the measurement of globalization for each dimension.

Many authors examining the measurement of globalization concur with the view that 'culture is the most visible manifestation of globalization' (Kluver \& Fu, 2004a). However, despite culture's importance to globalization, no index has yet provided an adequate solution to its measurement. Martens and Zywietz (2006c) sidestep the issue by stating that the concepts of culture and communication are inherently intractable and difficult to quantify. Yet one then risks dismissing the importance of culture. Clearly, it would be useful if indices would include some element of cultural globalization.

To this end Kluver and Fu (2004c) have constructed a Cultural Globalization Index. They argue that it is impossible to measure the diffusion of cultural values and ideas across national borders in a direct way. So they use channels by which cultural units - ideas, beliefs and values - are disseminated as cultural determinants. Although cultural global- 
ization is adequately conceptualised, the available empirical indicators once again fall short. Kluver and Fu (2004) use the imports and exports of books, brochures, newspapers and periodicals, because other possible indicators lack systematic data sources. Countries at the top of their cultural globalization rankings are therefore generally affluent and English-speaking.

Several other globalization indices have approached 'cultural' or 'social' globalization in relation to the use of a particular transmission or communication technology such as cellular phones. Yet such indicators are also problematic, especially when substitutes exist. What really matters is the net increase in (global) communication or transmission (based on 'old' and 'new' technologies), if that could be measured. The mix of technologies that are used and the processes of substitution (from old to new technologies) might also differ from one country (or other unit of analysis) to another. Moreover, in certain circumstances people might leapfrog technological stages: for example, from not having a telephone at all to having a cellular phone.

The problem with focusing on a particular technology in order to capture the intensity and scope of global communication can further be illustrated with reference to data on postal services (Ansón \& Helble, 2013). Statistics from the Universal Postal Union (UPU) are based on data from national postal services. The privatization of postal services is therefore likely to underestimate the exchanges. In addition, as the average weight of parcels is increasing, one might think that postal services are increasingly about trade (goods), instead of about communication (messages).

Also difficult to measure along cultural axes of globalization is global consciousness. As many analysts with a constructivist bent have emphasized, awareness of a global existence is central to global existence (Robertson, 1992). Yet what sorts of indicators could be used to measure global consciousness? Some experimental research has broached this question by exploring the degree to which people in different countries across the world are prepared to contribute resources to finance global public goods (Buchan et al., 2009). However, on the whole, quantitative research in this area lags far behind that on other economic and cultural measures of globalization.

Finally, alongside culture and consciousness it is also difficult to measure the ecological dimension of globalization, all the more so on territorial bases (Dreher et al., 2008). Global ecological developments such as land-use, climate change, and natural resource depletion do not occur as cross-border transactions between territorial units. Ecological globalization needs to be measured in terms of changes at locations rather than as movements between locations. Moreover, global ecology arguably needs to be measured on a planetary scale: thus as global demography, global warming, and so on. The only composite indicator that includes the ecological domain is the MGI, which employs 
the Ecological Footprint. A point to be made, however, is that ecological developments may rather be the consequence of (economic) globalization, and hence should be treated and analyzed as such (Dreher et al., 2008; Rennen \& Martens, 2003). To this end, Ghemawat and Altman (2016) argue that globalization should only be measured in terms of actual (economic) flows - the ecological (and other) consequences could then be assessed by linking respective variables in regression analysis. In this thesis the ecological dimension is treated as a feature (in chapter three) and as a consequence (In chapters four and five).

In sum, after more than a decade of work globalization indices remain underdeveloped on several crucial dimensions. Once one accepts - as most academic and lay observers would now do - that globalization is more than a narrowly economic phenomenon, then measurement becomes vastly more complicated. If the current basis of measuring globalization is so theoretically unsatisfactory, we need to question why we should pursue the construction and maintenance of indices which may be too limited to understand globalization.

\subsection{Unit of measurement}

A third key methodological issue in measuring globalization is the unit of analysis. Whose globalization is being calculated? Most existing indices seek to quantify (and often also to rank) the globalization of countries. The unit of analysis underpinning this work is the country-nation-state-society. From this perspective the question becomes how globalized is Bolivia, or Germany, or Nigeria, or Singapore - and which country is more globalized than the others?

This framing of the measurement of globalization reflects the widespread 'methodological territorialism' (Scholte, 2005), methodological nationalism (Beck, 2004), and embedded statism (Sassen, 2000) of modern social science. Thus reigning postulates affirm that social geography equates to bounded countries, that social solidarity equates to nationhood, and that social governance equates to the state. Society is assumed to take form as a country-nation-state unit, where geography, community and governance converge in the same 'natural' container of economic, cultural and political processes. These methodological suppositions have also informed the construction of databases. The majority of indicators - and therefore most of the statistical data available and usable for the construction of a globalization index - take the country-nation-state as their unit of analysis (De Lombaerde \& lapadre, 2007; Scholte, 2005). Indeed, 'statistics' - as testified by the etymology of the word - came into being as an instrument of 'state' administration (Moses \& Knutsen, 2012). To this extent the choice of the country-nation-state unit of analysis in existing globalization indices has been influenced - 
even dictated - by the practical question of the availability of data required to construct the tool. In this situation data availability has tended to guide the research questions, rather than (as ought to be) the other way around.

Certainly there are some good reasons to measure globalization in relation to countrynation-states. These units continue to be key reference points in the everyday lives of the vast majority of humanity today (Ray, 2007). Indeed, the state contributes substantially to shaping globalization processes, furnishing much of the infrastructures, particularly for transport and communications, which make possible transnational global flows (Axford, 2007). More generally, too, states continue to be prominent policy actors across all issue-areas in today's more global world. Also, contemporary history may have witnessed significant deterritorialization while the country contexts continue to shape social life, and global dynamics have differential effects depending on country locations. Globalization can furthermore involve reterritorialization processes that give new life to country borders, national identities and state power (Scholte, 2008).

Yet while there may be good grounds for measuring globalization in relation to countrynation-states, it cannot be justified to measure globalization only in these terms. After all, countries are not the only relevant social spaces in the contemporary world, where cities, regions and planetary realms are also often key geographical contexts. Moreover, not all relationships among people are mediated by their shared national-territorial belonging (Sen, 2002). Similarly, much regulation in contemporary world politics involves trans-state, supra-state and non-state institutions (Scholte, 2010). Thus while social relations in a global world continue to be shaped by countries, nations and states, it is a misrepresentation to reduce society to country-nation-state units, as the main existing globalization indices have done. Keeping this limitation in mind chapters three to five of this thesis do the same. Chapter six puts forth an alternative, by looking at the global policy discourse on globalization

The lack of fit between global relations and country-nation-state-society units is especially pronounced in respect of deterritorialized or supraterritorial flows (Sassen, 2000; Scholte, 2005). For example, as noted earlier, one cannot effectively measure key global ecological developments in terms of territorial units. Climate change, biodiversity loss, stratospheric ozone levels, and the like are not territorially bounded, have no particular intersection with national sentiments, and cannot be regulated by states alone. Likewise, it is not particularly meaningful to divide such items as digital communications, electronic financial transactions, global discourses, transborder nongovernmental regulation, transnational corporations, and transplanetary diseases amongst country-nation-state units. Any approach to globalization that omits such supraterritorial items can hardly claim to measure the phenomenon. Indeed, it is precisely the deterritorialized dynamics that differentiate globalization from internationalization. 
Hence a purely territorial approach to measuring globalization is arguably highly distorting, yielding data that 'in the best of cases are irrelevant and in the worse misleading, or even false' (Beck-Gernsheim 2004, cited in Caselli (2008)).

Hence there is an urgent need to diversify measures of globalization away from their current bias towards methodological territorialism, nationalism and statism. Various authors have proposed the city as an alternative focus for globalization research (Beck, Clarke, Groff, Keefer, \& Walsh, 2001; Sassen, 2007; Taylor, 2004; Taylor, Catalano, \& Walker, 2002). A.T.Kearney has in fact reoriented the unit of analysis in its recent globalization measures away from the country to the city (Hales \& Pena, 2012; Hales et al., 2016). Thus far this alternative formula has been applied to 66 cities, which does not allow for a truly 'global' assessment. However, the initiative illustrates the possibility of measuring globalization in relation to non-country units.

Other scholars have suggested measuring globalization in relation to the person (Caselli, 2012), transnational practices (Sklair, 1991), and global social relations (Shaw, 1994). Similarly one could imagine globalization measures for regional units or the planet as a unit of analysis in its own right (Alamuti, 2011). So far these suggestions have not been followed by the development of a concrete measure of globalization, and work on these new lines is a clear priority for future research.

Also important is to assess globalization in respect of non-geographical categories. Within the same spatial context - no matter how circumscribed - globalization can vary across individuals and social groups (Holton, 2005; Kennedy, 2009). For example, Bauman (1998) suggests a new class division between the globalized upper classes and the localized lower classes. It would therefore be useful to have a tool that enables comparison, within a specific territorial context or in general terms, of the level of globalization among members of different classes, ethnic groups, genders, professions, age categories, etc. One way forward is to assess globalization trends in terms of cultural units: applied cultural theory has already mapped the cultural composition of global scenario studies (Beumer \& Martens, 2010, 2013) - thereby revealing the underlying value structures.

Thus, to capture the trans-scalarity, multiple territorial, supraterritorial and nonspatial dimensions can be rightly used, along with the country-nation-state, as a unit of analysis for measuring globalization processes. The larger challenge in the long-run is perhaps to develop a multi-scalar approach to this question. Thus globalization measures based on individual, city, country, regional and planetary units - as well as different social categories such as class and gender - would be available concurrently, to give a fuller appreciation of the trans-scalarity and trans-dimensionality of globalization (Sassen, 2007). In addition, one should not forget that interactions between micro- and 
macro-levels can also be considered as essential aspects of trans-scalar globalization (Rosenau, 2007), and this should also be reflected in the measurement and assessment tools.

The endeavor to develop alternative units of analysis for the measurement of globalization is not necessarily in conflict with the most common approach based on the country-nation-state. Globalization is an extraordinarily complex process which can be analysed and interpreted from numerous standpoints which are not in competition but complementary. As Beck puts it, the logic that guides us when analysing globalization should not be that of 'either-or' but rather 'both-and' (Beck, 2004). Making combined use of measurement tools that employ different units of analysis would make it possible to grasp diverse aspects of globalization and would yield a more thorough understanding of the phenomenon.

As remarked repeatedly in this discussion, however, the construction of globalization measures in respect of other units of analysis is premised on the availability of relevant data. Without sufficient data for individual, municipal, regional, cultural and other engagements of global relations, alternative approaches to globalization (indices) cannot be more than propositions. Efforts to achieve better capacities for measuring globalization therefore must be devoted not only to the development of tools suited for the purpose, but also to the collection and production of new types of primary data on which such tools depend.

\subsection{A way forward}

The quantitative measurement of globalization contains so many pitfalls that it is tempting to retreat to purely qualitative analyses. However, this surrender would burn the fragile bridge between qualitative and quantitative analysis of globalization. The qualitative side of research generally focuses on constructing frameworks and concepts through which to understand globalization. This approach provides some tools, but theory without measurement runs the risk of unsubstantiated and unscientific speculation. The quantitative side of research assesses globalization using data, statistics and indices. While this approach runs the risk of oversimplification and may take on an overly enthusiastic air of 'objective truth', it lends important descriptive precision to understandings of globalization.

The gap between theory and measurement in globalization studies can be bridged. Instead of rejecting the possibility of quantifying globalization adequately, the measurement of globalization needs to be, and can be, improved. A new mode of thinking, such as trans-scalarity and trans-dimensionality, can trigger new ideas on both the 
analysis and quantification of globalization. A continuous interaction between theoretical and empirical work can yield more ontological clarity. This process of broadening and deepening knowledge of globalization needs to be an interdisciplinary cooperation. Academics from the quantitative side (econometrics, modelling, conclusive statements, certainty and proofs) can collaborate with those on the qualitative side (frameworks, discourse and text analysis). For all of their differences the methodologies can be complementary.

Composite indices of globalization can provide a starting point or forum for different approaches. Composite indices need matters to be conceptually analyzed and continually reformulated. Further do they also have interesting technical features that enable them to be used in statistical work. But while recognizing the potential of designing 'better' composite globalization indicators, one must also guard against excessive optimism with respect to their use. By adding more and more sub-indices, composite indices risk to become more abstract and more difficult to interpret.

For purposes of empirical research, a better strategy might well be to work towards a set of complementary approaches. Rather than focus on finding and promoting 'the best' composite globalization index, complementary approaches should be sought. Especially to better capture the cultural and ecological dimensions, and also to move towards new units of analysis. The way forward might be to differentiate globalization in terms of the level of analysis (without losing sight of interplays between scales), in terms of the dimensions (without losing sight of interrelations of the political, the social, the economic, and the cultural), and in terms of the distinction between de facto globalization and globalization policies. Apart from finding new approaches, however, it remains an important task to maintain, update, extend and revise existing indices. For instance the MGI, which has been available so far only for two points in time, 2000 and 2008 and for 117 countries. 
CHAPTER 3

Globalization continues:

The Maastricht Globalization Index

revisited and updated 
"When modern social science exerts itself to establish the world's formula, what occurs thereby is this: the being of entities has resolved itself into the method of the totally calculable, ${ }^{\prime 3}$

Martin Heidegger, philosopher

\begin{abstract}
Globalization leads to an increasing connectedness and inter-relatedness in the political, economic, social and cultural, technological and environmental domain on many different scales. While this is a global phenomena, it has different impacts and manifestations in different geographic localities. As a result, different nations exhibit different levels of globalization or connectedness. Composite Indices are a powerful tool to capture and measure complex concepts and allow monitoring complex systems over time and yield relative rankings and comparisons. This chapter presents a revised and updated Maastricht Globalization Index for 117 countries and three points in time, 2000, 2008 and 2012, including a new calculation methodology and data. Results show that globalization still continues but has slowed down, due to the recent economic crisis.
\end{abstract}

Published as:

Figge, L., \& Martens, P. (2014). Globalization continues: The Maastricht Globalization Index revisited and updated. Globalizations, 11(6), 875-893. doi:

10.1080/14747731.2014.887389

Figge, L., \& Martens, P. (2016). Globalisation continues: The Maastricht Globalisation Index revisited and updated. In R. Cörvers, J. de Kraker, R. Kemp, P. Martens, \& H. van Lente (Eds.), Sustainable Development Research at ICIS (pp. 381-392). Maastricht: ICIS.

\footnotetext{
${ }^{3}$ Slightly adjusted, the original quote said physics instead of social science
} 


\section{Introduction}

One powerful tool to illustrate, monitor and communicate complex issues or concepts that exhibit trans-dimensionality, such as globalization, are composite indices $(\mathrm{Cl})$. Cls are constructed by aggregating individual quantitative or qualitative indicators into a final index. Most Cls are constructed on a national level, and therefore allow for a relative ranking or comparison of country performance (OECD, 2008). It is important to acknowledge that $\mathrm{Cls}$ are quantitative, mathematical or computational models and the construction process involves many subjective choices of the craftsman who puts them together. In his critique, Caselli (2012) argues that globalization can only be indirectly measured. Accordingly, there is not one right or objective way to do it, and it is rather important that subjective methodological choices are made transparent. This is contradictory to previous claims of absolute, exact and objective measurement of both causes and consequences of globalization (Dreher et al., 2008; Dreher et al., 2010; Ghemawat \& Altman, 2016). If the primary objective is to derive a comprehensive quantitative model of globalization, then there are several conditions that a composite index of globalization needs to fulfil. In particular, it has to be valid, relevant, robust, transparent and it needs to add value (i.e., to not be redundant) (Caselli, 2012; De Lombaerde \& lapadre, 2008; Dreher et al., 2008).

The Maastricht Globalization Index (MGI) has been first developed by Martens and Zywietz (2006c) for 117 countries and the year 2000. The index is based on the initial A.T. Kearney index of globalization and the main objective was to embrace transscalarity and to move beyond the economic dimension by including indicators for the political, cultural and ecological dimensions of globalization. The MGI has been further developed and updated by Martens and Raza (2009). In this chapter we revise and update the Maastricht Globalization Index regarding its data-base and calculation methodology. This is the foundation for the subsequent chapters, which will look at the ecological consequences of globalization. Further, the update allows us to answer the research question 'What is the current state and recent trends in globalization for the period 2000 - 2008 - 2012'? a sub-question that this chapter addresses is 'does globalization exhibit converging trends - are countries that were initially less globalized catching up with the more globalized countries?

The new 2012 edition of the MGI incorporates two key changes as compared to the previous 2008 edition. The first one is the logarithmic transformation of indicators, which is included for reasons explained in section 3.2. Further, two indicators have been changed. The indicator Cell Phone replaced Phone, which had been defined as "incoming and outgoing international telephone traffic in minutes per capita", and the ecological footprint of imports and exports as a share of biocapacity replaced ecological deficit in global ha (see Table 3.1 and Martens \& Raza, 2009 for a comparison). The 
following sections motivate these changes and describe the subsequent steps of the index construction, namely the choices of domains and variables and the calculation methodology in more detail.

\subsection{Components of the MGI}

The choice which domains and indicators to include and which not is a subjective one. Different scholars would and already have made different choices for their own reasons, as the variety of indices has shown. Where one researcher includes a domain/indicator or not, another would make a contradictory choice with arguments which may be equally valid; the same holds for the calculation method which is to be explained later. The choices reflect a person's perception of what he or she thinks are the most important aspects. These are influenced by their beliefs and worldviews. The choice is also subject to data availability and quality. Indicators included in a $\mathrm{Cl}$ should therefore be seen as exemplifiers of the major themes within the globalization debate, as perceived by its author. However, stating that one makes an objective measurement or that a $\mathrm{Cl}$ represents an objective truth about globalization creates the danger of hiding behind a 'curtain of quantitative and statistical objectivity'.

The MGI (Martens \& Zywietz, 2006c) was an effort to improve on the indices which had a neo-liberal focus on the economic dimension of globalization. The first step is to choose the domains. In line with the multi-dimensional definition of globalization as laid out above, the MGI is made up of 5 domains: the political, economic, socio-cultural, technological and environmental. Table 3.1 lists all the sub-indicators, which were chosen. Log means that the data has been transformed by taking the logarithms. What makes the $\mathrm{MGI}$ unique compared to other multi-dimensional globalization indices, is the inclusion of the environmental domain and an indicator for the globalization of the military-industrial complex of a country. This version of the MGI covers 117 countries (see Figure 3.1 and Table 3.4). The main source of data was the World Development Indicators of the World Bank. It is explicitly stated in the description of the indicators below, when other sources have been used. 
Table 3.1: Maastricht Globalization Index (MGI) Indicators.

\begin{tabular}{|c|c|c|c|}
\hline Domain & $\begin{array}{l}\text { Indicator name, } \\
\text { abbreviation }\end{array}$ & $\begin{array}{l}\text { Weight / } \\
\text { transfor-mation }\end{array}$ & Indicator definition \\
\hline \multirow[t]{3}{*}{ Political } & $\begin{array}{l}\text { Embassies } \\
(\text { Emb) }\end{array}$ & $1 / 15$ & $\begin{array}{l}\text { Absolute number of in-country embas- } \\
\text { sies and high commissions }\end{array}$ \\
\hline & $\begin{array}{l}\text { Organizations } \\
\text { (Org) }\end{array}$ & $1 / 15$ & $\begin{array}{l}\text { Absolute number of memberships in } \\
\text { international organizations }\end{array}$ \\
\hline & $\begin{array}{l}\text { Military } \\
\text { (Mil) }\end{array}$ & $\begin{array}{l}1 / 15 \\
\log \end{array}$ & $\begin{array}{l}\text { Trade in conventional arms as a share of } \\
\text { military spending }\end{array}$ \\
\hline \multirow[t]{3}{*}{ Economic } & $\begin{array}{l}\text { Trade } \\
\text { (Tra) }\end{array}$ & $1 / 15$ & $\begin{array}{l}\text { Imports + exports of goods and services } \\
\text { as a share of GDP }\end{array}$ \\
\hline & $\begin{array}{l}\text { FDI } \\
\text { (Fdi) }\end{array}$ & $\begin{array}{l}1 / 15 \\
\log \end{array}$ & $\begin{array}{l}\text { Gross foreign direct investment, stocks } \\
\text { (\% of GDP) }\end{array}$ \\
\hline & $\begin{array}{l}\text { Capital } \\
\text { (Cap) }\end{array}$ & $\begin{array}{l}1 / 15 \\
\log \end{array}$ & $\begin{array}{l}\text { absolute value of net private capital } \\
\text { flows ( } \% \text { of GDP) }\end{array}$ \\
\hline \multirow[t]{2}{*}{ Social \& Cultural } & $\begin{array}{l}\text { Migrants } \\
\text { (Mig) }\end{array}$ & $\begin{array}{l}1 / 10 \\
\log \end{array}$ & $\begin{array}{l}\text { International migrant stock as a share of } \\
\text { population }\end{array}$ \\
\hline & $\begin{array}{l}\text { Tourism } \\
\text { (Tou) }\end{array}$ & $\begin{array}{l}1 / 10 \\
\log \end{array}$ & $\begin{array}{l}\text { International arrivals + departures per } \\
100 \text { inhabitants }\end{array}$ \\
\hline \multirow[t]{2}{*}{ Technological } & $\begin{array}{l}\text { Cell Phone } \\
\text { (Cel) }\end{array}$ & $1 / 10$ & $\begin{array}{l}\text { Mobile cellular subscriptions per } 100 \\
\text { inhabitants }\end{array}$ \\
\hline & $\begin{array}{l}\text { Internet } \\
\text { (Int) }\end{array}$ & $1 / 10$ & Internet users as a share of population \\
\hline Environmental & $\begin{array}{l}\text { Eco footprint } \\
\text { (Env) }\end{array}$ & $\begin{array}{l}1 / 5 \\
\text { Log }\end{array}$ & $\begin{array}{l}\text { Ecological footprint of imports and } \\
\text { exports as a share of biocapacity }\end{array}$ \\
\hline
\end{tabular}

Note: Log means that the data were transformed by taking logarithms

\subsubsection{Political domain}

The first indicator to measure political connectedness is the absolute number of incountry embassies, which are crucial communication channels for international relations. The more important a country is in the realm of international relations, the more countries will have an embassy there. Since no aggregated statistics on diplomatic relations are available at a global level, the number of in-country embassies and high commissions as listed in the Europe World Yearbook are used.

Membership in international organizations is a complementary indicator which measures the extensity of a country's multilateral engagement. The CIA World Factbook provides information on membership. This indicator however does not say anything about the real engagement (e.g. financial or political) of a country in an organization.

Military measures the involvement of a country's military-industrial complex with the rest of the world. This indicator offers an insight into weapons proliferation and international military aid. Of the quantitative military indicators proposed by Held et al (1999), trade (i.e. imports and exports) in conventional arms, compiled by the Stock- 
holm International Peace Research Institute (SIPRI), is the only variable available for a reasonable number of countries. To make the data comparable, a country's trade in conventional arms is divided by its total military expenditure. Military trade often involves 'big-ticket' items and programs that are approved and recorded in one year but may actually take several years to be delivered. To smooth the data and account for infrequent, large purchases a moving three-year average is used.

\subsubsection{Economic domain}

The first indicator to measure enmeshment in the global economy is trade as a share of GDP. It gives a good idea of how much a country's economy is involved in international trade. However, it does not say anything about trade imbalances.

Gross Foreign Direct Investment (FDI) Stocks as a share of GDP is the second indicator for the financial enmeshment of an economy. FDI is defined as an investment involving a long-term relationship of an investor in a foreign business enterprise. The FDI includes the initial and all subsequent transactions between the domestic and the foreign affiliates. The FDI stock is defined as the value of the share of their capital and reserves (including retained profits) attributable to the parent enterprise, plus the net indebtedness of affiliates to the parent enterprises' (UNCTAD, 2012). As such it measures the investments of multinational corporations and their involvement in an economy.

The third measure is net private capital flows (as a percentage of GDP). This is the absolute values of direct, portfolio and other investment inflows and outflows recorded in the balance of payments financial accounts, excluding changes in the assets and liabilities of monetary authorities and the government. It measures the wider involvement of international capital in an economy and complements the FDI stock measures. For data smoothing the moving three-year average is employed.

\subsubsection{Social and cultural domain}

We used the international migrant stock as an indicator for the outcomes of crossborder migration of the last generation. It is defined as the share of foreign-born residents of a given country. It is only an imperfect indicator for the reason that it does not count in people with a migration background. As a result, a country may be much more culturally diverse, if immigration was higher in previous generations. Nevertheless, it is a good variable to catch the migration effects from the last few decades, since immigrants often maintain close connections to their home countries based on family ties and cultural similarities, often sending remittances home. While a detailed analysis of migrant stocks and flows, specified by type and reason of migration would certainly be instructive, again only limited data are available on a global scale. As immigration and 
naturalisation policies vary widely internationally and illegal immigration is widespread, the stock of migrants will have to suffice as a measure of the intensity of this dimension of globalization.

Tourism brings people in contact with each other. It changes attitudes and promotes understanding between cultures that would otherwise have little contact. As a major economic activity, it can bring prosperity to regions with no other resources than the natural beauty of the surroundings or the cultural value of historic sites. Tourism has grown steadily in the last century, the major impetus being cheaper air travel. Tourism here is defined as the sum of international inbound and outbound tourists per capita, i.e., the number of visitors who travel to a country other than their usual residence for a period not exceeding twelve months and whose main purpose is not employment related. The quality of the data is to be treated with caution though, since data collection takes place at the national level and is subject to highly diverging standards and practices.

Ideally, the cultural domain would include an indicator that captures people's attitudes, values and norms with respect to globalization. More specifically indicators that capture (a) the people's awareness of global issues such as climate change, but also those of economic and political nature, (b) attitudes towards global values such as human rights and democracy and peace (which are arguably rather western values) and (c) the consumption of global media and communication flows. Unfortunately, such indicators are not available. Arguably point (c) is partly captured by the technological domain.

\subsubsection{Technological domain}

There is common agreement among scholars that technological change has played a significant role in globalization processes. Specifically, communication and transport technologies that lead to a shrinking of time and space (Dicken, 2011). Due to data availability, the choice here is limited to communication technology.

The share of a country's population that uses the internet is an important indicator in the contemporary world, since it indicates how many people in a population have access to the worldwide network. Having access to the internet enables people to participate in a truly global social space, (more or less) independent of where they live. Among many other possibilities, they can 'consume' global media flows, attend global events (such as the jump from the Stratosphere by Felix Baumgartner, the presidential elections in the US, sport events), and consume cultural goods that have received global attention (such as Gangman Style). But much more, thanks to social media platforms, such as Facebook, YouTube, twitter and also blogs, people can also 'produce' or contribute to the global flows of communication. Whether informing the international community about human rights abuses or giving farmers access to commodity prices on 
the world's exchanges, as a global medium that transmits information cheaply over large distances it is an important factor. However, the indicator is limited in the sense, that it does not differentiate between consumption of local vs. global media flows. Further it does not adjust for the digital divide, which stems from differences in bandwidth, national restrictions (e.g. in Russia and China), internet literacy, and the capability to speak English etc. Dicken (2011) provides some compelling evidence that there is a very uneven geography of the internet, which is not taken into consideration here.

The second component is mobile cellular subscriptions per 100 people, which replaced 'international telephone traffic'. The reason for this switch is the rising importance of cell phones in developing countries, especially in Africa. Due to 'leapfrogging', many countries skip the step of setting up an infrastructure of landlines and install mobile networks instead. In those countries, telecommunication technology is used for much more than just calling and texting (and mobile internet). It is also used for banking, access to markets and many more. One shortcoming of the new indicator is that it does not say anything about relative intensity. Nevertheless it is an important indicator of how connected a country's population is internally and also externally.

\subsubsection{Environmental domain}

The MGI is the only globalization index that incorporates the environmental dimension of globalization. Held, McGrew, Goldblatt, and Perraton (1999) investigate global environmental degradation and the corresponding political and societal responses. These responses, however, are very difficult to track on a country-by-country basis. Another approach is to look at environmental aspects (or impacts) of traded goods and services. While trade may be good in increasing overall welfare, it allows for the externalization of environmental costs of production and consumption (Peters \& Hertwich, 2008; Yu, Feng, \& Hubacek, 2013). Accordingly, we include the ecological footprint of trade (exports and imports) as a share of (national) biocapacity. The Ecological Footprint is a measure of 'how much area of biologically productive land and water a certain economic unit or activity (in this case the traded good and services) requires to produce all the resources it consumes and to absorb the waste it generates, using prevailing technology and resource management practices' (Global Footprint Network, 2012a). Biocapacity is a measure of land productivity. This indicator replaced the previously used 'ecological deficit' and is not so much an indicator of the state of the environment, but rather one for the environmental dimensions of trade. As such this indicator is to be seen complementary to the indicator of trade.

A high score in the environmental dimension means that the ecological deficit of traded goods and services for a country is high, relative to national biocapacity. This, however, must neither be good nor bad. Trade enables countries with a relatively low biocapacity 
to import environmentally intensive goods from countries with abundant biocapacity, instead of degrading the domestic environment. Accordingly, there are strong arguments that trade may be beneficial for the environment (Copeland \& Taylor, 2004). However, as mentioned before, it may also dislocate the negative externalities of consumption to other countries (Borghesi \& Vercelli, 2003).

\subsection{Calculation of the MGI}

The calculation of the index is the next step in the construction process. For an overview of the different methodological approaches we refer to the OECD 'Handbook on Constructing Composite Indicators' (OECD, 2008). The calculation methodology is as subjective as the choice of domains and indicators to be included. This section shortly explains the calculation methodology as applied here.

The first step is calculation of indicators and imputation of missing data. Calculation is necessary for those indicators that are not directly available as used in the index. Imputation of missing data is done through extrapolation from historical data. Secondly, indicators, which have strongly skewed distributions, are transformed by taking the logarithm, this is a necessary step for the normalization of the data and is applied to the variables military, FDI, capital, migrants, tourism and Eco Footprint (see table 3.1). Thirdly, Following (Dreher, 2006), indicator scores are calculated, by applying panel normalization and using the formula $\left(\left(\mathrm{V}_{\mathrm{i}}-\mathrm{V}_{\min }\right) /\left(\mathrm{V}_{\max }-\mathrm{V}_{\min }\right) * 100\right)$, with $\mathrm{V}_{\max }$ and $\mathrm{V}_{\min }$ being the absolute maximum and minimum value as observed over the three points of time. Normalization scales all the different indicators, which have different units, to values between 0 and 100 . As a result of the previous steps, we can then finally aggregate the indicators first at the domain level and subsequently at the MGI level. Here equal weighting is applied in both aggregation steps, in coherence with our trans-dimensional definition of globalization. We assume that there is no hierarchy of domains, but that each is equally important. The final score (a value between 0 and 100) is then used to rank and compare countries. The higher the score, the more 'globalized' a country is (see table 3.4). The calculation methodology implies, that the scores can only interpreted relative to each other.

This calculation methodology is different from the 2008 edition of the MGI (Martens \& Raza, 2009). The one key difference is the logarithmic transformation of those indicators with skewed distributions. The motivation to include this step is to make the index more robust and coherent with the trans-dimensional definition of globalization and the argument that all indicators and domains should be equally weighted. The distribution of the underlying data has significant implications for the final index score and ranking, especially when equal weighting is applied. When aggregating two equally 
weighted indicators, which have significantly different distributions, the actual (average) weight of the indicators or domains will not be equal in the domain or final index respectively, despite the application of equal weighting. For example, when subindicator 1 is skewed to the left and subindicator 2 is skewed to the right (or even normally distributed), then the latter one will make up a much greater percentage of the final index, and both indicators will effectively not be equally weighted.

This has to be taken into consideration especially when indicators are changed. For example, the 2008 edition used the ecological deficit, with a distribution skewed to the right, whereas the ecological footprint of imports and exports as a share of biocapacity, as employed in the 2012 edition is skewed to the left. Accordingly, the share of the ecological domain in the final index would have gone significantly down, if logarithmic transformation would not have been applied. Further, countries with extremely high values in the untreated data tend to be overvalued if not transformed and normalized. We looked at histograms in order to detect skewed distributions and graphs with the countries on the $x$ axis, from lowest to highest and the respective indicator values on the $y$-axis in order to detect exponential patterns. Logarithmic transformation has been applied to the indicators Military, FDI, Capital, Migrants, Tourism, and Eco Footprint (see also table 3.1).

As a result of the inclusion of this new step, the average weight of the domains as actually observed in the final index is more balanced. On average, the sub-domains make up the following percentage of the final MGI Score for the 2008 and 2012 edition of the MGI respectively: political ( $26 \rightarrow 15 \%)$, economic (16 $\rightarrow 22 \%)$, (socio-) cultural (12 $\rightarrow$ $24 \%$ ), technological (16 $\rightarrow$ 18\%) and environment (30 $\rightarrow 21 \%$ ), keeping in mind that perfect equal weighting would imply a weight of $20 \%$ for each.

\subsubsection{Assumptions and limitations}

The data used in the MGI does not distinguish explicitly between globalization, internationalization and regionalization. Whereas some see this as a problem (Caselli, 2012; De Lombaerde \& lapadre, 2008), we rather argue that this is in line with our multi-scalar definition. Accordingly, internationalization and regionalization are seen as integral subprocesses of globalization rather than being something distinguishable. Accordingly, we do not claim to measure globalization as defined by Scholte as supraterritoriality (2008). We make the implicit assumption that countries with many international and regional links also have a greater number of global linkages. Furthermore we do not distinguish between the globalization based on the two criteria of functional (economic) integration and the extent of geographical spread as laid out by Dicken (2011). An index of globalization as a distinctive process is definitely interesting, but cannot be 
constructed with the data at hand. Concluding one could argue that the MGI should rather be called Maastricht Globalization / Internationalization / Regionalization index.

As expected, international statistics on eleven different indicators ranging from politics and military to the environment have widely varying degrees of data quality, reflecting the different capabilities and priorities of the organizations collecting the data. In addition, many countries are reluctant to share information about activities related to their national security, which creates data gaps that are not easily filled. The fact that countries with fewer international linkages tend to publish less data and are less likely to be included in international statistics biases against states that are less globalized. Additionally, despite being members of the UN and most other international bodies, countries with totalitarian or communist economic systems (e.g., North Korea, Cuba) are often excluded in international financial statistics. Therefore, this also leads to their exclusion due to lack of data. Finally, yet importantly, countries that are too small to collect internationally coherent statistics and/or are strongly integrated into the economies of their big neighbours (e.g., Luxembourg, Monaco, Singapore and Hong Kong) are also missing from the statistics and therefore excluded from the MGI. Furthermore, not for all indicators there was data available for the target year. Several components of the indicator where therefore extrapolated from older data. Since year-to-year changes tend to be small in those domains we don't expect this to have a large impact on the results (see Martens \& Raza, 2009). Table 3.2 below gives an overview of the coverage of the countries included in the MGI for the economic, political and environmental dimensions of globalization (as \% of world). The 117 countries included (out of a potential of 193) cover $95 \%$ of world GDP, $92 \%$ of world trade, $94 \%$ of the global biocapacity.

Table 3.2: Coverage of countries included in the MGI for various aspects for 2010

\begin{tabular}{|lr|}
\hline Indicator & Coverage \\
\hline embassies receiving & $80 \%$ \\
\hline total org membership & $68 \%$ \\
\hline population & $91 \%$ \\
\hline 2010 GDP & $95 \%$ \\
\hline Total Trade 2010 & $92 \%$ \\
\hline Tourism & $89 \%$ \\
\hline Biocapacity & $94 \%$ \\
\hline Ecological Footprint & $81 \%$ \\
\hline FDI inflows & $81 \%$ \\
\hline FDI outflows & $84 \%$ \\
\hline
\end{tabular}



Both the sensitivity to extreme values, correlation between indicators, and year-to-year variations are a major concern for the robustness of globalization indices (Dreher et al., 2008; OECD, 2008). Table 3.3 shows the correlation coefficients for the MGI 2012. All indicators are significantly correlated with the final index. The indicators 'Internet', 'Eco Footprint' and 'Tourism' are highly correlated with the index, with Spearman rank correlation coefficients of 0,905, 0,838 and 0,852 respectively. Surprisingly, the economic indicators 'Trade' and 'Capital' have the lowest correlation coefficients with 0,262 and 0,22 respectively. On the domain level, the final $\mathrm{MGI}$ is correlated strongest (as expected from the individual indicators correlations) with the technological domain (Spearman correlation $(r s)=0,926)$, followed by the ecological ( $r s=0,844)$, social and cultural domain ( $r s=0,838$ ), and political domain ( $r s=0.621$ ). The MGI is least correlated with the economic domain ( $r s=0,526)$. This implies that the MGI has indeed achieved one of its key objectives: to create a multi-dimensional globalization index that captures more than just economic development (Martens \& Zywietz, 2006c) and hence adds to the (quantitative) understanding of globalization.

\subsection{Results}

Composite indicators allow for several types of observations. First, observations can be made about general trends (e.g. increasing, decreasing, convergence, divergence). Secondly, the scores and rankings give insights into relative changes of individual countries. Thirdly, observations can be made for groups of countries that are clustered according to certain characteristics (e.g. geographic regions, economic performance, and level of globalization). And lastly, indicators that have been constructed with different methodologies can be compared. This analysis is limited to the first two types of observations, as the primary objective of this chapter has been to get insights into the current state and recent trends in globalization for the period $2000-2008-2012$ ?

On average, countries have been globalizing between 2000 and 2012 from a score of 40,56 in 2000 to 51,19 , an increase of $26,2 \%$. The most significant driver has been the technological domain, which increased from 1,89 to 9,08 (increase of $380 \%$ ). This, however, should not be surprising, given that the indicators for this domain are internet users and cell phone subscriptions. Further, on average, globalization has been slower between 2008 and 2012 than in the period before, with an absolute decrease in the economic domain. This is partly due to the global economic crisis which started in 2008 and was still not fully overcome in 2012 and which would explain a temporary slowdown of globalization processes. This interpretation has been later confirmed by various other globalization indices (Ghemawat \& Altman, 2016; Guo \& Schwarz, 2016). 
Another reason for the slowing down could be that globalization processes, as defined and measured by the MGI are slowing down in general and more importantly for highly globalized countries, since they are asymptotically reaching a saturation level of globalization. Table 3.4 gives an elaborate overview of ranks, scores and developments over time. The first column is the rank according to the MGI for 2012 and ' $\mathrm{dR} 00-12$ ' is the change ( $d=$ delta) in rank between 2000 and 2012. The results for the MGI score of 2012 can also be observed in figure 3.1 .

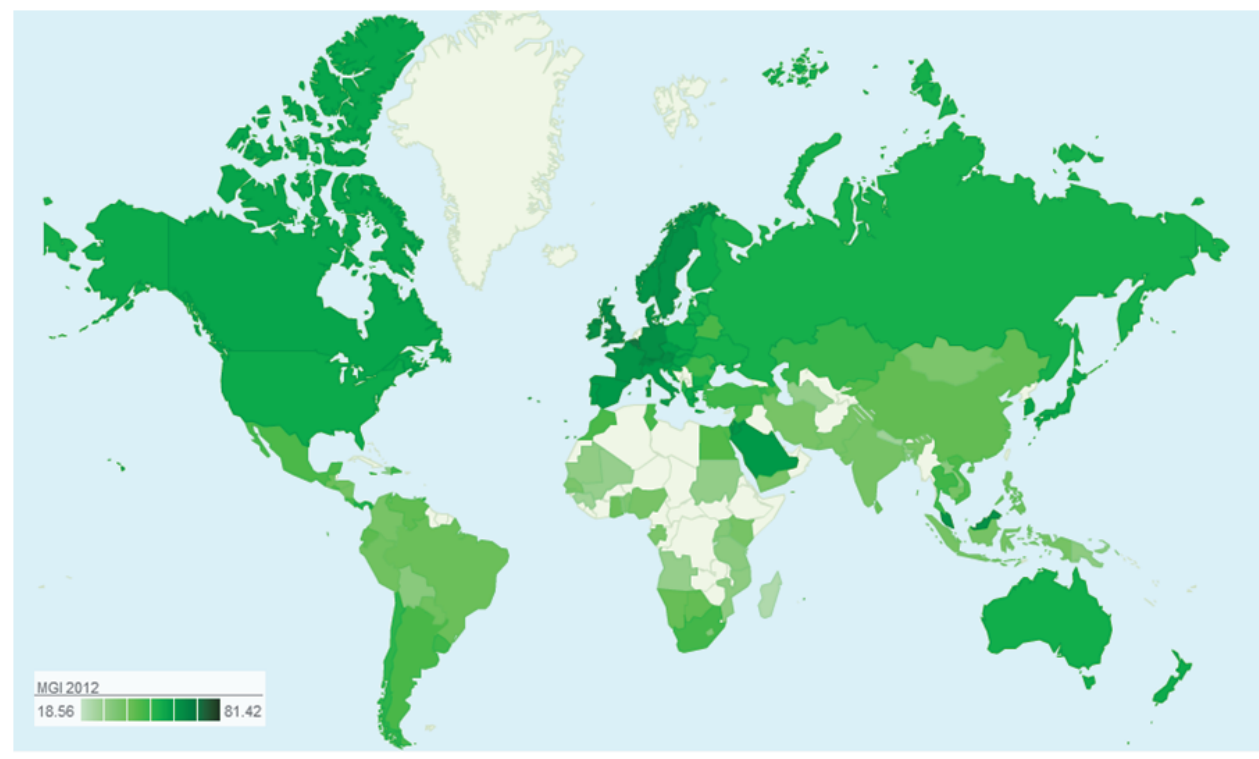

Figure 3.1: World Map of MGI 2012

In 2012, the most globalized country is Belgium, followed by the Netherlands, Switzerland, the UK, Austria and Germany. In general the top end of the list is dominated by European countries. Interestingly, however, Malaysia managed to make a jump by 10 ranks and is now the $9^{\text {th }}$ most globalized country and Jordan is on rank 12 . The BRICS countries, which are said to be the biggest emerging economies of the $21^{\text {st }}$ century rank 39 (Russia), 53 (South Africa), 71 (China), 75 (Brazil) and 85 (India). Most interestingly here is that South Africa actually lost 6 ranks, while all the others increased their rank between 11 and 18 ranks. The lowest ranked countries are Burundi, Madagascar, Nepal, Guinea, Mali, Angola and Turkmenistan.

The next three columns give the scores for 2000, 2008 and 2012. Further 'dS 00-12' is the change in score between 2000 and 2012, which can also be observed in figure 3.2. The colouring of the columns visualizes the previous observation that the general trend is towards more globalization. Only two countries, Papua New Guinea and Burundi 
were (slightly) 'de-globalizing' in absolute terms. Most notably, Albania increased its rank by 42 and its score by 25,24 points.

Another question of interest is whether there has been convergence in levels of globalization. Figure 3.1 and the table 3.4 indicate that there are significant differences in levels of globalization. Convergence takes place when countries with lower initial index values have a greater increase in the score in subsequent years. This can be analysed by regressing ds 00-12 as dependent variable (Y-axis) against the MGI Score of 2000 (Xaxis). Regression results have shown that also the squared term of the MGI Score 2000 is statistcially significant and should be included. Figure 3.3 shows the results of the regression model. MGI Score 2000 and the squared term are both significant at the $1 \%$ level. $\mathrm{R}^{2}$ is relatively low with 0,1454 , so that the model does not explain a lot of the variation. However, it indicates that there is a negative quadratic relationship, which means that on average countries with lower scores had smaller increases. Countries with a score of about 50 in 2000 had the highest increases and countries with high scores had relatively lower increases. There is no evidence for convergence. Variation is rather high, some countries are catching up while others remain stuck with low levels of globalization.

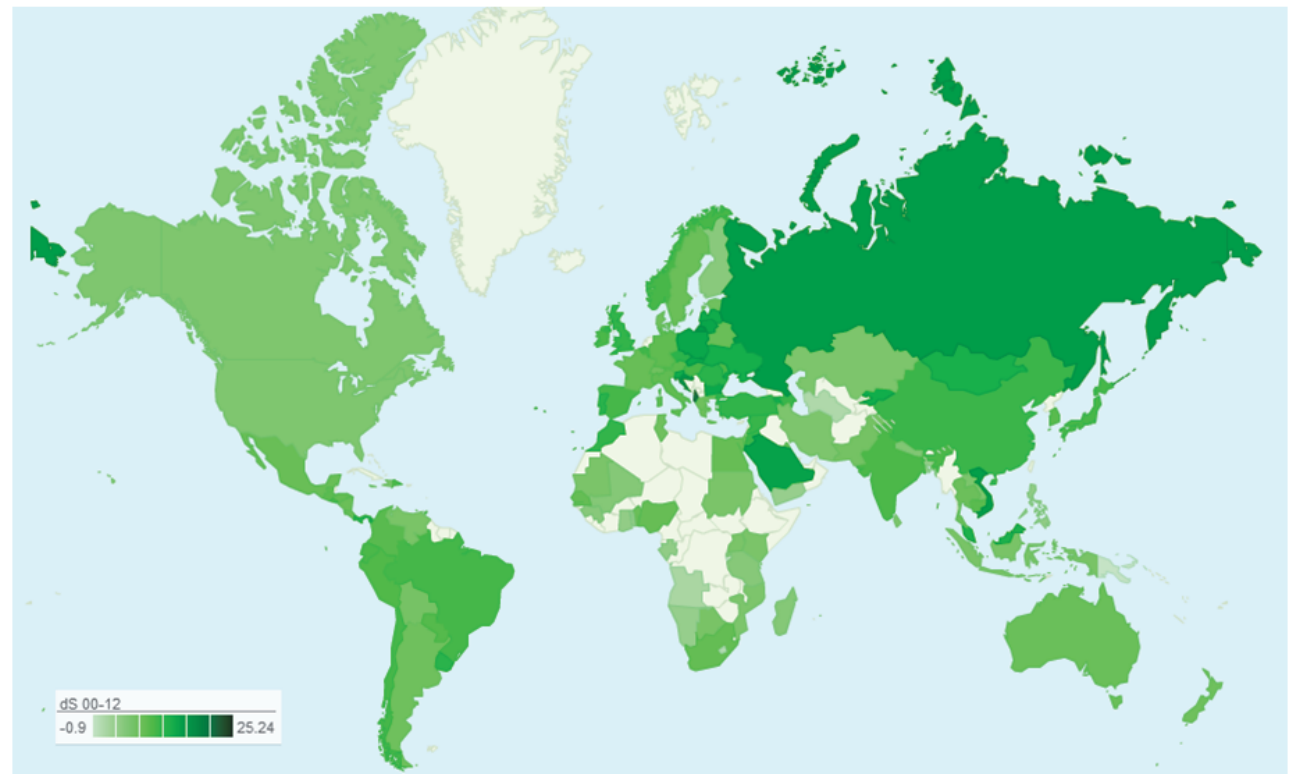

Figure 3.2: World Map of Score changes between 2000 and 2012 


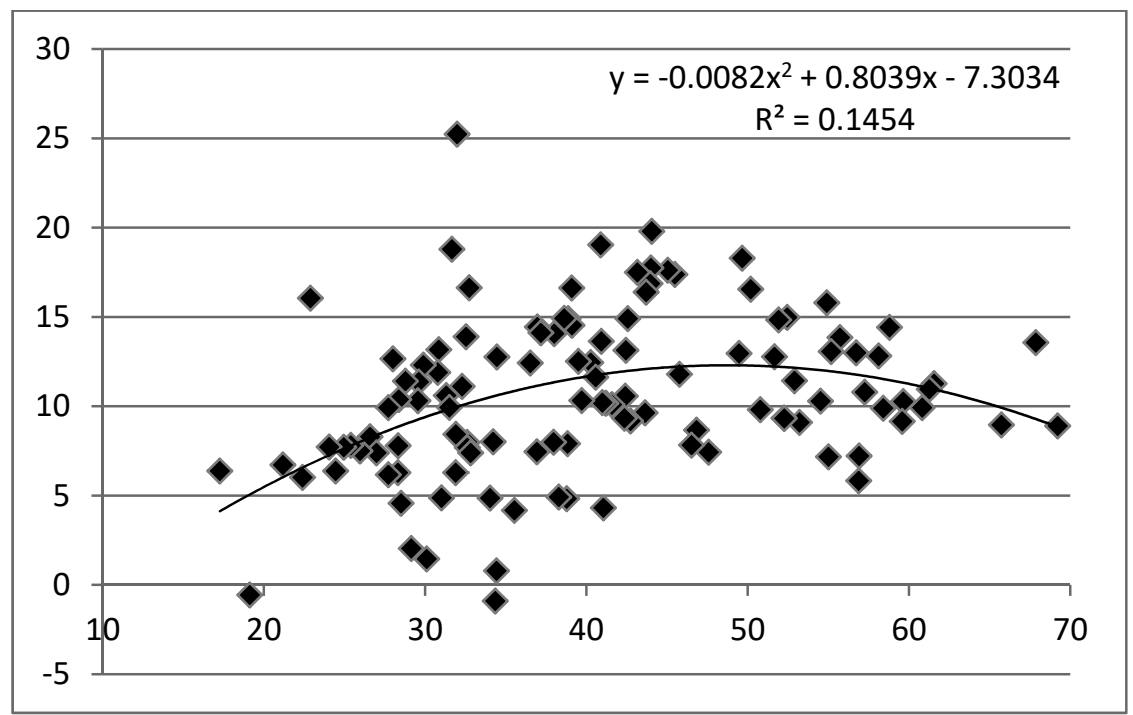

Figure 3.3: Regression results with MGI Score 2000 on the $X$-axis and dS 00-12 on the $Y$-axis

The last column, 'more G recently', is the per annum change between 2000 and 2008 minus the per annum change between 2008 and 2012. Accordingly, a positive number means that countries have been globalizing more in the period between 2008 and 2012 than in the period between 2000 and 2008. Highest scoring countries here are Armenia, Botswana, Turkmenistan, Nepal and Mongolia. A general observation is that this is rather the case for some countries that are ranked lower, whereas globalization processes have been slowing down in the higher ranked countries. There are two plausible explanations. First, those countries had a strong momentum of globalization and secondly they have been less integrated in the global capitalist system initially. Accordingly, the economic crisis had a smaller impact on them. 
Table 3.4: Maastricht Globalization Index (2012)

\begin{tabular}{|c|c|c|c|c|c|c|c|}
\hline country & Rank 12 & dR 00-12 & Score 00 & Score 08 & Score 2012 & dS 00-12 & $\begin{array}{l}\text { more G } \\
\text { recently }\end{array}$ \\
\hline Belgium & 1 & 1 & 67,86 & 77,25 & 81,42 & 13,56 & $-0,13$ \\
\hline Netherlands & 2 & -1 & 69,22 & 78,72 & 78,12 & 8,90 & $-1,34$ \\
\hline Switzerland & 3 & 0 & 65,72 & 73,78 & 74,69 & 8,96 & $-0,78$ \\
\hline United Kingdom & 4 & 5 & 58,79 & 71,18 & 73,21 & 14,42 & $-1,04$ \\
\hline Austria & 5 & -1 & 61,55 & 72,11 & 72,81 & 11,27 & $-1,15$ \\
\hline Germany & 6 & -1 & 61,26 & 68,97 & 72,22 & 10,96 & $-0,15$ \\
\hline Ireland & 7 & 4 & 58,11 & 68,17 & 70,94 & 12,82 & $-0,56$ \\
\hline Sweden & 8 & -2 & 60,82 & 69,49 & 70,74 & 9,92 & $-0,77$ \\
\hline Malaysia & 9 & 10 & 54,89 & 65,79 & 70,69 & 15,80 & $-0,14$ \\
\hline France & 10 & -3 & 59,65 & 68,60 & 69,91 & 10,27 & $-0,79$ \\
\hline Norway & 11 & 4 & 56,72 & 67,77 & 69,71 & 13,00 & $-0,90$ \\
\hline Jordan & 12 & 4 & 55,71 & 66,70 & 69,57 & 13,85 & $-0,66$ \\
\hline Denmark & 13 & -5 & 59,58 & 70,20 & 68,73 & 9,15 & $-1,70$ \\
\hline Israel & 14 & -4 & 58,40 & 66,24 & 68,29 & 9,89 & $-0,47$ \\
\hline Spain & 15 & 2 & 55,17 & 66,41 & 68,23 & 13,06 & $-0,95$ \\
\hline Italy & 16 & -4 & 57,25 & 65,25 & 68,04 & 10,80 & $-0,30$ \\
\hline Saudi Arabia & 17 & 13 & 49,66 & 63,37 & 67,95 & 18,30 & $-0,57$ \\
\hline Portugal & 18 & 5 & 52,45 & 64,06 & 67,43 & 14,98 & $-0,61$ \\
\hline Czech Republic & 19 & 7 & 51,91 & 65,45 & 66,76 & 14,84 & $-1,37$ \\
\hline Slovenia & 20 & 9 & 50,19 & 61,89 & 66,74 & 16,56 & $-0,25$ \\
\hline Kuwait & 21 & -1 & 54,51 & 64,85 & 64,80 & 10,29 & $-1,31$ \\
\hline Hungary & 22 & 5 & 51,65 & 64,62 & 64,43 & 12,78 & $-1,67$ \\
\hline Korea, Rep. & 23 & -1 & 52,89 & 63,93 & 64,33 & 11,43 & $-1,28$ \\
\hline Canada & 24 & -11 & 56,90 & 61,34 & 64,13 & 7,22 & 0,14 \\
\hline Croatia & 25 & 13 & 44,04 & 61,00 & 63,84 & 19,79 & $-1,41$ \\
\hline Slovak Republic & 26 & 10 & 45,49 & 62,06 & 62,87 & 17,39 & $-1,87$ \\
\hline Finland & 27 & -13 & 56,88 & 61,09 & 62,72 & 5,84 & $-0,12$ \\
\hline Poland & 28 & 9 & 45,05 & 59,56 & 62,66 & 17,62 & $-1,04$ \\
\hline Japan & 29 & 2 & 49,47 & 59,25 & 62,43 & 12,96 & $-0,43$ \\
\hline Estonia & 30 & -9 & 53,21 & 61,08 & 62,31 & 9,10 & $-0,67$ \\
\hline United States & 31 & -13 & 55,00 & 61,41 & 62,18 & 7,18 & $-0,61$ \\
\hline Lithuania & 32 & 7 & 43,99 & 59,89 & 61,74 & 17,75 & $-1,53$ \\
\hline New Zealand & 33 & -8 & 52,25 & 60,33 & 61,59 & 9,34 & $-0,69$ \\
\hline Greece & 34 & -10 & 52,26 & 61,56 & 61,59 & 9,32 & $-1,15$ \\
\hline Latvia & 35 & 5 & 43,95 & 59,73 & 60,81 & 16,87 & $-1,70$ \\
\hline Bulgaria & 36 & 7 & 43,16 & 61,52 & 60,66 & 17,50 & $-2,51$ \\
\hline Australia & 37 & -9 & 50,78 & 58,67 & 60,59 & 9,81 & $-0,51$ \\
\hline Ukraine & 38 & 3 & 43,70 & 56,92 & 60,09 & 16,39 & $-0,86$ \\
\hline Russian Federation & 39 & 15 & 40,88 & 54,39 & 59,92 & 19,04 & $-0,31$ \\
\hline Trinidad \& Tobago & 40 & -5 & 45,77 & 55,05 & 57,56 & 11,80 & $-0,53$ \\
\hline Panama & 41 & 4 & 42,56 & 51,85 & 57,47 & 14,92 & 0,24 \\
\hline
\end{tabular}




\begin{tabular}{|c|c|c|c|c|c|c|c|}
\hline country & Rank 12 & dR 00-12 & Score 00 & Score 08 & Score 2012 & dS 00-12 & $\begin{array}{l}\text { more G } \\
\text { recently }\end{array}$ \\
\hline Albania & 42 & 42 & 31,98 & 51,61 & 57,22 & 25,24 & $-1,05$ \\
\hline Armenia & 43 & 17 & 39,08 & 43,98 & 55,71 & 16,63 & 2,32 \\
\hline Chile & 44 & 2 & 42,45 & 52,45 & 55,58 & 13,13 & $-0,47$ \\
\hline Jamaica & 45 & -12 & 46,82 & 56,81 & 55,49 & 8,67 & $-1,58$ \\
\hline Kazakhstan & 46 & -14 & 47,57 & 50,94 & 55,00 & 7,43 & 0,60 \\
\hline Macedonia & 47 & 6 & 40,92 & 52,62 & 54,56 & 13,64 & $-0,98$ \\
\hline Mauritius & 48 & -14 & 46,51 & 53,36 & 54,34 & 7,82 & $-0,61$ \\
\hline Romania & 49 & 12 & 38,87 & 53,63 & 53,78 & 14,91 & $-1,81$ \\
\hline Turkey & 50 & 9 & 39,10 & 51,45 & 53,64 & 14,54 & $-1,00$ \\
\hline Uruguay & 51 & 13 & 38,62 & 51,19 & 53,55 & 14,93 & $-0,98$ \\
\hline Thailand & 52 & -10 & 43,64 & 52,35 & 53,27 & 9,63 & $-0,86$ \\
\hline South Africa & 53 & -6 & 42,41 & 51,25 & 52,97 & 10,57 & $-0,67$ \\
\hline Dominican Republic & 54 & 2 & 40,26 & 47,35 & 52,71 & 12,45 & 0,45 \\
\hline Georgia & 55 & 0 & 40,58 & 48,89 & 52,21 & 11,63 & $-0,21$ \\
\hline Azerbaijan & 56 & 10 & 38,00 & 48,29 & 52,07 & 14,06 & $-0,34$ \\
\hline Moldova & 57 & 1 & 39,51 & 49,76 & 52,03 & 12,52 & $-0,72$ \\
\hline Tunisia & 58 & -14 & 42,73 & 53,33 & 51,91 & 9,18 & $-1,68$ \\
\hline Argentina & 59 & -11 & 42,35 & 49,12 & 51,69 & 9,34 & $-0,20$ \\
\hline Belarus & 60 & -11 & 41,58 & 47,62 & 51,68 & 10,10 & 0,26 \\
\hline Morocco & 61 & 8 & 36,95 & 47,86 & 51,40 & 14,45 & $-0,48$ \\
\hline Mexico & 62 & -12 & 41,21 & 46,98 & 51,38 & 10,17 & 0,38 \\
\hline Syria & 63 & 5 & 37,18 & 46,05 & 51,29 & 14,11 & 0,20 \\
\hline Costa Rica & 64 & -12 & 40,99 & 49,67 & 51,20 & 10,21 & $-0,70$ \\
\hline Viet Nam & 65 & 22 & 31,67 & 44,59 & 50,46 & 18,79 & $-0,15$ \\
\hline Egypt, Arab Rep. & 66 & -9 & 39,71 & 47,74 & 50,04 & 10,33 & $-0,43$ \\
\hline Kyrgystan & 67 & 12 & 32,73 & 46,13 & 49,36 & 16,63 & $-0,87$ \\
\hline El Salvador & 68 & 3 & 36,51 & 45,94 & 48,93 & 12,42 & $-0,43$ \\
\hline Ecuador & 69 & 4 & 34,44 & 40,36 & 47,20 & 12,76 & 0,97 \\
\hline Venezuela, RB & 70 & -8 & 38,83 & 45,81 & 46,74 & 7,91 & $-0,64$ \\
\hline China & 71 & 11 & 32,54 & 41,59 & 46,44 & 13,90 & 0,08 \\
\hline Botswana & 72 & -5 & 37,96 & 38,94 & 45,95 & 7,99 & 1,63 \\
\hline Namibia & 73 & -22 & 41,05 & 46,92 & 45,37 & 4,32 & $-1,12$ \\
\hline Sri Lanka & 74 & -4 & 36,93 & 42,15 & 44,39 & 7,46 & $-0,09$ \\
\hline Brazil & 75 & 16 & 30,84 & 39,35 & 44,01 & 13,17 & 0,10 \\
\hline Ghana & 76 & -13 & 38,78 & 42,15 & 43,61 & 4,83 & $-0,05$ \\
\hline Guatemala & 77 & 6 & 32,30 & 41,22 & 43,41 & 11,11 & $-0,57$ \\
\hline Philippines & 78 & -13 & 38,29 & 41,68 & 43,21 & 4,92 & $-0,04$ \\
\hline Paraguay & 79 & 13 & 30,78 & 40,49 & 42,67 & 11,89 & $-0,67$ \\
\hline Gambia, The & 80 & -4 & 34,22 & 40,42 & 42,23 & 8,01 & $-0,32$ \\
\hline Peru & 81 & 13 & 29,89 & 41,44 & 42,20 & 12,31 & $-1,25$ \\
\hline Honduras & 82 & 7 & 31,31 & 40,69 & 41,91 & 10,61 & $-0,87$ \\
\hline Nicaragua & 83 & 5 & 31,50 & 37,26 & 41,44 & 9,93 & 0,32 \\
\hline
\end{tabular}




\begin{tabular}{|c|c|c|c|c|c|c|c|}
\hline country & Rank 12 & dR 00-12 & Score 00 & Score 08 & Score 2012 & dS 00-12 & $\begin{array}{l}\text { more G } \\
\text { recently }\end{array}$ \\
\hline Cambodia & 84 & 11 & 29,61 & 39,57 & 40,96 & 11,36 & $-0,90$ \\
\hline India & 85 & 18 & 28,00 & 35,13 & 40,66 & 12,66 & 0,49 \\
\hline Indonesia & 86 & -5 & 32,60 & 36,54 & 40,58 & 7,98 & 0,52 \\
\hline Pakistan & 87 & -2 & 31,91 & 39,09 & 40,34 & 8,44 & $-0,58$ \\
\hline Kenya & 88 & -8 & 32,62 & 36,92 & 40,31 & 7,69 & 0,31 \\
\hline Iran & 89 & -11 & 32,82 & 36,78 & 40,21 & 7,39 & 0,36 \\
\hline Colombia & 90 & 8 & 28,78 & 38,48 & 40,19 & 11,41 & $-0,78$ \\
\hline Nigeria & 91 & 5 & 29,56 & 38,00 & 39,87 & 10,31 & $-0,59$ \\
\hline Yemen & 92 & -20 & 35,54 & 39,89 & 39,72 & 4,18 & $-0,59$ \\
\hline Mongolia & 93 & 20 & 22,89 & 30,71 & 38,95 & 16,05 & 1,08 \\
\hline Gabon & 94 & -17 & 34,03 & 38,20 & 38,89 & 4,86 & $-0,35$ \\
\hline Senegal & 95 & 5 & 28,37 & 36,98 & 38,75 & 10,38 & $-0,63$ \\
\hline Cote d'Ivoire & 96 & -10 & 31,89 & 37,32 & 38,17 & 6,28 & $-0,47$ \\
\hline Benin & 97 & 8 & 27,72 & 35,50 & 37,65 & 9,92 & $-0,43$ \\
\hline Uganda & 98 & 3 & 28,32 & 33,90 & 36,12 & 7,80 & $-0,14$ \\
\hline Togo & 99 & -9 & 31,02 & 35,21 & 35,90 & 4,88 & $-0,35$ \\
\hline Lesotho & 100 & -26 & 34,43 & 35,39 & 35,22 & 0,80 & $-0,16$ \\
\hline Bolivia & 101 & 6 & 26,58 & 33,37 & 34,87 & 8,30 & $-0,47$ \\
\hline Rwanda & 102 & 0 & 28,31 & 31,47 & 34,59 & 6,28 & 0,38 \\
\hline Laos & 103 & 3 & 26,98 & 31,24 & 34,38 & 7,40 & 0,25 \\
\hline Tanzania & 104 & 0 & 27,72 & 33,97 & 33,89 & 6,17 & $-0,80$ \\
\hline Mozambique & 105 & 3 & 25,96 & 32,08 & 33,46 & 7,50 & $-0,42$ \\
\hline Papua New Guinea & 106 & -31 & 34,35 & 33,25 & 33,45 & $-0,90$ & 0,19 \\
\hline Haiti & 107 & 2 & 25,39 & 31,79 & 33,20 & 7,81 & $-0,45$ \\
\hline Bangladesh & 108 & -9 & 28,51 & 33,24 & 33,08 & 4,58 & $-0,63$ \\
\hline Mauritania & 109 & 1 & 24,96 & 29,31 & 32,67 & 7,71 & 0,29 \\
\hline Sudan & 110 & 2 & 24,05 & 31,88 & 31,77 & 7,72 & $-1,01$ \\
\hline Turkmenistan & 111 & -18 & 30,10 & 27,10 & 31,56 & 1,46 & 1,49 \\
\hline Angola & 112 & -15 & 29,14 & 30,77 & 31,18 & 2,04 & $-0,10$ \\
\hline Mali & 113 & -2 & 24,45 & 27,94 & 30,84 & 6,39 & 0,29 \\
\hline Guinea & 114 & 0 & 22,40 & 27,84 & 28,42 & 6,02 & $-0,54$ \\
\hline Nepal & 115 & 0 & 21,18 & 21,82 & 27,91 & 6,72 & 1,44 \\
\hline Madagascar & 116 & 1 & 17,27 & 23,84 & 23,65 & 6,38 & $-0,87$ \\
\hline Burundi & 117 & -1 & 19,13 & 17,15 & 18,56 & $-0,57$ & 0,60 \\
\hline
\end{tabular}




\subsection{Discussion and conclusions}

Globalization indices by themselves do not contribute so much to the sustainability debate. The MGI includes indicators, which are not necessarily positive or sustainable. Most importantly, the ecological footprint of trade as a percentage of domestic biocapacity is rather a negative indicator. Countries that score high on this indicator put greater pressures on ecosystems, either at home or elsewhere. The Netherlands, for example scores relatively high in this domain, which is because of a relatively low domestic biocapacity and a high ecological footprint of trade. Other countries, such as Bolivia, have a relatively high biocapacity and a smaller ecological footprint of trade. Whether the interpretation of the MGI as a measure of connectedness is something positive or negative is also a matter of argumentation and underlying perspectives. Connectedness can be good in the sense that it makes a system more resilient, if the other systems to which it is connected are also more resilient. However, if the overall system, which could be said to be global capitalism, has certain undesirable properties, than this translates also to less desirable properties in the sub-system. Further, more connected countries are also more affected by spill over effects from other countries.

Linking the MGI to indicators of sustainability may give better insights to what extent it is sustainable. Previous studies with the MGI have shown that countries that are more globalized are also more sustainable, and in general also healthier (Martens et al., 2010b; Martens \& Raza, 2010). However, taking an ecological perspective on sustainable development, it would be interesting to analyze the effects of globalization on Ecological Footprints. 
CHAPTER 4

\section{The effects of globalization on Ecological Footprints: An empirical analysis using the Maastricht Globalization Index}


"Globalization is not a monolithic force but an evolving set of consequences some good, some bad and some unintended. It is the new reality."

John B. Larson, member of the U.S. house of representatives

\begin{abstract}
Whether globalization is sustainable is a contested issue. The quantitative literature on the Maastricht Globalization Index (MGI) and the KOF Index of globalization shows that globalization contributes positively to economic \& human development, environmental performance, mortality, gender equality and physical integrity rights. However, globalization also drives within-country income inequality, especially in developing countries. Evidence on the effects of globalization on the ecological environment is limited and does not provide clear patterns; various dimensions of globalization have different effects on various pollutants. This chapter analyzes the statistical relationship between the most recent MGI (2012 edition) and the ecological dimension of sustainable development. The latter will be operationalized by considering four variants of the Ecological Footprint. The relation between globalization and sustainable development will be controlled for by GDP per capita as a proxy for affluence. We report the results for Pearson correlations and multivariate regressions for up to 171 countries. We conclude that globalization significantly increases the Ecological Footprint of consumption, exports and imports. Apart from the political dimension, all dimensions drive human pressures and demands on the environment. Globalization needs to go into new directions if it is to make a contribution towards all aspects of sustainable development.
\end{abstract}

\title{
Published as
}

Figge, L., Oebels, K., \& Offermans, A. (2016). The effects of globalization on Ecological Footprints: an empirical analysis. Environment, Development and Sustainability, 1-14. doi:10.1007/s10668-016-9769-8 


\section{Introduction}

Globalization as well as its causes and consequences are defined and analyzed in different ways by different scholars depending on their discipline and worldview (Dreher et al., 2008; Jones, 2010). Notwithstanding the vast amount of literature on the topic of globalization, it remains hard to get the drift of this phenomenon. This partially results from the various ways in which globalization is defined. A commonly accepted definition of globalization is "the intensification of cross-national interactions that promote the establishment of trans-national structures and the global integration of cultural, economic, ecological, political, technological and social processes on global, supranational, national, regional and local levels" (Rennen \& Martens, 2003). This definition's focus on multiple scales and domains imposes methodological challenges to measure the phenomenon of globalization. From a global systems perspective, globalization can be approached as the growing interconnectedness of sub-systems resulting in increasing system complexity at various scales (Jessop, 2000; Urry, 2005), further exacerbating the methodological challenges of assessment.

Measurement and quantitative assessment of globalization and its consequences is important to provide sound empirical facts on its nature and consequences, since the debate is ridden by conceptual ambiguity, ambivalent causal claims and conflicting worldviews. One powerful tool to measure, illustrate, monitor and communicate the complexity and multi-dimensionality inherent to globalization are Globalization Indices (GI). Gls allow for a relative ranking or comparison of country performance (OECD, 2008) with respect to globalization, on the basis of indicators. Two scientifically validated indices are the Maastricht Globalization Index (MGI) (Chapter 3, Martens and Raza (2009)) and the KOF index of (Dreher, 2006; Dreher et al., 2008). Previous indices usually praised those countries which have been most globalized, implying that being more globalized is a desirable outcome (Dreher, et al., 2008). However, being more globalized does not necessarily imply positive outcomes as illustrated by the MGI which, for example, includes the Ecological Footprint of trade as a percentage of domestic biocapacity as a measure of ecological globalization (see previous chapter). This means that a more globalized country puts larger pressures on ecosystems, either at home or elsewhere, which can be considered negative from a sustainability perspective. Therefore, the most globalized countries are not necessarily the most sustainable countries. Gls by themselves do not say anything about the effects or consequences of globalization and are unable to conclude whether globalization is sustainable.

In the in introduction we stated that "Sustainable development is made up of three 'pillars': the economic, social and environmental/ ecological (Kemp \& Martens, 2007; Martens, 2006). The social dimension includes health, justice, equity, equality and education. The economic dimension includes affluence, income, employment and wealth. 
Finally, the ecological dimension requires that socio-economic development does not threaten the integrity of ecological systems (Griggs et al., 2013)" (p. 7) Further, we "defined sustainable globalization as a form of globalization that ... contributes (positively) to the three pillars of sustainable development: the economic, social and ecological" (p. 9). In an ideal scenario, globalization would simultaneously contribute to sustainable development in the social, economic and ecological domain. However, sustainable development in one domain may not necessarily coincide with sustainable development in another domain. Literature already suggests that globalization is unlikely to achieve these objectives simultaneously (Dreher et al., 2008; Martens \& Raza, 2010; Martens \& Rotmans, 2002; Potrafke, 2014). There is an increasing need for empirical evidence on the sustainability of globalization, for instance through researching the (statistical) effects of GIs on sustainability indicators in the ecological, economic and social domain. One of the most pressing sustainability issues of our times are the increasing human demands on ecosystems, which have been quantified as environmental footprints. The evidence shows that humanity's environmental footprint is highly unsustainable and that radical changes in the global human organization are warranted (Hoekstra \& Wiedmann, 2014).

Section two of this chapter reviews the quantitative globalization literature in more depth and reveals that very little is known about the effects of globalization on ecological aspects related to human consumption and production. This represents a crucial gap in the academic literature that is addressed in this chapter. From a global perspective it is relevant to know whether externalized pressures are intensified by the process of globalization, irrespective of the geography of their impact. Our research question is: To what extent does globalization and its different domains intensify environmental footprints and/or contribute to ecologically sustainable development?

\subsection{Literature review}

\subsubsection{On MGI}

Analyzing the relation between globalization and sustainable development is not entirely new. Martens and Raza (2010) already analyzed whether globalization is sustainable by regressing the 2008 edition of the MGI for 117 countries against a selection of sustainability indices: the Human Development Index (HDI), the Environmental Performance Index (EPI), the Global Environment Facility Benefits Index (GBI), the Responsible Competitiveness Index (RCI) and the Sustainable Society Index (SSI). The results of their analysis do not provide clear patterns as the MGI correlates positively with the HDI, EPI and $\mathrm{RCI}$, negatively with the $\mathrm{GBI}$ and has no significant correlation with the SSI. When controlling for the potential effects of GDP per capita, the results change, but stay am- 
biguous: the coefficient of the MGI (and therewith the relation between globalization and sustainability) turns negative for the $\mathrm{HDI}$, remains negative for the $\mathrm{GBI}$ and positive for the $\mathrm{RCl}$ and has no significant correlation with the EPI and SSI. Furthermore, the authors showed that the means of high- and low globalized countries significantly differ for the HDI, EPI and RCl, but not for the GBI and the SSI. Martens and Raza (2010) conclude that the relationship between sustainability and globalization is a complex one since it may be positive in one domain (e.g. economic or human development) and negative in another one (e.g. environmental). This however may also be due to conceptual and empirical ambiguity of sustainability. In their review of sustainability indices, Pillarisetti and van den Bergh (2010) show that the different indices produce contradicting results that vary greatly - countries deemed sustainable according to one index, are un-sustainable according to another. Accordingly, the usefulness and particularly the accurateness of linking Gls to a multitude of diverging sustainability indices can be questioned. We argue that part of the ambiguity can be explained by the use and inclusion of (too) many indices that are too broad. For instance, the study of Martens and Raza (2010) looks at a wide ranging diversity of topics, and as a consequence, no clear conclusions on and recommendations for a sustainable globalization can be reached. It may therefore be better to focus on one issue (sustainability indicator) at a time, also because economic and ecological developments may conflict.

Another study with the MGI examined the question whether globalization is healthy (Martens et al., 2010b) by looking at mortality rates of infants, under-five year olds and adults. The study gives an overview of potential positive and negative impacts of globalization on health outcomes. Overall, the MGI and its five sub-domains (political, economic, social, technological and ecological) are all significantly and negatively correlated with the mortality indicators. The more globalized countries can thus be considered to have lower mortality rates. Martens et al. (2010b) included control variables and tested their relevance in multiple regression models. In this procedure, the coefficient of the MGI remains negative and significant in multiple regression models for all three health indicators. The authors conclude that countries which are more globalized achieve better health results.

\subsubsection{On KOF}

The KOF index of globalization has been used in more than 100 studies which reveal diverging results in terms of the economic and social sustainability effects of globalization. None of those framed the study of globalization in terms of ecological sustainability and/or sustainable development. A review study by Potrafke (2014) has shown that globalization has positive effects on economic growth, human development, gender equality, women's rights and physical integrity rights (social and economic dimension of SD). However also negative effects were revealed as globalization has been shown to 
increase within-country income inequality, especially in developing countries (socioeconomic aspect of SD) (Potrafke, 2014). The review study does not discuss the ecological consequences or effects of globalization, which is due to the absence of articles on those issues.

The only exemption is the book by Dreher et al. (2008). They use the KOF index to analyze the effects of globalization on various ecological pressures: carbon dioxide, sulphur dioxide, biochemical oxygen demand (a proxy for water pollution) and round wood production. The authors estimated a panel $(1970-2000)$ and a 30 year cross-sectional average. The panel regressions show that overall globalization reduces sulfur dioxide emissions and water pollution, and find no effect on carbon dioxide and round wood production. When splitting up the globalization index in three subcomponents (economic, political and social), the study finds that economic globalization has a small increasing effect on round wood production; social globalization has a small and positive effect on the emission of carbon dioxide and political globalization decreases water pollution. The 30 year cross-section approach (to capture long-term effects) yields that overall globalization increases water pollution and round wood production, economic globalization increases sulfur dioxide emissions, social globalization increases water pollution and round wood production while the political dimension has no effect at all. These results can be considered ambiguous and even contradictory, which comes from the fact that the study looks at a diverse set of ecological pressures, instead of focusing on one specific issue. This further justifies more research to conceptualize, operationalize and analyze the effects of globalization on the ecological dimension of sustainable development.

Although the current literature covers the effects of globalization on various (sustainability) indicators, there is not a lot of attention to the effects on globalization on ecological footprints. This represents a crucial gap that is addressed in this chapter. The next section presents a method to analyze the relation between the multiple dimensions of globalization and the ecological aspects of sustainable development. Innovative in our approach is the inclusion of environmental footprints to expand the focus of the current literature in two ways: first we go beyond social, health and economic factors and explicitly add the ecological sustainability domain in the analysis. Second, we do so by focusing on a single issue (human demands on ecosystems) rather than employing a collection of indices and/or indicators. 


\subsection{Method and data}

In order to address our research question we use the MGI to measure globalization and include Ecological Footprints to operationalize the ecological dimension of sustainable development.

\subsubsection{The Ecological Footprint}

Environmental footprints quantify the human demand on the natural environment and have the advantage that they can be linked to the (theoretical) carrying capacity of our earth's ecosystems (Borucke et al., 2013; Global Footprint Network, 2012c; Hoekstra \& Wiedmann, 2014). This is crucial as development can only be deemed sustainable if it stays within the (global) boundary conditions of the ecological environment (or the ecological budget constraint (Lianos, 2013)) - otherwise it is expected to have detrimental effects on the Earth's life support systems (Griggs et al., 2013). Recent research makes clear that humanity's pressures on the environment is currently unsustainable (Hoekstra \& Wiedmann, 2014; Steffen, Broadgate, Deutsch, Gaffney, \& Ludwig, 2015; Steffen, Richardson, et al., 2015). One of the most advanced concepts and measures that quantifies human demands on the ecological environment is the Ecological Footprint (Borucke et al., 2013; Global Footprint Network, 2012c; Hoekstra \& Wiedmann, 2014).

The Ecological Footprint (EF) was developed in a response to the incapacity of monetary analyses to capture the consequences of the accelerating depletion of natural capital stocks. The EF has been designed as direct biophysical measurement of stocks and flows to comprehend human demands on natural capital (Wackernagel \& Rees, 1996). It captures the productive capacity of nature to provide resources for consumption (provisioning services) and its capacity as a sink to take up waste (regulating services) (Ewing et al., 2010). More specifically, biocapacity represents "a measure of the amount of biologically productive land and sea area available to provide the ecosystem services that humanity consumes - our ecological budget or nature's regenerative capacity" (Borucke et al., 2013, p. 519). The EF is quantified by multiplying the productive area (standardized to global hectares) with the specific domestic yield factor of a country (Global Footprint Network, 2012c). The EF accounts for six different land use types in terms of bioproductive area: cropland, forest, grazing land, marine and inland water, built-up land and carbon uptake land. The built-up land represents constructed areas like cities. Uptake land is an expression for the demand on waste disposal in equivalent $\mathrm{CO}_{2}$ emissions to be taken up by vegetation and also referred to as the energy footprint (Borucke et al., 2013). 
To increase the relevance of the concept of EFs in the discussion on globalization we need to realize that in a world with increasingly globalized trade flows many products are not consumed at their place of production (Weinzettel, Hertwich, Peters, SteenOlsen, \& Galli, 2013). To analyze the effect of globalization on human pressures, it would therefore not be enough to only analyze a (country-specific) footprint of production; what we need is a consumption based quantification of the EF. Therefore, the EF of consumption is calculated as the sum of the EF of production and imports minus the EF of exports (see Borucke et al., 2013). As such, it considers the EF necessary to fulfill the (present) consumption demands of countries while considering the externalities that the production of these consumption goods exert on the countries of production. We employ the 2011 edition of the National Footprint Accounts (Global Footprint Network, 2012c) and look at the per capita EF of consumption, production, exports and imports, at the national level, to make it comparable across countries. It is important to make this distinction, as according to Chen and Han (2015) one third of global arable land use is embodied in trade flows.

\subsubsection{The extended and adjusted Maastricht Globalization Index}

In this study we employ the extended 2012 edition of the Maastricht Globalization Index (chapter 3). The MGI was first developed by Martens and Zywietz (2006a) and later on improved by (Martens \& Raza, 2009) and in chapter 3. The MGI covers five domains: the political, economic, social-cultural, technological and ecological. Except for the latter, these domains are further operationalized by different variables (see table 4.1). The choice of variables and their data sources have been documented and elaborated before and are therefore not addressed in more detail here. For a recent critical perspective and overview on the measurement of globalization, we refer to chapter two.

To calculate the globalization indices each variable is transformed on a zero to hundred scale using the formula $\left(\left(V_{i}-V_{\text {min }}\right) /\left(V_{\max }-V_{\min }\right) \times 100\right)$ with $V$ meaning value. Indicator values are aggregated by simple addition, using equal weighting on the domain and index level. Values closer to hundred denote more globalization. To be able to disentangle the effects of the different domains we use the overall index and the sub-indices although previous studies with the MGI only employed the overall index in multivariate regressions (Martens et al., 2010b; Martens \& Raza, 2010) 
Table 4.1: Domains and indicators of the Maastricht Globalization Index (MGI),

\begin{tabular}{|c|c|c|}
\hline Domain & Indicator name & Indicator definition \\
\hline \multirow[t]{3}{*}{ Political (1/4) } & Embassies (1/3) & $\begin{array}{l}\text { Absolute number of in-country embassies and high } \\
\text { commissions }\end{array}$ \\
\hline & Organizations $(1 / 3)$ & $\begin{array}{l}\text { Absolute number of memberships in international } \\
\text { organizations }\end{array}$ \\
\hline & Military $(1 / 3)$ & $\begin{array}{l}\text { Trade in conventional arms as a share of military spend- } \\
\text { ing }\end{array}$ \\
\hline \multirow[t]{3}{*}{ Economic (1/4) } & Trade $(1 / 3)$ & Imports + exports of goods and services (\% of GDP) \\
\hline & FDI $(1 / 3)$ & Gross foreign direct investment, stocks (\% of GDP) \\
\hline & Capital (1/3) & absolute value of net private capital flows (\% of GDP) \\
\hline \multirow{2}{*}{$\begin{array}{l}\text { Social and cultural } \\
(1 / 4)\end{array}$} & Migrants (1/2) & International migrant stock as a share of population \\
\hline & Tourism (1/2) & International arrivals + departures per 100 inhabitants \\
\hline \multirow[t]{2}{*}{ Technological (1/4) } & Cell Phone (1/2) & Mobile cellular subscriptions per 100 inhabitants \\
\hline & Internet (1/2) & Internet users as a share of population \\
\hline $\begin{array}{l}\text { Environmental } \\
\text { (omitted) }\end{array}$ & Eco footprint & $\begin{array}{l}\text { Ecological footprint of imports and exports as a share of } \\
\text { biocapacity }\end{array}$ \\
\hline
\end{tabular}

Note: adjusted from chapter 3, Figge and Martens (2014)

The single indicator for the environmental dimension refers to the earlier-discussed EF of imports and exports as a share of biocapacity. In order to not include the same measurement (EF of imports and exports) in the dependent and independent variable at the same time we adjust the overall MGI by omitting the ecological dimension in the final index calculation. This is a necessary adjustment of the MGI which is in line with an argument put forward by Rennen and Martens (2003) that the environmental factors of globalization differ from the others in so far that those have rather been the consequence of globalization than a driving force (There are strong indications that more recently this is changing - ecological developments are increasingly re-shaping (other) globalization processes). This adjustment has to be taken into consideration when analyzing and interpreting the results. For the sake of completeness we report the results for the ecological dimension in the calculations when splitting up the index.

While the 2012 MGI edition (chapter 3) covered 117 countries, we extended the coverage to 183 countries for this study which is close to global coverage (results are presented in the appendix to this chapter). The addition of further countries is restricted due to the absence of available data. Also for the countries that are currently included in the MGI we sometimes face missing data, an often occurring problem when calculating composite indices (OECD, 2008). Two different methods are being used here; Cold check imputations and unconditional mean imputations (see OECD (2008) for more 
information) while using mean values for 19 different geographical regions intended to serve the accuracy of the results. The imputation of data is restricted to maximal four missing values in variables and the methods have been checked against their impact on the normal distribution of the indicators for every domain.

\subsubsection{Estimation strategy to relate globalization to Ecological Footprints}

In order to assess the extent to which globalization contributes to ecologically sustainable development we conduct a regression analysis with the footprints as the dependent and the globalization indices as the independent variables. First, we estimate Spearman correlations to assess the bivariate statistical relationship between the globalization indices and the EFs irrespective of other factors. This provides a first crude overview of the (potential) effects of globalization. Following Dreher et al. (2008), Martens et al. (2010b) and Martens and Raza (2010) we subsequently estimate multivariate equations of the following type, using ordinary least squares (OLS):

$$
Y_{i}=\alpha_{i}+\beta_{1} G_{l o b}+\beta_{2} A_{i}+\beta_{3} A_{i}^{2}+\varepsilon_{i}
$$

Where $\mathrm{Y}$ is the natural log of the EF per capita measure. Glob is overall globalization index or the respective sub-indices. $A$ is the level of affluence, measured as the natural log of GDP per capita (World Bank, 2014). Affluence is considered to be the key determinant of human demands on the environment and is consistently shown to have significant and sizable effects (Jorgenson \& Clark, 2011; Rosa, York, \& Dietz, 2004; York et al., 2003a). We include the squared term to test for non-linear relationships. Other control variables have been suggested and will be introduced in chapter 5 . We consciously do not include those here, in order to estimate the upper limits of the consequences of globalization. $\alpha$ is the intercept and $\varepsilon$ is the standard error term. In order to disentangle the effects of the domains of globalization we conduct stepwise inclusion based on the individual results of the spearman correlations. In the final models we only include or report those variables (dependent and independent) for which have found significant effects. If the ecological globalization index is found to be significant we also report the respective models. This will show which aspects of globalization (if any) have significant effects on the environmental footprints and therefore provide more nuanced insights. Coefficients that are significant and negative would provide evidence that globalization contributes to sustainable development as it contributes to decreasing environmental footprints. Insignificant coefficients mean that there is no relationship and coefficients that are positive and significant mean that globalization increases ecological demands and thereby contributes to ecologically un-sustainable development. 


\subsection{Results and discussion}

Table 4.2 and figure 4.1 indicate that overall globalization and the sub-indices positively and significantly correlate with all variants of the EF. This leads us to a first unambiguous conclusion that more globalized countries have higher EFs and therefore put higher pressures on ecosystems. This is different from the findings of Martens and Raza (2010) who found that globalization and all its dimensions correlate positively with the Environmental Performance Index (EPI). The EPI looks at two issues, protection of human health and ecosystems, and is therefore quite different from the EF in two respects: first, it contains aspects of human health, which correlate strongly with development indicators (and thereby globalization). Second, the ecosystem vitality aspects, which are more comparable to the $\mathrm{EF}$, look at efficiency and trend indicators issues, rather than actual impacts or levels. From an environmental perspective, trends (changes in flows) are of course important, but what matters more are the actual flows, which are better captured by the EFs.

Table 4.2: Spearman Correlations for MGI, its domains, the Ecological Footprint of consumption, exports, imports and production

\begin{tabular}{lllll}
\hline $\mathrm{n}=181$ & In $\mathrm{EF}_{\text {consumption }}$ & In $\mathrm{EF}_{\mathrm{Exports}}$ & In $\mathrm{EF}_{\text {Imports }}$ & In $\mathrm{EF}_{\text {Production }}$ \\
\hline $\mathrm{MGI}$ & $0.7505^{* *}$ & $0.7187^{* *}$ & $0.8891^{* *}$ & $0.5420^{* *}$ \\
\hline MGI Domains & & & & \\
Political & $0.3218^{* *}$ & $0.4135^{* *}$ & $0.2357^{* *}$ & $0.4035^{* *}$ \\
Economic & $0.3420^{* *}$ & $0.1954^{* *}$ & $0.3935^{* *}$ & $0.1711^{*}$ \\
Social and cultural & $0.6207^{* *}$ & $0.5933^{* *}$ & $0.7710^{* *}$ & $0.4181^{* *}$ \\
Technological & $0.7373^{* *}$ & $0.7200^{* *}$ & $0.8386^{* *}$ & $0.5725^{* *}$ \\
Environmental & $0.5659^{* *}$ & $0.5294^{* *}$ & $0.8190^{* *}$ & $0.2848^{* *}$ \\
\hline
\end{tabular}

${ }^{*} \mathrm{p} \leq 0.05 ;{ }^{*} \mathrm{p} \leq 0.01 ;$ all dependent variables are in per capita terms 

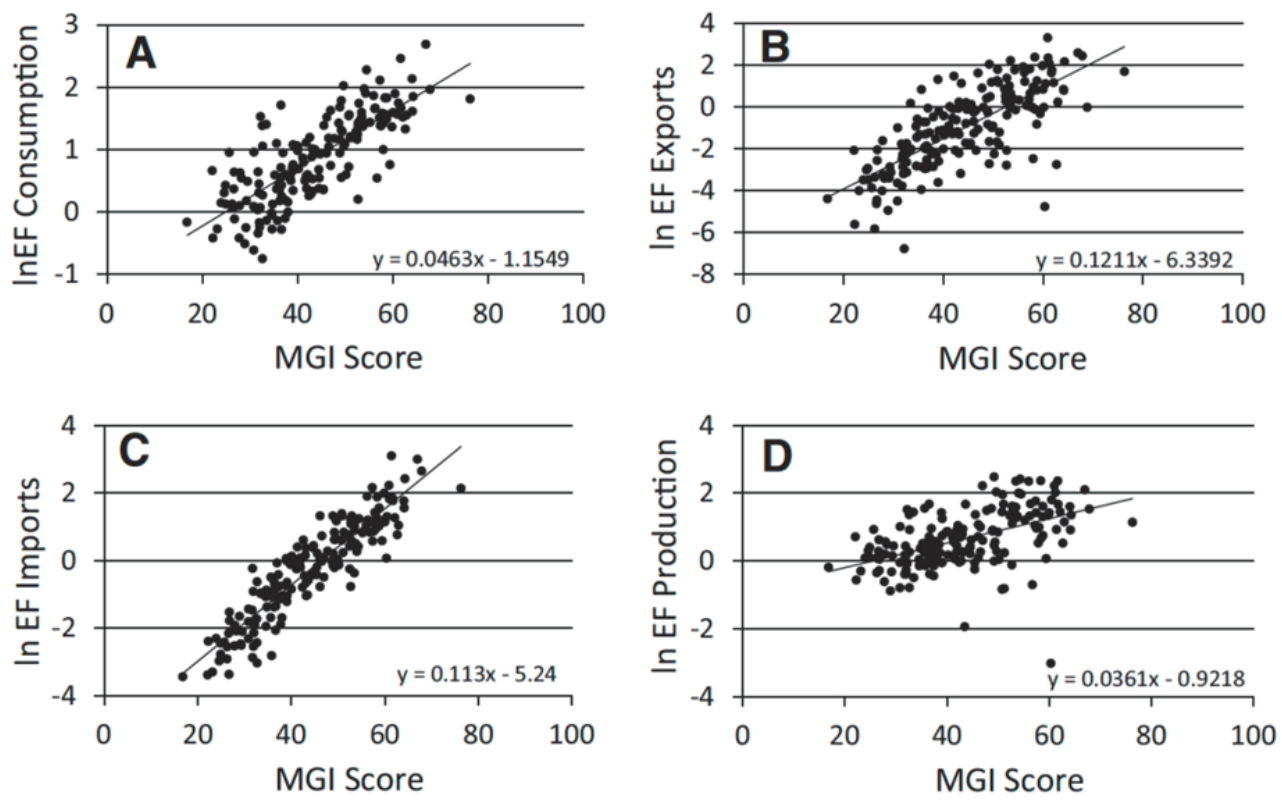

Figure 4.1: Scatterplots and linear regressions of the MGI and the logarithm of the Ecological Footprint of $A$ Consumption, B Exports, C Imports, D Production ( $n=181)$.

We now turn to the results for the multi-variate regressions while controlling for Affluence (GDP per capita and its squared term). For the EF of consumption we find that the overall MGI is positive and significant at the $10 \%$ level (note that we do not indicate the $10 \%$ significance level in the results tables, see table 4.3 ). Further, we see that this effect is not only significant, but also sizeable as a 1 point increase in globalization corresponds with a $1 \%$ increase of the EF of consumption. To put this into context, the standard deviation of the MGI is 12 points with a mean score of 44.88 . The results from chapter 3 found that on average countries globalized by about 11 points between 2000 and 2012, thereby increasing EFs by 11 percent. This corresponds to a difference in globalization, for example, between the Netherlands (64) and Poland (53). Globally the EF is approximately $50 \%$ beyond biocapacity. Accordingly, a reduction of the EF by approximately $30 \%$ would reconcile human demands with biophysical limits, a condition for sustainable development. In terms of globalization, this is the difference between the Netherlands (64) and Indonesia (34). A deglobalization of this magnitude on a global scale is probably neither possible nor desirable and certainly not put forward here. Much more, given the global development agenda and discourse, including the new set of sustainable development goals, this is obviously also not a policy consideration or option that would be taken seriously. A remaining policy question would rather be, how globalization could be used to steer and support development into more sustainable directions. 
While the explained variance is high $\left(r^{2}=0.74\right)$ and the F-value is highly significant, we do not find GDP per capita to be significant in explaining differences in the EF of consumption. This is in contrast with previous research where GDP had consistently been shown to be a significant and sizable determinant of EFs (Dietz, Rosa, \& York, 2007; Jorgenson \& Clark, 2009, 2011; Rosa et al., 2004; York et al., 2003a) and other pollutants (Dreher et al., 2008; Gassebner, Lamla, \& Sturm, 2011; Lamla, 2009). This raises some questions about the relation between affluence and globalization. One interpretation could be that in those other studies GDP captures effects that should be attributed to the process of globalization. The discussion around the Environmental Kuznets Curve switches the argument around and argues that globalization processes operate through GDP (see for instance Dinda (2004) and Stern (2004)), which makes controlling for globalization theoretically redundant. The globalization literature has consistently shown that globalization drives GDP and its growth rates (Dreher, 2006; Dreher et al., 2008; Potrafke, 2014). So there is no definite answer to this issue, as those processes are very likely to influence each other which creates a complexity that cannot be addressed with the methods employed here. It seems, nevertheless, that taken together affluence and globalization rather increase EFs.

This is supported by our further findings. For the EF of exports and imports the effects are even higher and more significant. A one point increase in globalization corresponds to an increase of $3.6 \%$ in EF of exports and $7.2 \%$ in EF of imports. Studies with the EF have shown that almost a third of global arable land use is embodied in international trade (Chen \& Han, 2015), so these effects of globalization need to be taken seriously.

Table 4.3: Multivariate regression models of the MGI, the Ecological Footprint of consumption, exports, imports and production, controlling for GDP per capita and its squared expression.

\begin{tabular}{lllll}
\hline Model & In $\mathrm{EF}_{\text {consumption }}$ & In $\mathrm{EF}_{\text {Exports }}$ & In $\mathrm{EF}_{\text {Imports }}$ & In $\mathrm{EF}_{\text {Production }}$ \\
\hline MGI & $0.0098(1.92)$ & $0.0366^{*}(2.39)$ & $0.0725^{* *}(9.39)$ & $-0.0124(-1.70)$ \\
In GDPpc & $-0.0468(-0.23)$ & $1.6744^{* *}(2.78)$ & $0.8930^{* *}(3.12)$ & $-0.0140(-0.05)$ \\
(In GDPpc $)^{2}$ & $0.0223(1.88)$ & $-0.0521(-1.46)$ & $-0.0319(-1.90)$ & $0.0282(1.71)$ \\
Constant & $-0.7938(-0.97)$ & $-12.8458^{* *}(-5.19)$ & $-8.6368^{* *}(-7.36)$ & $-0.6888(-0.60)$ \\
Adj. $r^{2}$ & 0.7391 & 0.6871 & 0.8718 & 0.5691 \\
$F$ Value & $159.67^{* *}$ & $125.45^{* *}$ & 384.20 & $74.53^{* *}$ \\
$n$ & 169 & 171 & 170 & 168 \\
\hline
\end{tabular}

${ }^{*} p \leq 0.05 ;{ }^{* *} p \leq 0.01 ; \mathrm{t}$-values in parentheses; all dependent variables are in per capita $(\mathrm{pc})$ terms

The further elaboration of multivariate models builds on the previous findings; as the results indicate that the EF of production is not significantly influenced by globalization we omit this variable in the subsequent analysis. Table 4.4 reports the final multivariate regression models of globalization (the MGI sub-indices) and the EF of consumption, exports and imports. Table 4.5 summarizes the main findings. Overall, we find that 
globalization moderately contributes to higher environmental footprints and thereby to ecologically un-sustainable development.

Table 4.4: Multivariate regression models of MGI dimensions and the Ecological Footprints under the control of GDP per capita and its squared term. Only significant variables are mentioned.

\begin{tabular}{l|llll}
\hline Model & In $\mathrm{EF}_{\text {Cons }}$ & In $\mathrm{EF}_{\text {Exports }}$ & In $\mathrm{EF}_{\text {Imports }}$ & In $\mathrm{EF}_{\text {Imports }}$ \\
\hline Technological & - & - & $0.0106^{* *}(3.03)$ & $0.0143^{* *}(3.43)$ \\
Social \& Cultural & - & $0.0152^{*}(2.02)$ & $0.0118^{* *}(3.34)$ & $0.0183^{* *}(4.53)$ \\
Ecological & - & - & $0.0265^{* *}(8.08)$ & - \\
Economic & $0.0107^{* *}(3.61)$ & - & $0.0203^{* *}(4.85)$ & $0.0194^{* *}(4.10)$ \\
Political & - & - & - & - \\
In GDPpc & $-0.0291(-0.15)$ & $1.7842^{* *}(2.96)$ & $-0.4241(-1.89)$ & $0.9526^{* *(3.23)}$ \\
(In GDPpc) $^{2}$ & $0.0238^{*}(2.07)$ & $-0.0514(-1.44)$ & $0.1893^{* *}(4.45)$ & $-0.0288(-1.68)$ \\
Constant & -1.0660 & $-13.0659^{* *}$ & $-4.3302^{* *}$ & $-8.5738^{* *}$ \\
Adj. $r^{2}$ & $(-1.33)$ & $(-5.25)$ & $(-12.06)$ & $(-6.89)$ \\
$F$ Value & 0.7528 & 0.6842 & 0.9008 & 0.8664 \\
$n$ & $171.58^{* *}$ & $123.75^{* *}$ & $253.88^{* *}$ & $220.12^{* *}$ \\
\hline
\end{tabular}

${ }^{*} p \leq 0.05,{ }^{*} p \leq 0.01, \mathrm{t}$-values in parentheses; all dependent variables are in per capita $(\mathrm{pc})$ terms

We also find that not all dimensions of globalization have significant effects on the different footprints. The results show that it is indeed worthwhile to split up the MGI into its sub-indices in multi-variate regressions. This allowed us to see which aspects of globalization are driving which footprints. While this has been common practice in studies with the KOF, previous studies with the MGI refrained from splitting up the globalization index. Why is this important? Despite finding significant bi-variate effects in the Spearman correlations, some of those cancel each other out in the multi-variate regressions models: different dimensions of globalization have different effects on EFs (see table 4.5). Further, as was the case before, some of the effects are cancelled out by the inclusion of GDP per capita. As argued before, globalization has been shown to enhance GDP and its growth. So despite some of the direct effects decreasing or disappearing, the overall effects of globalization are not to be neglected as indirect ones are captured by GDP. The same can and should be expected for other indicators and indices, for instance those looked at in the study by Martens and Raza (2010). They find ample significant effects for the sub-indices of the MGI in the bi-variate regressions, but then do not include those separately in the multi-variate regressions.

Table 4.5: summarizing the \% effects of a one-point increase in Globalization on the Footprints

\begin{tabular}{|c|c|c|c|c|}
\hline & EF cons. & EF prod. & EF imports & EF exports \\
\hline MGI overall & $+1 \%$ & & $+7.2 \%$ & $+3.6 \%$ \\
\hline Economic & $+1 \%$ & & $+2 \%$ & \\
\hline \multicolumn{5}{|l|}{ Political } \\
\hline Socio-cultural & & & $+1.5 \%$ & $+1.8 \%$ \\
\hline Technological & & & $+1.4 \%$ & \\
\hline
\end{tabular}


For the ecological dimension we find significant effects for the EF of imports, however, for the reasons mentioned before those results should not be further taken into consideration. A point to be made however is that the omission of the ecological domain leads only to small changes in the size of the effects of the variables. The overall explained variances $\left(r^{2}\right)$ do not change much. This shows that the omission of the ecological dimension is unproblematic when assessing the impacts of globalization. While composite indices capture and map the state and trends of (overall) globalization (as done in chapter 3), the application in regressions demands that Gls are (also) split up in order to enhance the understanding of its consequences. For GDP per capita we find very similar effects as in the previous models when looking at overall globalization.

We do not find any effects for political globalization. While this is suspicious, Dreher et al. (2008) find the same when looking at the effects of globalization on different pollutants, without discussing it further. Although we did not investigate this empirically we see three potential reasons and/or complications: first, the level to which a country is politically globalized does indeed not have an effect on ecological pressures. Second, it may be a measurement issue. The indicators used to proxy the political dimension may not capture the phenomenon precisely. Also, and more importantly, the political indicators are measured in different units: absolute number of embassies and organizations for instance, rather than in per capita terms or as a percentage of the economy, as all of the other indicators (see table 4.1). They therefore may not be fit for purpose and more suitable indicators and data may be necessary. A third possible explanation is that positive and negative effects cancel each other out.

This third option is not an unlikely explanation as integration into international organizations and more diplomatic relations, for example, may result in better policies and actions for the environment, by enhancing knowledge and improving international cooperation on environmental issues. But it may equally also result in policies and actions that rather intensify ecological pressures, by opening up markets and thereby creating new pressures on the environment. Other globalization indicators and domains may of course suffer from the same issues. Globalization and its sub-domains describe and capture abstract societal processes which may have ambiguous effects on the environment and are difficult to disentangle with the data and the estimation techniques used in this study.

We want to discuss two limitations and suggestions for further research. First, we recommend employing panel data, which allows studying a longer time period instead of looking at one point in time only. This would allow filtering out time and countryspecific effects. Using the KOF index which is available from 1971 onwards, may be a promising strategy in this respect. Second, the broad variation in results between the different employed methods (simple regression and multi variate regression) reveals 
the necessity to further investigate confounding factors that potentially effect the relation between globalization and sustainability and that could be taken into consideration. In this study we control only for GDP per capita while the literature looking at the determinants of EFs and pollution suggests many more potential variables (e.g. (Dietz et al., 2007; Gassebner et al., 2011; Jorgenson \& Clark, 2011; Lamla, 2009). This means that the results have to be interpreted as upper limits as they may suffer from an omitted variable bias. Chapter 5 will address those two issues.

\subsection{Conclusions}

The ecological consequences have not been a main concern of the quantitative globalization literature so far. The few studies that do include environmental aspects solely focus on water- and air pollutants. In this study we put forward and employ the Ecological Footprint as a comprehensive indicator to assess 'to what extent does globalization and its different domains intensify environmental footprints and/or contribute to ecologically sustainable development?' Methodologically, we have shown that it is worthwhile to split up the MGI in multi-variate regression models as it draws a more nuanced picture. Further, the omission of the ecological dimension from the index has been necessary for this study but remains unproblematic. Recent evidence on the MGI has shown that globalization continues to increase despite the economic crisis which started unfolding in 2008 (Chapter 3). However, in its current form it does not simultaneously contribute to sustainable development in the social, economic and ecological domains. Our results show that globalization contributes to increasing pressures on the environment. While previous studies with the MGI and KOF have found ambiguous results on the sustainability of globalization, this study provides unambiguous results. While, yes, for some variants of the EF we do not find effects it is very clear that globalization does not have decreasing effects on EFs. Reconciling human demands within the Earth's carrying capacity remains one of the greatest challenges (Griggs et al., 2013; Hoekstra \& Wiedmann, 2014). Globalization in its current form has not been contributing to the ecological dimension of sustainable development.

A key issue or question remains whether humanity will be able to re-direct the globalizing trends in new directions in which we continue to improve human and economic development while maintaining the health of our ecosystems - the Earth's life support systems. This calls for new directions and forms of future globalizations if humanity is to develop in an ecologically robust way. Deterioration of the ecological environment may also result in un-intended and undesirable effects in the social and economic domain. For the future it will be crucial to embrace the positive aspects of globalization while mitigating the related risks of an increasingly inter-connected world, which is also inevitable for social robustness, which will be addressed in chapter 6 . 


\section{Appendix 4}

Table A.4.1: the extended Maastricht Globalization Index (2012) for 183 Countries

\begin{tabular}{|c|c|c|c|c|c|c|c|}
\hline Country / Variable & Pol & Econ & Cul & Tech & Env & MGI & Rank \\
\hline Singapore & 50,18 & 73,39 & 85,49 & 72,24 & 100,00 & 76,26 & 1 \\
\hline Hong Kong SAR, China & 28,37 & 88,54 & 92,82 & 84,90 & 49,49 & 68,82 & 2 \\
\hline Belgium & 75,77 & 59,09 & 72,02 & 65,88 & 66,44 & 67,84 & 3 \\
\hline Luxembourg & 44,13 & 63,31 & 81,77 & 81,71 & 63,88 & 66,96 & 4 \\
\hline Netherlands & 63,67 & 42,34 & 73,64 & 75,25 & 66,48 & 64,28 & 5 \\
\hline Switzerland & 64,36 & 51,20 & 76,55 & 72,93 & 55,67 & 64,14 & 6 \\
\hline United Arab Emirates & 48,58 & 51,15 & 81,86 & 75,91 & 62,72 & 64,04 & 7 \\
\hline United Kingdom & 69,69 & 46,98 & 72,22 & 75,85 & 49,90 & 62,93 & 8 \\
\hline Antigua and Barbuda & 27,97 & 52,72 & 81,00 & 87,65 & 63,98 & 62,66 & 9 \\
\hline Germany & 75,35 & 43,32 & 67,03 & 73,79 & 51,05 & 62,11 & 10 \\
\hline Austria & 65,90 & 38,36 & 80,03 & 73,24 & 51,17 & 61,74 & 11 \\
\hline Qatar & 49,00 & 44,80 & 84,52 & 74,62 & 55,34 & 61,66 & 12 \\
\hline Bermuda & 14,59 & 42,07 & 84,48 & 77,29 & 88,54 & 61,40 & 13 \\
\hline Sweden & 67,89 & 43,66 & 75,94 & 75,04 & 43,52 & 61,21 & 14 \\
\hline Norway & 59,73 & 48,22 & 70,36 & 76,65 & 49,98 & 60,99 & 15 \\
\hline Iceland & 39,99 & 63,51 & 78,07 & 75,66 & 47,20 & 60,89 & 16 \\
\hline Bahrain & 40,04 & 60,03 & 83,24 & 58,67 & 60,31 & 60,46 & 17 \\
\hline Cayman Islands & 14,94 & 63,62 & 91,06 & 77,46 & 54,52 & 60,32 & 18 \\
\hline Macao, China & 26,56 & 47,72 & 97,23 & 79,66 & 49,49 & 60,13 & 19 \\
\hline France & 75,77 & 41,66 & 72,73 & 64,61 & 45,24 & 60,00 & 20 \\
\hline Malaysia & 63,60 & 53,15 & 68,56 & 58,14 & 55,70 & 59,83 & 21 \\
\hline Jordan & 56,38 & 51,05 & 82,44 & 46,04 & 61,09 & 59,40 & 22 \\
\hline Ireland & 41,26 & 62,12 & 80,89 & 61,79 & 47,77 & 58,77 & 23 \\
\hline Cyprus & 44,37 & 58,13 & 78,02 & 50,19 & 62,96 & 58,74 & 24 \\
\hline Spain & 66,71 & 40,15 & 73,40 & 61,36 & 51,93 & 58,71 & 25 \\
\hline Malta & 41,26 & 61,86 & 70,34 & 59,29 & 59,31 & 58,41 & 26 \\
\hline Finland & 53,73 & 43,92 & 67,76 & 83,24 & 43,05 & 58,34 & 27 \\
\hline Portugal & 62,66 & 44,44 & 67,33 & 61,15 & 54,43 & 58,00 & 28 \\
\hline St. Kitts and Nevis & 26,52 & 55,12 & 72,99 & 76,62 & 58,73 & 57,99 & 29 \\
\hline Barbados & 29,23 & 48,86 & 73,93 & 67,58 & 69,69 & 57,86 & 30 \\
\hline Israel & 49,81 & 30,24 & 79,40 & 66,29 & 61,88 & 57,52 & 31 \\
\hline Saudi Arabia & 47,87 & 41,64 & 75,19 & 66,85 & 55,39 & 57,39 & 32 \\
\hline Denmark & 51,01 & 37,29 & 71,79 & 76,49 & 50,00 & 57,32 & 33 \\
\hline Italy & 66,77 & 33,22 & 69,39 & 64,21 & 52,32 & 57,18 & 34 \\
\hline Andorra & 28,45 & 45,20 & 98,96 & 60,84 & 50,01 & 56,69 & 35 \\
\hline Czech Republic & 51,34 & 46,90 & 66,35 & 68,98 & 48,07 & 56,33 & 36 \\
\hline
\end{tabular}




\begin{tabular}{|c|c|c|c|c|c|c|c|}
\hline Country / Variable & Pol & Econ & Cul & Tech & Env & MGI & Rank \\
\hline Slovenia & 45,36 & 47,68 & 73,06 & 61,41 & 53,55 & 56,21 & 37 \\
\hline Canada & 66,13 & 41,44 & 76,95 & 59,43 & 35,95 & 55,98 & 38 \\
\hline Croatia & 48,18 & 41,64 & 78,08 & 66,30 & 41,87 & 55,21 & 39 \\
\hline Kuwait & 35,13 & 45,84 & 71,98 & 58,81 & 60,65 & 54,48 & 40 \\
\hline Australia & 58,96 & 41,74 & 73,04 & 63,98 & 33,80 & 54,30 & 41 \\
\hline United States & 72,31 & 35,57 & 64,81 & 60,39 & 36,96 & 54,01 & 42 \\
\hline Poland & 58,46 & 42,44 & 61,85 & 62,22 & 43,73 & 53,74 & 43 \\
\hline Korea, Rep. & 60,19 & 35,42 & 46,98 & 68,03 & 56,87 & 53,50 & 44 \\
\hline Russian Federation & 79,75 & 30,99 & 65,50 & 62,80 & 28,31 & 53,47 & 45 \\
\hline New Zealand & 44,16 & 34,85 & 76,09 & 71,09 & 41,13 & 53,46 & 46 \\
\hline Greece & 61,29 & 36,56 & 71,90 & 49,32 & 48,19 & 53,45 & 47 \\
\hline Seychelles & 31,52 & 57,25 & 76,88 & 54,19 & 46,98 & 53,36 & 48 \\
\hline Lithuania & 46,53 & 45,25 & 63,55 & 68,36 & 42,54 & 53,25 & 49 \\
\hline Oman & 33,87 & 36,01 & 73,25 & 72,42 & 49,00 & 52,91 & 50 \\
\hline Japan & 60,09 & 36,68 & 50,62 & 63,52 & 52,86 & 52,75 & 51 \\
\hline Latvia & 44,34 & 40,17 & 76,87 & 62,02 & 40,31 & 52,74 & 52 \\
\hline Montenegro & 44,19 & 48,18 & 70,45 & 71,99 & 28,63 & 52,69 & 53 \\
\hline Aruba & 16,39 & 50,61 & 88,41 & 51,48 & 56,36 & 52,65 & 54 \\
\hline Ukraine & 56,62 & 44,20 & 70,60 & 51,86 & 39,26 & 52,51 & 55 \\
\hline Bulgaria & 55,55 & 49,83 & 58,43 & 56,85 & 41,56 & 52,44 & 56 \\
\hline Hungary & 46,33 & 39,11 & 68,23 & 63,05 & 44,50 & 52,24 & 57 \\
\hline Dominica & 27,79 & 49,11 & 69,72 & 62,42 & 47,11 & 51,23 & 58 \\
\hline Liechtenstein & 26,27 & 51,03 & 81,43 & 65,52 & 31,73 & 51,19 & 59 \\
\hline Brunei Darussalam & 38,31 & 44,85 & 76,93 & 52,37 & 42,80 & 51,05 & 60 \\
\hline Estonia & 32,13 & 36,30 & 76,65 & 68,48 & 40,83 & 50,88 & 61 \\
\hline St. Lucia & 29,23 & 53,18 & 69,59 & 48,41 & 53,47 & 50,78 & 62 \\
\hline Slovakia & 37,73 & 39,80 & 59,91 & 67,88 & 48,55 & 50,77 & 63 \\
\hline Albania & 42,81 & 44,84 & 64,69 & 57,75 & 40,77 & 50,18 & 64 \\
\hline Panama & 35,54 & 53,22 & 59,76 & 67,00 & 34,21 & 49,95 & 65 \\
\hline Lebanon & 40,36 & 48,89 & 71,30 & 32,40 & 55,54 & 49,70 & 66 \\
\hline Trinidad and Tobago & 34,96 & 45,65 & 55,52 & 59,41 & 52,66 & 49,64 & 67 \\
\hline Bahamas, The & 29,41 & 52,36 & 77,04 & 52,57 & 35,55 & 49,39 & 68 \\
\hline Armenia & 41,77 & 43,81 & 65,86 & 53,11 & 41,49 & 49,21 & 69 \\
\hline Maldives & 34,10 & 48,78 & 59,48 & 52,55 & 51,05 & 49,19 & 70 \\
\hline Grenada & 27,42 & 51,01 & 72,90 & 45,56 & 49,07 & 49,19 & 71 \\
\hline Libya & 52,28 & 49,60 & 45,90 & 48,72 & 48,08 & 48,92 & 72 \\
\hline Serbia & 50,17 & 42,80 & 56,84 & 53,63 & 41,13 & 48,92 & 73 \\
\hline Macedonia & 41,96 & 43,30 & 57,40 & 52,25 & 49,51 & 48,88 & 74 \\
\hline Kazakhstan & 47,57 & 45,10 & 67,28 & 46,58 & 36,85 & 48,67 & 75 \\
\hline Puerto Rico & 14,57 & 55,65 & 71,04 & 42,57 & 56,36 & 48,04 & 76 \\
\hline
\end{tabular}




\begin{tabular}{|c|c|c|c|c|c|c|c|}
\hline Country / Variable & Pol & Econ & Cul & Tech & Env & MGI & Rank \\
\hline Chile & 54,92 & 38,36 & 54,09 & 51,44 & 39,99 & 47,76 & 77 \\
\hline Moldova & 54,30 & 46,21 & 55,27 & 42,20 & 36,83 & 46,96 & 78 \\
\hline Uruguay & 44,77 & 36,90 & 60,74 & 56,77 & 35,52 & 46,94 & 79 \\
\hline Romania & 56,58 & 39,00 & 50,99 & 48,50 & 37,72 & 46,56 & 80 \\
\hline Cape Verde & 37,91 & 49,04 & 59,59 & 33,58 & 52,54 & 46,53 & 81 \\
\hline Mauritius & 36,03 & 37,58 & 62,52 & 36,98 & 57,58 & 46,14 & 82 \\
\hline South Africa & 65,20 & 37,46 & 57,36 & 30,54 & 40,05 & 46,12 & 83 \\
\hline Turkey & 59,14 & 32,73 & 56,17 & 41,14 & 41,17 & 46,07 & 84 \\
\hline Belarus & 48,75 & 42,23 & 57,57 & 42,63 & 36,63 & 45,56 & 85 \\
\hline Georgia & 41,64 & 48,16 & 63,46 & 35,65 & 38,19 & 45,42 & 86 \\
\hline Dominican Republic & 41,25 & 38,93 & 61,08 & 42,13 & 43,70 & 45,42 & 87 \\
\hline Costa Rica & 34,47 & 42,70 & 68,34 & 34,59 & 43,60 & 44,74 & 88 \\
\hline Jamaica & 27,27 & 41,11 & 53,84 & 41,75 & 58,88 & 44,57 & 89 \\
\hline Syria & 46,48 & 36,19 & 69,49 & 24,50 & 45,97 & 44,53 & 90 \\
\hline Azerbaijan & 46,67 & 27,82 & 58,67 & 48,18 & 41,12 & 44,49 & 91 \\
\hline Argentina & 42,40 & 31,78 & 57,06 & 53,00 & 33,87 & 43,62 & 92 \\
\hline West Bank and Gaza & 18,94 & 45,88 & 71,71 & 31,04 & 49,82 & 43,48 & 93 \\
\hline Viet Nam & 49,25 & 52,66 & 22,29 & 56,90 & 34,75 & 43,17 & 94 \\
\hline Egypt, Arab Rep. & 66,39 & 36,98 & 38,11 & 34,83 & 39,41 & 43,14 & 95 \\
\hline Bosnia and Herzegovina & 44,66 & 38,10 & 41,44 & 46,99 & 44,40 & 43,12 & 96 \\
\hline Thailand & 42,34 & 39,01 & 52,64 & 35,95 & 45,07 & 43,00 & 97 \\
\hline Morocco & 49,28 & 36,52 & 36,00 & 49,66 & 42,55 & 42,80 & 98 \\
\hline Mexico & 50,15 & 36,57 & 46,27 & 35,49 & 44,40 & 42,58 & 99 \\
\hline Kyrgystan & 37,91 & 46,88 & 60,86 & 33,95 & 32,34 & 42,39 & 100 \\
\hline Gabon & 43,91 & 44,27 & 68,11 & 29,44 & 24,90 & 42,13 & 101 \\
\hline Swaziland & 35,29 & 42,89 & 67,07 & 19,37 & 45,04 & 41,93 & 102 \\
\hline Tunisia & 29,01 & 44,49 & 46,27 & 44,59 & 44,79 & 41,83 & 103 \\
\hline Venezuela, RB & 56,64 & 28,37 & 51,04 & 41,82 & 31,18 & 41,81 & 104 \\
\hline Algeria & 60,79 & 30,70 & 40,86 & 28,66 & 46,70 & 41,54 & 105 \\
\hline Belize & 27,83 & 51,72 & 70,85 & 21,41 & 34,58 & 41,28 & 106 \\
\hline Ecuador & 47,28 & 32,20 & 51,93 & 39,69 & 34,34 & 41,09 & 107 \\
\hline El Salvador & 33,84 & 38,67 & 43,71 & 38,22 & 46,57 & 40,20 & 108 \\
\hline Botswana & 30,33 & 38,49 & 67,03 & 31,43 & 33,16 & 40,09 & 109 \\
\hline Iran & 55,04 & 26,00 & 54,20 & 28,64 & 36,24 & 40,02 & 110 \\
\hline Suriname & 34,41 & 41,94 & 64,04 & 57,48 & 1,28 & 39,83 & 111 \\
\hline China & 68,35 & 33,81 & 22,52 & 33,22 & 37,49 & 39,08 & 112 \\
\hline Gambia, The & 33,77 & 42,54 & 59,84 & 25,25 & 33,91 & 39,06 & 113 \\
\hline Brazil & 59,05 & 36,02 & 33,52 & 46,26 & 20,44 & 39,06 & 114 \\
\hline Djibouti & 34,76 & 54,43 & 58,80 & 7,54 & 39,31 & 38,97 & 115 \\
\hline Namibia & 42,61 & 33,40 & 63,06 & 19,37 & 36,23 & 38,93 & 116 \\
\hline
\end{tabular}




\begin{tabular}{|c|c|c|c|c|c|c|c|}
\hline Country / Variable & Pol & Econ & Cul & Tech & Env & MGI & Rank \\
\hline Sao Tome and Principe & 36,73 & 46,34 & 48,05 & 24,52 & 37,35 & 38,60 & 117 \\
\hline Ghana & 42,82 & 43,07 & 52,15 & 22,01 & 32,19 & 38,45 & 118 \\
\hline Cote d'Ivoire & 41,47 & 35,14 & 59,78 & 19,50 & 34,11 & 38,00 & 119 \\
\hline Zimbabwe & 41,18 & 43,11 & 55,10 & 20,54 & 29,98 & 37,98 & 120 \\
\hline Uzbekistan & 41,02 & 38,08 & 52,85 & 28,26 & 28,41 & 37,73 & 121 \\
\hline Sri Lanka & 39,60 & 33,06 & 46,33 & 26,22 & 42,01 & 37,44 & 122 \\
\hline Tajikistan & 38,91 & 35,18 & 49,87 & 26,69 & 36,26 & 37,38 & 123 \\
\hline Guatemala & 38,09 & 32,40 & 41,18 & 35,69 & 38,77 & 37,22 & 124 \\
\hline Guyana & 35,67 & 57,68 & 49,91 & 33,20 & 8,20 & 36,93 & 125 \\
\hline Liberia & 33,56 & 68,02 & 48,69 & 12,84 & 20,30 & 36,68 & 126 \\
\hline Senegal & 45,50 & 34,95 & 46,26 & 24,33 & 32,10 & 36,63 & 127 \\
\hline Pakistan & 64,47 & 28,57 & 35,20 & 22,31 & 32,56 & 36,62 & 128 \\
\hline Peru & 42,67 & 38,78 & 31,62 & 41,96 & 27,56 & 36,52 & 129 \\
\hline Mongolia & 49,77 & 56,30 & 39,18 & 28,55 & 8,72 & 36,50 & 130 \\
\hline Honduras & 31,23 & 44,88 & 38,55 & 35,87 & 31,47 & 36,40 & 131 \\
\hline Cambodia & 38,10 & 46,98 & 53,05 & 14,30 & 29,06 & 36,30 & 132 \\
\hline Iraq & 48,30 & 33,15 & 30,84 & 19,35 & 49,40 & 36,21 & 133 \\
\hline Nicaragua & 32,67 & 49,46 & 46,94 & 20,70 & 30,50 & 36,05 & 134 \\
\hline India & 71,87 & 32,45 & 29,03 & 18,49 & 27,04 & 35,78 & 135 \\
\hline Paraguay & 31,20 & 35,72 & 50,82 & 32,32 & 28,01 & 35,61 & 136 \\
\hline Nigeria & 57,75 & 38,18 & 29,65 & 27,91 & 24,44 & 35,59 & 137 \\
\hline Colombia & 42,95 & 33,71 & 33,45 & 42,13 & 23,89 & 35,23 & 138 \\
\hline Indonesia & 57,41 & 33,43 & 20,46 & 27,13 & 35,48 & 34,78 & 139 \\
\hline Congo, Rep. & 41,59 & 59,18 & 43,57 & 25,11 & 3,85 & 34,66 & 140 \\
\hline Kenya & 47,73 & 22,34 & 43,55 & 28,18 & 31,17 & 34,59 & 141 \\
\hline Philippines & 36,96 & 27,05 & 33,73 & 33,57 & 41,36 & 34,53 & 142 \\
\hline Yemen & 38,48 & 31,52 & 41,64 & 17,29 & 38,51 & 33,49 & 143 \\
\hline Bhutan & 31,93 & 37,95 & 50,59 & 19,95 & 26,76 & 33,43 & 144 \\
\hline Laos & 49,68 & 40,56 & 40,32 & 18,99 & 13,86 & 32,68 & 145 \\
\hline Mauritania & 31,18 & 49,49 & 40,34 & 20,50 & 21,84 & 32,67 & 146 \\
\hline Timor-Leste & 44,14 & 41,86 & 39,89 & 12,71 & 24,62 & 32,65 & 147 \\
\hline Turkmenistan & 37,62 & 46,04 & 45,05 & 16,20 & 18,07 & 32,59 & 148 \\
\hline Equatorial Guinea & 37,80 & 51,39 & 40,21 & 16,63 & 15,05 & 32,22 & 149 \\
\hline Lesotho & 35,65 & 49,72 & 38,34 & 12,69 & 24,49 & 32,18 & 150 \\
\hline Mozambique & 40,67 & 44,91 & 47,88 & 9,30 & 17,59 & 32,07 & 151 \\
\hline Zambia & 39,76 & 44,06 & 45,46 & 15,04 & 15,68 & 32,00 & 152 \\
\hline Uganda & 37,21 & 39,60 & 43,49 & 15,49 & 23,73 & 31,91 & 153 \\
\hline Benin & 29,21 & 32,61 & 43,03 & 20,71 & 33,83 & 31,88 & 154 \\
\hline Rwanda & 41,04 & 28,70 & 51,50 & 14,54 & 22,86 & 31,73 & 155 \\
\hline Cuba & 45,27 & 27,21 & 34,31 & 10,09 & 41,70 & 31,72 & 156 \\
\hline
\end{tabular}




\begin{tabular}{lccccccc}
\hline Country / Variable & Pol & Econ & Cul & Tech & Env & MGI & Rank \\
\hline Togo & 37,56 & 28,47 & 44,62 & 12,32 & 35,19 & 31,63 & 157 \\
Bolivia & 31,98 & 37,07 & 48,32 & 27,69 & 9,16 & 30,84 & 158 \\
Comoros & 32,25 & 34,71 & 43,71 & 7,74 & 35,61 & 30,80 & 159 \\
Afghanistan & 41,80 & 31,72 & 40,80 & 11,59 & 28,10 & 30,80 & 160 \\
Sudan & 43,52 & 35,93 & 37,35 & 14,79 & 15,99 & 29,52 & 161 \\
Tanzania & 34,77 & 35,26 & 37,85 & 16,76 & 21,82 & 29,29 & 162 \\
Malawi & 34,40 & 36,94 & 44,52 & 5,74 & 24,21 & 29,16 & 163 \\
Haiti & 33,18 & 29,59 & 32,32 & 13,73 & 35,78 & 28,92 & 164 \\
Guinea & 37,52 & 42,75 & 37,44 & 9,88 & 13,46 & 28,21 & 165 \\
Mali & 38,32 & 37,99 & 33,37 & 12,80 & 17,24 & 27,94 & 166 \\
Guinea-Bissau & 35,39 & 31,75 & 44,31 & 10,43 & 17,32 & 27,84 & 167 \\
Bangladesh & 39,44 & 22,97 & 32,92 & 12,78 & 30,60 & 27,74 & 168 \\
Cameroon & 33,72 & 29,67 & 34,78 & 12,42 & 23,28 & 26,77 & 169 \\
Angola & 33,80 & 35,77 & 29,07 & 16,21 & 18,97 & 26,77 & 170 \\
Chad & 41,30 & 50,72 & 33,39 & 6,29 & 1,71 & 26,68 & 171 \\
Somalia & 31,51 & 42,46 & 38,84 & 1,89 & 18,32 & 26,61 & 172 \\
Sierra Leone & 34,85 & 33,30 & 39,87 & 8,03 & 15,27 & 26,27 & 173 \\
Congo, Dem. Rep. & 50,75 & 45,12 & 17,62 & 4,33 & 13,42 & 26,25 & 174 \\
Niger & 35,56 & 43,08 & 31,04 & 6,00 & 12,59 & 25,65 & 175 \\
Ethiopia & 49,03 & 25,67 & 25,44 & 2,00 & 22,31 & 24,89 & 176 \\
Burkina Faso & 31,06 & 17,66 & 47,61 & 8,77 & 19,28 & 24,88 & 177 \\
Central African Republic & 39,43 & 42,15 & 35,14 & 6,22 & 0,00 & 24,59 & 178 \\
Madagascar & 35,83 & 41,90 & 20,62 & 9,55 & 11,78 & 23,94 & 179 \\
Nepal & 23,12 & 14,20 & 47,73 & 11,22 & 19,38 & 23,13 & 180 \\
Eritrea & 32,39 & 33,50 & 26,87 & 3,28 & 15,16 & 22,24 & 181 \\
Myanmar & 43,04 & 32,30 & 18,89 & 0,01 & 16,18 & 22,08 & 182 \\
Burundi & 27,92 & 3,23 & 29,79 & 4,03 & 19,04 & 16,80 & 183 \\
\hline & & & & & & & \\
& & & & \\
& 340 &
\end{tabular}





\section{CHAPTER 5}

Determinants of Ecological Footprints: what is the role of globalization? An empirical analysis using the KOF index of globalization 
"(globalized) capitalism is taken as a background 'given': an irredeemable fact and seemingly irreversible reality of contemporary social and economic life whose implications it hardly seems worth naming, let alone systematically examining in relation to particular (human) ecologies."

Peter Newell, professor of international relations

\begin{abstract}
This chapter empirically analyzes the ecological consequences of globalization, by employing the Ecological Footprint (EF) as a proxy for human demands on the environment and the KOF index of Globalization. We develop an unbalanced data set covering 146 countries over the 1981-2009 period and are thus able to address the influence of countries' development over time. After empirically showing that globalization is an explanatory factor of ecological demands, an Extreme Bounds Analysis (EBA) identifies a robust set of impact factors. Subsequently, specific hypotheses on economic, political, social and overall globalization guide the empirical analysis. The findings suggest that economic globalization drives the EF of consumption, production, imports and exports. Social globalization correlates negatively with the EF of consumption and production, while increasing the EF of imports and exports. No effects are found for political globalization while overall globalization is positively correlated with EFs of imports and exports. The findings show that globalization may have different effects on EFs depending on the dimension (consumption, production, exports and imports) referred to.
\end{abstract}

\title{
Published as
}

Rudolph, A., \& Figge, L. (2017). Determinants of Ecological Footprints: What is the role of globalization? Ecological Indicators, 81, 348-361.

https://doi.org/10.1016/j.ecolind.2017.04.060

Previous versions accessible as

Rudolph, A., \& Figge, L. (2015). How does globalization affect ecological pressures? A robust empirical analysis using the Ecological Footprint. Discussion Paper series. Department of Economics. University of Heidelberg. Retrieved from http://www.uniheidelberg.de/md/awi/forschung/dp599.pdf

A previous version has been used as chapter 4 in Alexandra Rudolph's PhD dissertation "Challenges of Globalization for International Mobility, Social Security and Environmental Sustainability" which was defended in 2015 at Heidelberg University. See https://www.die-gdi.de/uploads/media/Rudolph_eDiss.pdf 


\section{Introduction}

The previous chapter concludes that globalization in its current form contributes to increasing human demands on the ecological environment and therefore does not contribute to reconciling human demands with the Earth's carrying capacity. We continue to explore the question "to what extent does globalization and its different domains intensify environmental footprints and/or contribute to ecologically sustainable development?". We address this question by extending the analysis from one point in time to a panel data set. For this we introduce the KOF index of Globalization which is available as of 1970 and hence cover the period 1981-2009 for up to 146 countries. Employing multi-dimensional indicators of globalization and human demands provides the possibility of systematically assessing this relationship without risking problems of multicollinearity and omitted variable bias in empirical work (Dreher et al., 2008). With this approach, we are able to control for countries' development over time (by including time and country fixed effects). By using the Granger causality test (Granger, 1969), we test whether globalization indeed determines the level of human demands and address reverse causality issues, which may spuriously bias our results. Further, we test 28 demographic, economic, geographic, cultural and political variables, that have been suggested to affect human demands and pressures on the environment in order to identify robust control variables. For this, we apply a variant of the Extreme Bounds Analysis (EBA) suggested by Sala-i-Martin (1997), Sturm and De Haan (2005) and Gassebner et al. (2011)..

The remainder of this chapter is organized as follows. In Section 2 we relate to the relevant literature, provide theoretical considerations for our hypotheses, and develop testable hypotheses. Section 3 explains the concept and empirical operationalization of human demands as well as of globalization. Subsequently, we explain the EBA to identify robust determinants of these demands. Then, we specify the econometric model. The results are presented and discussed in relation to the findings of the previous chapter in section 4 . Section 5 concludes and discusses the relevance of the results for global decision-making processes.

\subsection{Literature review and hypotheses}

Addressing the relationship between globalization and human demands or ecological sustainability has not so far been a central question in the quantitative empirical literature on the consequences of globalization. A recent survey of more than 100 studies using the KOF Index of Globalization shows that the effects of globalization on the natural environment have been neglected (Potrafke (2014). To our knowledge, there has been no peer-reviewed study that systematically analyzes the environmental conse- 
quences of globalization over time, addressing endogeneity concerns. Many ecological studies, however, have shown that trade plays a significant role in changing land-use, in the displacement of people and in pollution, driven by human demands (Caro, LoPresti, Davis, Bastianoni, \& Caldeira, 2014; Lambin \& Meyfroidt, 2011; Peters \& Hertwich, 2008; Weinzettel et al., 2013).

We now turn to arguments why and how the different dimensions of globalization may impact human demands in order to formulate hypotheses. An overview of all hypotheses and arguments are detailed in Table 5.1.

\subsubsection{Economic Globalization}

Economic globalization can lead to the growth of more pollution-intensive industries in countries with lower environmental regulations, which is the case in many developing countries (Copeland \& Taylor, 2004). In general, across all countries, we would expect economic globalization to intensify human demands. Our argument is based on three considerations; first, no effective (global) framework for governing land-use and carbon emissions has formed, that could have given rise to globally binding regulations. Second, more developed countries are inclined to intensify agricultural production and energy use, which increases ecological stressors (UNEP, 2012a). Third, economic globalization may contribute to a "race to the bottom" (Dinda, 2004), where countries that are more globalized economically through trade and investment are more likely to avoid footprint mitigation in order to safeguard economic objectives. We therefore formulate the "intensification" hypothesis (1), which states that economic globalization intensifies human demands.

However, economic globalization may also have alleviating effects on human demands on the environment. For instance, foreign direct investments (FDI) may lead to technology transfer and thereby diffuse clean production technologies, allowing developing countries to leapfrog less efficient production processes (Gallagher, 2009; Tamazian, Chousa, \& Vadlamannati, 2009; Tamazian \& Rao, 2010). Zeng and Eastin (2012) provide evidence that these effects even work when firms from less-developed countries invest in wealthier countries. Global market integration, according to this logic, may then improve the allocative efficiency of domestic markets and promote private property, thereby contributing to the internalization of ecological externalities (Dinda, 2004). Therefore, our "markets for the global environment" hypothesis (2) states that economic globalization decreases human demands. 


\subsubsection{Political globalization}

Political integration ties states to one another through bilateral diplomatic contacts, international organizations and trans-national agreements. The evidence on whether closer political integration can reduce human demands is rather mixed (Lemos \& Agrawal, 2006). Stiglitz (2007) points out that economic globalization has outpaced political globalization and, therefore, there is a lack of governance institutions that can effectively address global issues such as climate change and inequality. Up until now, no strictly enforceable global framework for greenhouse gas emissions exists. Studies show that the Kyoto protocol was not able to effectively tackle climate change (e.g., Den Elzen and De Moor (2002)), and it is still unclear whether the Paris agreement (UNFCCC, 2015) will prove to be an effective successor. For global environmental issues other than climate change, measurable progress has only been made with respect to stratospheric ozone and lead in gasoline. Progress on other environmental issues, such as deforestation, desertification or overfishing, is mostly lagging behind (UNEP, 2012e). Thus, it appears that global governance is insufficiently managing the adverse environmental effects of economic development. Global governance exposes both nations and people to institutions and structures with varying degrees of democracy, accountability and transparency. This may contribute to power abuses (Grant \& Keohane, 2005) and potential adverse ecological impacts as, for instance, more attention is given to investment goals rather than environmentally sustainable consumption, production and trade. This brings us to the "global environmental governance failure" hypothesis (3), which expects that political globalization increases human demands.

On the other hand, Lemos and Agrawal (2006) conclude that political integration can have beneficial effects on the capacity and effectiveness of governance institutions to mitigate human demands. Countries that are more politically integrated, they argue, benefit from access to global institutions, know-how and monitoring systems. Furthermore, political cooperation often builds institutional capacity, which advances institutions for environmental regulation and facilitates negotiations. Therefore, rather than a race to the bottom, there may also be a lifting of those from the lower levels of development, through the dissemination of environmental governance in developing countries (Dinda, 2004). Consequently, the "global environmental governance" hypothesis (4) suggests that political globalization decreases human demands.

\subsubsection{Social globalization}

Global mobility of people may physically and mentally distance individuals from the negative environmental (and social) impacts of the global economy (Dinda, 2004). Physical distancing refers to simply moving or staying away from environmental problems (in a geographical-spatial sense). Mental or cognitive distancing are the result of socioeconomic and cultural tele-connections, which inhibit the understanding of how social 
and ecological problems elsewhere are connected to one's own individual behavior (Steffen et al., 2005). Thus, more information about environmental problems does not necessarily result in greater environmental awareness and, more importantly, behavioral change. Additionally, global media exposes people to advertisements and other media contents that disseminate materialistic and consumerist lifestyles which value (personal) consumption over environmental conservation (Najam, Runnalls, \& Halle, 2007; Rennen \& Martens, 2003). Norgaard (2011) has shown that despite increasing evidence on the impacts of climate change, people may live in what she calls "socially organized denial", which leads to an inadequate or no response. Thus, we put forward the "living in denial" hypothesis (5), which states that social globalization increases human demands.

On the other hand, social globalization exposes people and nations to global streams of information and knowledge (Rennen \& Martens, 2003). Countries are also more socially globalized if the population can access and use these media sources and has more personal international contacts. In principle, we would expect more socially globalized societies to know more about (global) environmental problems through the availability of information based on newspapers and increased access to the internet, social media and telephone lines. As people have increasing access to education and information about negative side effects of consumption and production, environmental awareness increases, together with demand for "cleaner" products (Motoshita, Sakagami, Kudoh, Tahara, \& Inaba, 2015). At the same time, producers promote their "clean" products, increasing public understanding even more (Najam et al., 2007). Thus, social integration can give rise to more informal regulation, by empowering not only civil society and consumers, but also businesses and governments to cooperate in new governance structures and create general pressure for pro-environmental behavior, adaption and regulation (Dinda, 2004). The "global environmental awareness" hypothesis (6) suggests that social globalization decreases human demands. 
Table 5.1: Summary of Hypotheses and key arguments (own elaboration)

\begin{tabular}{|c|c|c|c|}
\hline \multicolumn{2}{|c|}{ Hypotheses } & \multirow{2}{*}{$\begin{array}{l}\text { Description } \\
\text { Economic globalization } \\
\text { intensifies human (ecologi- } \\
\text { cal) demands }\end{array}$} & \multirow[b]{2}{*}{$\begin{array}{l}\text { Key arguments } \\
\text { - } \quad \text { Growth of ecologically intensive pro- } \\
\text { duction and consumption } \\
\text { Intensification of agricultural produc- } \\
\text { tion and energy use } \\
\text { Avoidance of footprint mitigation to } \\
\text { safeguard objectives }\end{array}$} \\
\hline (1) & Intensification & & \\
\hline (2) & $\begin{array}{l}\text { Markets for the global } \\
\text { environment }\end{array}$ & $\begin{array}{l}\text { Economic globalization } \\
\text { decreases human demands }\end{array}$ & $\begin{array}{l}\text { FDI drives transfer of clean technolo- } \\
\text { gies and leapfrogging } \\
\text { Enhanced allocative efficiency and } \\
\text { private-property rights lead to inter- } \\
\text { nalization of externalities }\end{array}$ \\
\hline (3) & $\begin{array}{l}\text { Global environmental } \\
\text { governance failure }\end{array}$ & $\begin{array}{l}\text { Political globalization intensi- } \\
\text { fies human demands }\end{array}$ & $\begin{array}{l}\text { - No effective institutions in place to } \\
\text { govern global ecological issues } \\
\text { Global governance suffers from lack of } \\
\text { democracy, accountability and trans- } \\
\text { parency }\end{array}$ \\
\hline (4) & $\begin{array}{l}\text { Global environmental } \\
\text { governance }\end{array}$ & $\begin{array}{l}\text { Political globalization de- } \\
\text { creases human demands }\end{array}$ & $\begin{array}{l}\text { Enhancing capacity and effectiveness } \\
\text { of governance institutions }\end{array}$ \\
\hline (5) & Living in denial & $\begin{array}{l}\text { Social globalization intensi- } \\
\text { fies human demands }\end{array}$ & $\begin{array}{l}\text { - Physical and cognitive distancing leads } \\
\text { to a lack of awareness, concern and } \\
\text { necessary behavioral changes }\end{array}$ \\
\hline (6) & $\begin{array}{l}\text { Global environmental } \\
\text { awareness }\end{array}$ & $\begin{array}{l}\text { Social globalization decreas- } \\
\text { es human demands }\end{array}$ & $\begin{array}{l}\text { Exposure to information, education } \\
\text { and knowledge }\end{array}$ \\
\hline
\end{tabular}

\subsection{Methods}

In order to address the relationship between globalization human demands we use multidimensional indicators and different empirical methods. In this section we first describe the indicators and then turn to the description of the empirical methods.

\subsubsection{The Ecological Footprint of nations}

Similar to the method used in chapter 4, we employ the Ecological Footprint (EF) as proxy for human demands (in per capita terms). The EF captures a precise sub-set of human demands on the environment (Borucke et al., 2013) by "measuring how much area of biologically productive land and water an individual, population or activity requires to produce all the resources it consumes and to absorb the waste (carbon dioxide) it generates, using prevailing technology and resource management practices" (Global Footprint Network, 2012a). We use it to assess the relationship between globalization and human demands, since it has the following advantages.

First, the aggregation is based on six bioproductive land-use types: i) cropland, ii) grassland and pasture (food and fiber), iii) fishing grounds (seafood), iv) forest land (timber and paper products) as well as v) area required for built infrastructure (e.g. roads and 
buildings) and vi) land for carbon sequestration. Second, the indicator is globally comparable. The EF is measured in global hectares (gha), which captures equivalent land units or hectare equivalents. Hence the measurement unit does not reflect a physical area (for instance ha), but rather the bio-productivity thereof. For a detailed description of gha we refer to Galli (2015) not only refers to a physical area (in terms of ha), but also takes its ecological productivity (yield factor) into account (Borucke et al., 2013). Third, the EF is scientifically rigorous and widely accepted across the social sciences (Jorgenson \& Clark, 2011). Fourth, it is commonly used and employed in policy reports, such as the Global Environment Outlook (UNEP, 2012a) and the yearly Living Planet Report (WWF, 2014). In the 2011 edition of the National Footprint Accounts (NFA) (Global Footprint Network, 2012c), which we employ, data are available for 240 countries and territories for the years 1961-2009, covering most of the time period described as "contemporary globalization" (Rennen \& Martens, 2003). Fifth, the NFA takes the effects of trade into account, by reporting Ecological Footprints from different perspectives, composed of production, imports and exports in the following form:

$$
E F_{\text {consumption }}=E F_{\text {production }}+E F_{\text {imports }}-E F_{\text {exports }}
$$

Last, National Footprint Accounts (NFAs) are a conservative measure of human demands and are specifically constructed to underestimate EFs and overestimate biocapacity (Borucke et al., 2013). These aspects need to be taken into account in the interpretation of our results, as the real effects can be considered to be higher than those we may find. This is rather an advantage since it makes sure that if we do find effects, they are truly influential in explaining the variation.

\subsubsection{The KOF index of globalization}

We employ the KOF Index of Globalization to measure globalization, which includes the political, economic and social dimensions. It is the most extensive measure of globalization across countries and time (Dreher, 2006; Dreher et al., 2008). The 2013 version of the KOF covers 187 countries for the 1970-2009 period and allows for the disentangling of the effects of different dimensions of globalization. Other indices trying to capture globalization have the disadvantage of being only available for a small group of countries, i.e. OECD countries (Andersen \& Herbertsson, 2005; Lockwood \& Redoano, 2005) or, as in the case of the Maastricht Globalization Index (MGI) (chapter 3), are only available for a few points in time. 
To provide some details on the KOF index ${ }^{4}$ : economic globalization includes variables on actual flows, such as trade, FDI and capital flows. Restrictions include hidden import barriers, tariffs, taxes on international trade, and capital controls; political globalization includes the number of embassies in the country, membership of international organizations and ratification of international treaties as well as participation in UN Security Council missions; and social globalization cumulates variables on personal contacts such as telephone traffic and international tourism, information flows including internet, newspapers and newspaper availability, and cultural proximity. The overall as well as the domain indices are scaled between 1 and 100, where 1 indicates a low level of globalization and 100 indicates a high level. We use the overall index as well as the three sub-indices (economic, political and social) to test our hypotheses. All four indices are widely used in the literature (see Potrafke (2014) and footnote 3). Before testing the globalization hypotheses, we employ the Extreme Bounds Analysis (EBA) in order to identify a robust set of control variables (out of 28). Our analysis covers up to 146 countries for the years 1980-2009 in an unbalanced data set.

\subsubsection{Test of reverse causation}

An important issue regarding the relationship between EFs and globalization is the potential reverse causality in the regression equation. It could be that an increase in EFs causes global integration rather than being its outcome. Arguably, greater local human demand on the environment might also lead to higher levels of globalization. For instance, greater human demands made by a country may increase that country's willingness to participate in international agreements or organizations to help reduce or meet these demands. We do two things to ensure that our estimates are not biased by reverse causation: first, we lag all explanatory variables. Second, we follow Dreher, Gassebner, and Siemers (2012) and perform Granger-causality tests. This test states that, according to Granger (1969), variable $x$ causes variable $y$, if past values of $x$ help explain $y$, once controlled for past influence of $y$ in the following way:

$$
y_{i t}=\sum_{j=1}^{m} \alpha_{j} y_{i t-j}+\sum_{j=1}^{m} \beta_{j} x_{i t-j}+\delta_{i}+\xi_{t}+\omega_{i t}
$$

where $i=1, \ldots, N$ and $t=1, \ldots, T$. We estimate a fixed-effects panel estimator where $\alpha_{j}$ and $\beta_{j}$ are the parameters, $m$ is the maximum lag length, $\delta_{i}$ is the country fixedeffect, $\xi_{t}$ is the time fixed-effect and $\omega_{i t}$ is the idiosyncratic error term clustered on the

\footnotetext{
${ }^{4}$ All variables included and their weights are detailed in Table A5.1 in the appendix. The index is available at http://globalization.kof.ethz.ch/. An extensive overview with studies using the KOF index can be found under http://globalization.kof.ethz.ch/papers/
} 
country level. The stationary assumption of the series is tested by employing a Maddala and Wu (1999) test for unbalanced panel data. The null hypothesis of all series being non-stationary can be rejected at the one percent level. We report the results of the Granger-causality test in table 5.2 where the F-statistic on $\beta_{j}$ together with the respective $p$-value is displayed testing the null hypothesis that $x$ Granger-causes $y$. This is the case if the $p$-value is lower or equal to 0.1 indicating an error probability of 10 percent or lower.

Table 5.2: Granger causality (1981-2009, 146 countries)

(1)

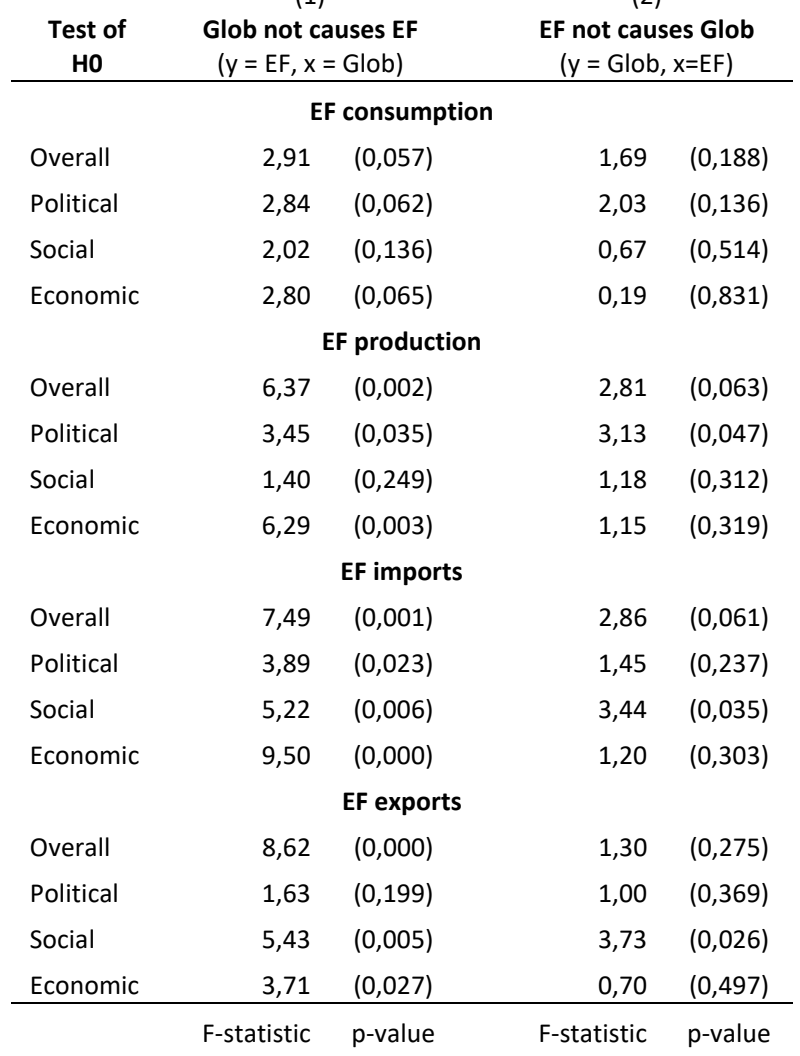

Notes: The table reports $F$-statistics (joint significance) and the respective p-values in parentheses using two lags.

The results in column 1 of Table 5.2 show the values testing the statistical null hypothesis that globalization does not Granger-cause Ecological Footprints (EFs). We find evidence that globalization Granger-causes EFs in most cases. Exceptions where the pvalue is larger than 0.1 are the effect of social globalization on the EF of consumption 
and production, and the effect of political globalization on the EF of exports. The second pair of results (column 2, table 5.2) tests for the null hypothesis that the Ecological Footprint does not Granger-cause globalization. Thus, we would expect $p$-values larger than 0.1 to not find the EF Granger-causing globalization. Most importantly, we cannot reject the null hypothesis for EF of consumption. Overall we have strong evidence that globalization Granger-causes the EF, but we have to be careful in the consideration of political and social globalization, where Granger causality seems to be unclear.

\subsubsection{Extreme Bounds Analysis (EBA)}

Since evidence on determinants of the Ecological Footprint so far is inconclusive, we follow the literature (e.g., Dreher et al. (2012); Gassebner et al. (2011); Yang, He, and Chen (2015) and use a variant of the EBA, based on Leamer (1983), Levine and Renelt (1992), Sala-i-Martin (1997) and Sturm and De Haan (2005)), to identify a robust vector of controls. The EBA is a statistical tool used to test whether the variables suggested in previous empirical studies are indeed robustly related to Ecological Footprints, independent of other explanatory variables included in the regression. We use the following general equation to conduct the EBA:

$$
\boldsymbol{Y}_{i t}=\beta_{M} \boldsymbol{M}_{i t-1}+\beta_{F} \boldsymbol{F}_{i t-1}+\beta_{z} \boldsymbol{Z}_{i t-1}+\vartheta_{t}+\tau_{i}+v_{i t}
$$

where $i=1, \ldots, N$ and $t=1, \ldots, T . \boldsymbol{Y}$ is the dependent variable; $\boldsymbol{M}$ is a vector of commonly accepted explanatory variables; $\boldsymbol{F}$ is a vector including the variable of interest; and $\boldsymbol{Z}$ is a vector of up to three additional variables (following Levine and Renelt (1992)). All variables are lagged by one year. Time-fixed effects $\left(\vartheta_{t}\right)$ and country fixedeffects $\left(\tau_{i}\right)$ as well as a standard error $\left(v_{i t}\right)$ clustered at the country level are included.

The EBA is applied in two steps. First, the robustness of the base model $(\boldsymbol{M})$ is tested by including one variable of the $\boldsymbol{F}$ vector while the remaining variables of the $\boldsymbol{Z}$ vector are used in all possible combinations of up to three at a time. In a second step, the $\boldsymbol{M}$ vector is held constant and we test whether additional variables should be among the explanatory variables when testing for the impact of globalization. In order to decide whether a variable in $\boldsymbol{F}$ is robust, we consider the whole distribution of the estimates as suggested by Sala-i-Martin (1997). The threshold value of 0.95 of the unweighted cumulative density function CDF(0) is suggested by Sturm and De Haan (2005). A CDF (0) of 0.95 indicates that at least 95 per cent of the distribution lies on one side of zero, which is regarded as support for a variable to have a robust statistical effect. We use a stricter cut-off value of 0.99 in order to be even more conservative in the choice of control variables. 
We base our selection for $\boldsymbol{M}$ on the existing theory and empirical findings to identify core determinants (base model). According to the IPAT identity, environmental impacts in a nation (I) are determined by the size and composition of the population ( $P$ ), the level of affluence (A) and the state of technology (T) (Dietz et al., 2007; Rosa et al., 2004; York et al., 2003a; York, Rosa, \& Dietz, 2003h). We use the share of economically active population, which has been shown to relate to the EF of consumption (Dietz et al., 2007; York et al., 2003a). Further, we use (In) GDP per capita as a measure of affluence or the standard of living in a country, and (In) GDP per capita squared to account for a potential non-linear relationship, as suggested by the Environmental Kuznets Curve (EKC) (Antweiler et al., 2001; Dinda, 2004; Gallagher, 2009; Stern, 2004). ${ }^{5}$ Third, we include the ratio of energy use to GDP, which is a measure for the energy intensity of production and therefore a good proxy for the state of the technology. All variables are from the World Development Indicators database World Bank (2014).

For the $\boldsymbol{F}$ vector we consider $\mathbf{2 8}$ additional variables, which have been tested and used in literature on the consequences of globalization and/or on the determinants of Ecological Footprints and pollution, drawing from environmental economics (Dinda, 2004; Gassebner et al., 2011; Lamla, 2009; Stern, 2004), political economy of globalization (Dreher et al., 2012; Dreher et al., 2008) and ecological sociology (Dietz et al., 2007; Dietz, Rosa, \& York, 2012; Jorgenson, 2003; Jorgenson \& Clark, 2011; Jorgenson, Clark, $\&$ Kentor, 2010; Rosa et al., 2004; York et al., 2003a, 2003h). ${ }^{6}$

Taking all factors into account, we might face multi-collinearity problems with variables that potentially overlap. This is most likely when variables are related to each other, as is the case for example by using land area and arable land as share of total land area. Therefore, we carefully investigated the correlations between our explanatory variables and take this into account when analyzing the results of the EBA in Section 5.3.1. ${ }^{7}$

\subsubsection{Estimation Model}

We test our six hypotheses by estimating equations of the following form:

$$
Y_{i, t}=\beta_{1} Y_{i, t-1}+\beta_{2} X_{i, t-1}+\beta_{3} G_{l o b}, t-1+\lambda_{t}+\mu_{i}+\varepsilon_{i, t}
$$

\footnotetext{
${ }^{5}$ Environmental and ecological economists reduce the discussion on the relationship between income and single environmental indicators and hypothesize an inverse u-shaped Environmental Kuznets Curve (EKC) for various aspects of environmental quality and respective pollutants (Copeland \& Taylor, 2004; Dinda, 2004; Gallagher, 2009).

${ }^{6}$ All variables, the respective arguments and sources are detailed in appendix Table A5.2. The definition and sources are listed in Table A5.3 in the appendix.

${ }^{7}$ The full pair-wise correlation table is provided in the appendix, Table A5.5.
} 
where $Y_{i, t}$ is the natural log of the annual EF per capita measure described above and $Y_{i, t-1}$ is the lag dependent variable which captures the persistence in the evolution of the EF. $X_{i, t-1}$ is a vector of robust factors influencing human demands identified by the EBA, and $G l o b_{i, t-1}$ is overall globalization or all of the three sub-indices. We assume the variables to affect the Ecological Footprints with a time lag of one year only, since the drivers affect the demand for a land-use type and the respective resources included in the calculation of the EF with only a short delay. The term $\lambda_{t}$ describes the time fixedeffects and $\mu_{i}$ is the country fixed- effects. ${ }^{8}$ Employing the within fixed-effects estimator with time fixed-effects has the advantage of controlling for unobserved time invariant (i.e. characteristics of counties such as geographical location) and time variant common shocks (i.e. business-cycle fluctuations), which capture cross-sectional dependence that is homogenous across countries. The idiosyncratic error term is $\varepsilon_{i, t}$. Consequently, our estimates exploit variation within countries around a common trend and our parameter vector of interest $\left(\beta_{3}\right)$ can be interpreted as the short-run effect of globalization on the EFs.

\subsection{Results}

We report the findings in three steps: first, we analyze the relevance (direction and magnitude) of the controls by discussing the EBA results. Second, we turn to our hypotheses. All robust variables of the EBA are included when evaluating the relationship between globalization and the EF.

\subsubsection{EBA results}

Table 5.3 reports the results of the EBA for the per capita Ecological Footprint of consumption. As expected, we find the lagged dependent variable to be a significant determinant of the EF in the following year. The same holds for the income level, energy intensity (technology) and the share of economically active population. All effects are positive and statistically significant at least at the 5 per cent level, indicating that the per capita EF of consumption is positively related to the standard of living, technology and population. This confirms the IPAT relation highlighted in literature on ecological sociology (Dietz et al., 2007; Rosa et al., 2004; York et al., 2003a, 2003h).

The average effect of income on the EF of consumption is positive, increasing and almost always significant (100 per cent for the level and 82 percent of the squared term). There is no indication in the data of an EKC relationship, which suggests a decrease in

\footnotetext{
${ }^{8}$ The Hausman test rejects using the random effects estimator at the one percent level of significance.
} 
human pressures as countries grow wealthier. This supports Stern's arguments against the EKC (Stern, 2004). He shows that the relationship is often rather monotonic. Much more, though, we find that higher GDP per capita is non-linearly correlated and relates to a disproportional increase of the EF of consumption. This is in line with findings in the literature on the determinants of EFs (Dietz et al., 2007; Rosa et al., 2004; York et al., 2003a, 2003h). The magnitude is economically relevant, since an increase of 5 percent in GDP per capita correlates with an increase of the EF of consumption of about 1.1 percent. Energy intensity also shows a positive and robust significant coefficient on average. An increase of energy intensity by 10 percent relates to rising EFs of consumption by almost 1 percent. Finally, an increase in the economically active population increases the EF of consumption consistently and is statistically significant at least at the 5 percent level. A 5 percent increase in the EF of consumption is driven by an increase in the share of the economically active population by 1 standard deviation (around 6 percent). On average, the effects seem plausible and sizable.

Using this baseline specification, we find that one additional variable is a robust statistical determinant of the EF of consumption, according to the strict threshold of a CDF (0) of 0.99 . The EF of consumption is also systematically and negatively related to the share of agriculture in total GDP. A decrease in the share of agriculture by one standard deviation (12.8 percent, which implies an equal increase in the share of the industrial and/or services sector) is associated with an average increase of 2.6 percent of the EF of consumption. This evidence supports observations by Stern (2004) that a shift away from agriculture to industry leads to an increase in human demands.

In sum, we find six variables to be robust determinants of human demands: the lagged state of the EF of consumption, the logarithm of income per capita and its square, the logged ratio of energy use to national income, the economically active population (15 to 65 years) and the share of agricultural value added to national income. 
Table 5.3: EBA results per capita Ecological Footprint of consumption (1981-2009, 146 countries)

\begin{tabular}{|c|c|c|c|c|c|c|c|c|}
\hline Variables & Avg. $B$ & Avg. $v$ & \%Sign. & $\operatorname{CDF}(0)$ & $\begin{array}{l}\text { lower } \\
\text { bound }\end{array}$ & $\begin{array}{l}\text { upper } \\
\text { bound }\end{array}$ & Combi & $\begin{array}{l}\text { Avg. } \\
\text { Obs }\end{array}$ \\
\hline \multicolumn{9}{|l|}{ Base model } \\
\hline$Y(\mathrm{t}-1)$ & 0,578 & 0,061 & 1,00 & 1,00 & 0,000 & 0,754 & 3682 & 2554 \\
\hline (In) GDP pc & 0,213 & 0,034 & 1,00 & 1,00 & 0,000 & 0,341 & 3682 & 2554 \\
\hline (In) GDP pc square & 0,011 & 0,005 & 0,81 & 0,98 & $-0,012$ & 0,035 & 3682 & 2554 \\
\hline (In) Energy/GDP & 0,103 & 0,017 & 1,00 & 1,00 & $-0,017$ & 0,188 & 3682 & 2554 \\
\hline Population (15-65 yrs) & 0,008 & 0,001 & 1,00 & 1,00 & 0,000 & 0,013 & 3682 & 2554 \\
\hline \multicolumn{9}{|l|}{ Extended model } \\
\hline Agriculture/GDP & $-0,002$ & 0,001 & 1,00 & 0,99 & $-0,004$ & 0,000 & 3303 & 2395 \\
\hline Urban population & $-0,002$ & 0,001 & 0,88 & 0,97 & $-0,007$ & 0,001 & 3303 & 2538 \\
\hline External conflict & 0,003 & 0,001 & 0,84 & 0,97 & $-0,002$ & 0,009 & 3303 & 2335 \\
\hline Bureaucratic quality & 0,008 & 0,004 & 0,86 & 0,97 & $-0,006$ & 0,020 & 3303 & 2335 \\
\hline Social globalization & $-0,001$ & 0,000 & 0,71 & 0,96 & $-0,003$ & 0,001 & 3303 & 2527 \\
\hline (In) Area pc & 0,059 & 0,032 & 0,37 & 0,91 & $-0,095$ & 0,442 & 3303 & 2538 \\
\hline Population growth & 0,007 & 0,005 & 0,29 & 0,90 & $-0,012$ & 0,025 & 3303 & 2535 \\
\hline Government stability & 0,002 & 0,002 & 0,23 & 0,89 & $-0,004$ & 0,007 & 3303 & 2335 \\
\hline Years in office & 0,001 & 0,000 & 0,32 & 0,89 & $-0,001$ & 0,002 & 3303 & 2531 \\
\hline Physical integrity rights & 0,002 & 0,002 & 0,07 & 0,88 & $-0,004$ & 0,009 & 3303 & 2455 \\
\hline GDP growth & 0,001 & 0,001 & 0,30 & 0,87 & $-0,001$ & 0,003 & 3303 & 2528 \\
\hline Corruption & 0,004 & 0,004 & 0,07 & 0,84 & $-0,009$ & 0,016 & 3303 & 2335 \\
\hline Road energy per capita & 0,000 & 0,000 & 0,73 & 0,83 & 0,000 & 0,000 & 3303 & 2516 \\
\hline Road energy consump. share & 0,001 & 0,001 & 0,58 & 0,78 & $-0,003$ & 0,004 & 3303 & 2516 \\
\hline Internal conflict & 0,001 & 0,001 & 0,01 & 0,77 & $-0,005$ & 0,006 & 3303 & 2335 \\
\hline Oil energy & 0,000 & 0,000 & 0,18 & 0,76 & $-0,001$ & 0,001 & 3303 & 2516 \\
\hline Alternative and nuclear energy & 0,000 & 0,000 & 0,01 & 0,67 & $-0,003$ & 0,002 & 3303 & 2516 \\
\hline Fuel energy consumption & 0,000 & 0,000 & 0,10 & 0,65 & $-0,003$ & 0,002 & 3303 & 2538 \\
\hline (In) Arable land share & 0,006 & 0,014 & 0,00 & 0,64 & $-0,057$ & 0,073 & 3303 & 2514 \\
\hline Economic globalization & 0,000 & 0,000 & 0,17 & 0,63 & $-0,001$ & 0,003 & 3303 & 2491 \\
\hline (In) Military exp./GDP & $-0,003$ & 0,009 & 0,00 & 0,63 & $-0,028$ & 0,023 & 3303 & 2043 \\
\hline Socio economic conditions & 0,001 & 0,002 & 0,00 & 0,62 & $-0,005$ & 0,006 & 3303 & 2335 \\
\hline Manufacturing/GDP & 0,000 & 0,001 & 0,07 & 0,59 & $-0,004$ & 0,003 & 3303 & 2250 \\
\hline Regime type & 0,002 & 0,004 & 0,05 & 0,59 & $-0,020$ & 0,042 & 3303 & 2537 \\
\hline (In) Population density & 0,018 & 0,039 & 0,09 & 0,57 & $-0,319$ & 0,472 & 3303 & 2515 \\
\hline Law and order & 0,000 & 0,003 & 0,00 & 0,55 & $-0,009$ & 0,011 & 3303 & 2335 \\
\hline Political globalization & 0,000 & 0,000 & 0,29 & 0,55 & $-0,001$ & 0,002 & 3303 & 2527 \\
\hline Democratic accountability & 0,000 & 0,002 & 0,01 & 0,54 & $-0,007$ & 0,008 & 3303 & 2335 \\
\hline
\end{tabular}

Notes: Dependent variable: EF of consumption per capita. The variables in the extended model are ordered according to the size of the CDF. $Y(t-1)$ lagged dependent variable. Avg. $b=$ average coefficient; Avg. $v=$ average Driscoll and Kraay adjusted standard error; \%Sign. = percentage share coefficient is significant; $\operatorname{CDF}(0)=$ unweighted cumulative density function (threshold 0.95), lower (upper) bound = lowest (highest) value of coefficient minus (plus) two standard deviation; Combi = \# of variable combinations; Avg. Obs. = average \# of observations. All variables are lagged by 1 year. 


\subsubsection{Globalization and human demands}

Turning to the hypotheses tests, the analysis of the relation between globalization and human demands reveals some interesting patterns. We report different specifications of the regression equations in table 5.4, using the EF of consumption in column 1 and $2^{9}$. Since the EF is constructed from different perspectives, we investigate whether globalization is differently related to the EFs of production, imports and exports. Columns 3 and 4 feature the effects on the EF of production, columns 5 and 6 on the EF of imports and the last two columns on the EF of exports. We show an overview of our hypotheses and the respective effects in table 5.5 below.

Table 5.4 displays the robust control variables in the top panels for all ecological footprint measures. Before turning to our hypotheses, we look at the effect of overall globalization. We do not find that globalization is significantly related to the EF of consumption or production. However, we do find it to be significant on the 1 percent level for the EF of imports and exports. This suggests that the multidimensional process of globalization can be associated with ecological demands of trade. Countries that are more globalized exhibit higher EF of exports and imports. The size of the effects for the EF of imports and exports translates into an increase of around 6.1 and 5.2 percent, respectively, when globalization increases by 10 units. Thus, ceteris paribus, countries that are more globalized have higher ecological footprints of imports and exports.

Turning to our hypotheses, we address the different dimensions of globalization separately. We find strong evidence for our intensification hypothesis for all dimensions of the ecological footprint. This suggests that countries that are more economically globalized, ceteris paribus, exhibit higher ecological footprints. The size of the effects indicates that a 10-point increase in economic globalization (out of 100), which is the difference between Switzerland and the US, for example, translates into a $0.7(0.8,0.33$, $0.16)$ percent increase in the EF of consumption (production, imports and exports, respectively). This provides strong evidence for intensification of human demands through economic globalization. We do not find any significant relationship between political globalization and one of the subcomponents of the EF in any of the specifications. Thus, we find no evidence for hypothesis three and four.

\footnotetext{
${ }^{9}$ For each variant of the $\mathrm{EF}$, the first column reports the results for the regression model with the overall globalization index and the second column for the model with the three sub-indices (economic, political and social) - see Table 5.4 .
} 


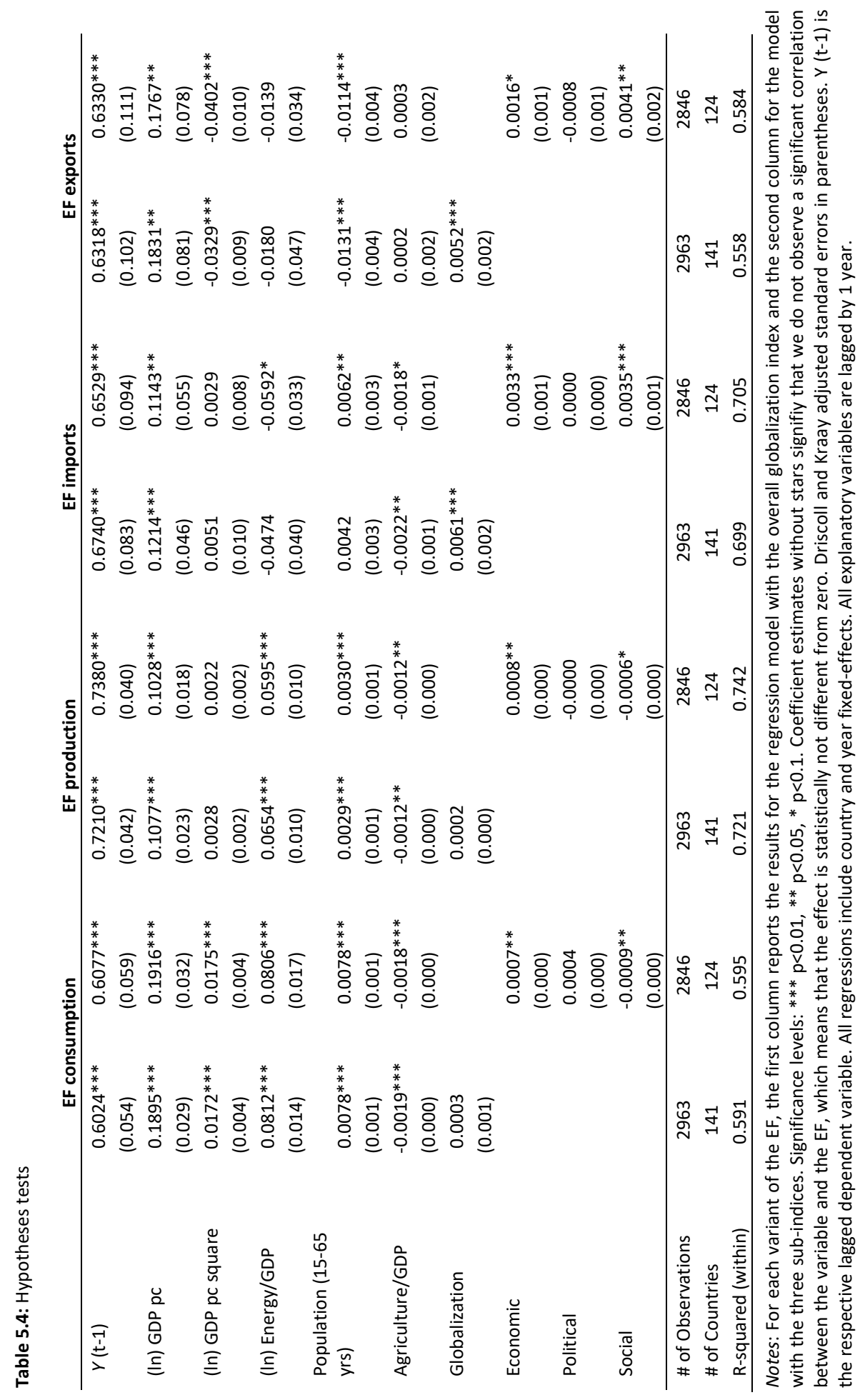


Finally, we find social globalization to be significantly and negatively related to the EF of consumption and production. An increase by 10 units is correlated with a decrease of the EF of consumption of 0.9 percent; increasing social globalization by one standard deviation (around 20 points) is related to a decrease in the EF of production by around 1.2 percent. This provides evidence for the "global environmental awareness" hypothesis whereby increased international connectedness seems to lead to a higher vigilance in national consumption and production. In contrast, however, in the case of EF of imports, we find a positive and significant correlation to social globalization. The magnitude of the effect translates into an increase of imported human demands by 7 percent if social globalization increases by one standard deviation (20-point increase, which corresponds to difference between Norway and Japan). One possible explanation is that societies that are more open to other cultures have a higher demand for international products, which translates into ecological pressures. The relation to ecological pressures of exports shows similar results. The coefficient is positive, and significant. Comparing the results to the results of table 5.2 (column 2), the results for social globalization have to be interpreted with care, since the Granger-causality test does not clearly identify the direction of causality for social globalization and the EF of imports and exports ( $p$-values smaller than 0.1).

\subsection{Discussion and conclusions}

We set out to provide deeper insights into the question "to what extent does globalization and its different domains intensify environmental footprints and/or contribute to ecologically sustainable development?". To address this question, we have provided a systematic empirical analysis of the drivers of human demands and examined more specifically the role of globalization as a multidimensional process.

Furthermore, we added to the empirical evidence on the ecological consequences of globalization, and complemented the evidence of chapter 4 by conducting a more robust and comprehensive analysis including the time dimension. Our model approximates the relation between globalization and human demands in the short-run considering a linear functional form with fixed country and year effects.

Table 5.5 shows an overview of the hypotheses and respective effects. It also relates the findings to the evidence of chapter 4 , which investigates the research question in a cross-section setting. In general, our findings in this chapter are qualitatively similar and support the results of chapter 4 . However, we find percentage effects that are significantly smaller in magnitude. 
Table 5.5: Overview of hypotheses and effects

\begin{tabular}{|c|c|c|c|}
\hline \multicolumn{2}{|c|}{ Hypotheses } & \multirow{2}{*}{$\begin{array}{l}\text { Effects } \\
+0.61 \% \text { on EF Imports } \\
+0.52 \% \text { on EF Exports }\end{array}$} & \multirow{2}{*}{$\begin{array}{l}\text { Comparison to MGI (Ch.4) } \\
+10 \% \text { on EF Cons } \\
+72 \% \text { on EF Imports } \\
+36 \% \text { on EF Exports }\end{array}$} \\
\hline & Overall globalization & & \\
\hline (1) & $\begin{array}{l}\text { Intensification } \\
\text { (Economic) }\end{array}$ & $\begin{array}{l}+0.7 \% \text { on EF Cons } \\
+0.8 \% \text { on EF Production } \\
+3.3 \% \text { on EF Imports } \\
+1.6 \% \text { on EF Exports }\end{array}$ & $\begin{array}{l}+10 \% \text { on EF Cons } \\
+20 \% \text { on EF Imports }\end{array}$ \\
\hline (2) & $\begin{array}{l}\text { Markets for the global envi- } \\
\text { ronment (Economic) }\end{array}$ & No effects & No effects \\
\hline (3) & $\begin{array}{l}\text { Global environmental gov- } \\
\text { ernance failure } \\
\text { (Political) }\end{array}$ & No effects & No effects \\
\hline (4) & $\begin{array}{l}\text { Global environmental gov- } \\
\text { ernance (Political) }\end{array}$ & No effects & No effects \\
\hline (5) & $\begin{array}{l}\text { Living in denial } \\
\text { (Social) }\end{array}$ & $\begin{array}{l}+3.5 \% \text { on EF Imports } \\
+4.1 \% \text { on EF Exports }\end{array}$ & $\begin{array}{l}+15 \% \text { on EF Imports } \\
+18 \% \text { on EF Exports }\end{array}$ \\
\hline (6) & $\begin{array}{l}\text { Global environmental aware- } \\
\text { ness } \\
\text { (Social) }\end{array}$ & $\begin{array}{l}-0.9 \% \text { on EF Cons } \\
-0.6 \% \text { on EF Production }\end{array}$ & No effects \\
\hline
\end{tabular}

Note: The effects mirror a 10-point increase in the respective globalization dimension.

Compared to chapter 4, we expect these findings to be closer to the "real effect" since we are able to control for more robust drivers, time trends and country-specific characteristics, and therefore identify the "pure and direct" effect of globalization. However, we may underestimate the true effect, since we include the lagged dependent variable. This has a strong tendency to reduce the effects and significance of the other independent variables, since we only test effects, which are independent of the EF of the previous year. Practically, we rather test and find the effects of globalization on the change in the EFs, which intuitively is smaller than the effects on the whole EF (as we did in chapter 4).

Further, the linearity of the model may over-simplify the complex reality of interrelations between globalization and human demands on the environment. For instance, globalization has been shown to drive affluence and GDP growth (Dreher, 2006; Dreher et al., 2008; Potrafke, 2014). This indicates that globalization influences human demands through GDP per capita. By closing this channel and controlling for the variable in the regression, we are more restrictive in our approach. To illustrate this point, we run additional estimations, excluding GDP per capita and its square (the results are reported in the Appendix, Table A5.6). Our main findings are generally not affected. However, the effect of globalization increases in size in all regressions. Thus, we do find that the effect of globalization is different in countries with different GDP levels. Includ- 
ing GDP in the regression reduces omitted variable bias and hence we are able to identify the "pure effect" of globalization that goes beyond income.

In chapter 4 we are not able to rigorously control for all underlying factors, such as country and time-specific effects, causing an omitted variable bias, as three robust determinants of ecological footprints were not considered. Using a panel setting here suggests that the effects are much smaller. Further, the underlying data of the two Gls is different with respect to the temporal coverage. Hence, statistically speaking, 1 point of globalization as measured by the MGI is not the same as 1 unit of globalization as measured by the KOF. Both indices use panel normalization to calculate globalization scores between 0 and 100. The data for the KOF index covers the period $1970-2009$, meaning that the minimum and maximium values used for normalization, differ considerably (see Figure 1.1 for the increasing global average level of globalization over time). We expect this to contribute to the difference in results.

Future research would benefit from the consideration of non- or semi-parametric approaches to address in more detail potential non-linearities. Our key findings are that economic globalization has an increasing effect on human demands, while social globalization has a decreasing effect. Future research could look into the specific effects of (eleven) sub-dimensions of social globalization (see table A5.1) to determine which of those have the strongest effects. Methodologically, we have shown that it is worthwhile to employ the KOF-index of globalization, as it provides additional insights into the consequences of globalization. We expect that this kind of research, which looks at macro trends, is important for providing decision-makers and researchers with a benchmark, and to enhance accountability towards future developments.

The empirical observation that, according to the EF data, humanity has lived in ecological overshoot since the 1970s and, in 2010 human consumption and production demanded 1.5 Earths (WWF, 2014) begs the question of what the effective leverage points are for reducing our common footprint to one Earth. Our findings for the 19812009 period show that the most robust determinants of the Ecological Footprint (of consumption) are GDP per capita, energy intensity, the economically active population, and the composition of the economy (share of agriculture in total GDP). With respect to globalization, policy makers should consider both economic and social connectedness more seriously when addressing and discussing sustainable development. 


\section{Appendix 5}

Table A5.1: the KOF index of Globalization (2014)

Indices and Variables

Weights

A. Economic Globalization

i) Actual Flows

Trade (percent of GDP)

Foreign Direct Investment, stocks (percent of GDP)

Portfolio Investment (percent of GDP)

Income Payments to Foreign Nationals (percent of GDP)

ii) Restrictions

Hidden Import Barriers

Mean Tariff Rate

Taxes on International Trade (percent of current revenue)

Capital Account Restrictions

B. Social Globalization

i) Data on Personal Contact

Telephone Traffic

Transfers (percent of GDP)

International Tourism

Foreign Population (percent of total population)

International letters (per capita)

ii) Data on Information Flows

Internet Users (per 1000 people)

Television (per 1000 people)

Trade in Newspapers (percent of GDP)

iii) Data on Cultural Proximity

Number of McDonald's Restaurants (per capita)

Number of IKEA (per capita)

Trade in books (percent of GDP)

C. Political Globalization

Embassies in Country

Membership in International Organizations

Participation in U.N. Security Council Missions

International Treaties

Source: Dreher (2006), updated version 2014. 
The Extreme Bounds Analysis enables the testing of additional variables that have been suggested by the literature as influencing ecological pressures. These are tested by including the $\boldsymbol{F}$ vector in the regression. As highlighted in the text, we refer mainly to the literature on the consequences of globalization, determinants of Ecological Footprints and pollution located in environmental economics, the political economy of globalization and ecological sociology. Demographic determinants other than economically active population are population growth and density (Gassebner et al., 2011; Lamla, 2009) and the share of the population living in urban areas (Dreher et al., 2008; Jorgenson \& Clark, 2011). The results for these variables have not been consistently positive or negative. Economic factors that have been tested by Lamla (2009) and Gassebner et al. (2011) are GDP growth and manufacturing share of GDP. Jorgenson and Burns (2007) include the agriculture share of GDP to test for the effect of the agricultural sector. We further include "socio-economic conditions" to control for general macro-economic conditions of the country. Geographic variables are per capita land area and arable land as a share of total land, since they have an influence on the capacity of the countries to compensate pollution and absorb waste (Dietz et al., 2007; Jorgenson \& Clark, 2011). Environmental awareness is argued to be a determinant of human demands on the environment, because it influences consumption patterns in mobility and energy consumption (UNEP, 2012a). Following the argument put forward by Stern (2004), we test various energy variables, including fossil fuel energy consumption, electricity production from oil sources, and the share of alternative and nuclear energy. To capture the effect of mobility, we employ road sector energy consumption in total and in per capita terms. (Environmental) governance structures and processes have an impact on ecological human pressures through regulation, standards, management and political and legal institutions (Dinda, 2004; Gallagher, 2009). The capacity and effectiveness of governance institutions are proxied by corruption, law and order, bureaucratic quality, government stability, democratic accountability and regime type (PRS Group, 2012). Another political variable suggested by Lamla (2009) is the number of years the chief executive has been in office (Beck et al., 2001), following the notion that long-term rule reduces the willingness to control for environmental stressors. Finally, Dreher et al. (2012) suggest that issues regarding the internal and external security of a population may play a crucial mediating role. Countries that face high levels of external or internal conflict may have weak institutions, low productivity and destroyed infrastructure, in addition to the hardship the population faces. This might weaken the capacity to produce and consume, and thereby reduce, human demands. Thus, we include variables for physical integrity rights, internal and external conflicts. Similarly, Jorgenson et al. (2010) emphasize the role of military actions on ecological pressures, which is captured by "military in politics" and military expenditure as a share of GDP provided in the WDI data (World Bank, 2014). The sources of all variables are detailed in the Table A5.3. 
Table A5.3: Variables and sources

\begin{tabular}{|c|c|c|}
\hline Variable & Description & Source \\
\hline (In) EF pc of consumption & $\begin{array}{l}\text { Natural logarithm of the Ecological Footprint (EF) per } \\
\text { capita of final consumption }\end{array}$ & $\begin{array}{l}\text { Global Footprint } \\
\text { Network (2014) }\end{array}$ \\
\hline Overall globalization & $\begin{array}{l}\text { Globalization multidimensional index: } 1 \text { (not global- } \\
\text { ized), } 100 \text { (completely globalized) }\end{array}$ & $\begin{array}{l}\text { Dreher (2006), } \\
\text { Dreher et al. (2008); } \\
2014 \text { Version }\end{array}$ \\
\hline Economic Globalization & $\begin{array}{l}\text { Economic globalization including restrictions and flows } \\
\text { (1 low; } 100 \text { high) }\end{array}$ & “ \\
\hline Social Globalization & $\begin{array}{l}\text { Social globalization including cultural proximity, per- } \\
\text { sonal contacts and information flows ( } 1 \text { low; } 100 \text { high) }\end{array}$ & “ \\
\hline Political Globalization & Political globalization (1 low; 100 high) & “ \\
\hline (In) GDP per capita & $\begin{array}{l}\text { Natural logarithm of GDP (constant } 2005 \text { US\$) per } \\
\text { capita }\end{array}$ & World Bank (2014) \\
\hline (In) GDP per capita squ. & $\begin{array}{l}\text { Squared natural logarithm of GDP (constant } 2005 \\
\text { US\$) per capita }\end{array}$ & “ \\
\hline Energy/GDP & $\begin{array}{l}\text { Energy use ( } \mathrm{kg} \text { of oil equivalent) per } \$ 1,000 \mathrm{GDP} \\
\text { (constant } 2005 \text { PPP) }\end{array}$ & “ \\
\hline Population (15 -65 years) & $\begin{array}{l}\text { Share of population between } 15 \text { and } 65 \text { of the total } \\
\text { population }\end{array}$ & “ \\
\hline (In) Arable land share & Natural logarithm of arable land (\% of land area) & “ \\
\hline Agriculture/GDP & Agriculture, value added (\% of total GDP) & “ \\
\hline Oil energy & Electricity production from oil sources (\% of total) & “ \\
\hline Altern. and nuclear energy & Alternative and nuclear energy (\% of total energy use) & “ \\
\hline (In) Area pc & Natural logarithm of total area available & $\begin{array}{l}\text { Global Footprint } \\
\text { Network (2014) }\end{array}$ \\
\hline Fuel energy consumption & Fossil fuel energy consumption (\% of total) & World Bank (2014) \\
\hline Road energy & Road sector energy consumption (kt of oil equivalent) & “ \\
\hline Road energy per capita & $\begin{array}{l}\text { Road sector energy consumption per capita ( } \mathrm{kg} \text { of oil } \\
\text { equivalent) }\end{array}$ & “ \\
\hline GDP growth & GDP growth (annual, percent) & “ \\
\hline (In) Military exp./GDP & $\begin{array}{l}\text { Natural logarithm of military expenditure as share of } \\
\text { GDP }\end{array}$ & “ \\
\hline Manufacturing/GDP & Manufacturing industry value added (percent of GDP) & “ \\
\hline (In) Population density & $\begin{array}{l}\text { Natural logarithm of population density (people per } \\
\text { square kilometer of land area) }\end{array}$ & “ \\
\hline Urban population & Urban population (percent of total population) & “ \\
\hline Population growth & Growth rate of the general population & “ \\
\hline Years in office & Chief executive years in office. & Beck et al. (2001) \\
\hline Regime type & $\begin{array}{l}\text { 0. Parliamentary democracy; } 1 \text {. Mixed (semi- } \\
\text { presidential) democracy; } 2 \text {. Presidential democracy; } 3 . \\
\text { Civilian dictatorship; } 4 \text {. Military dictatorship; } 5 \text {. Royal } \\
\text { dictatorship. }\end{array}$ & $\begin{array}{l}\text { Cheibub et al. } \\
(2010)\end{array}$ \\
\hline Physical integrity rights & $\begin{array}{l}\text { The composite index of physical integrity rights is the } \\
\text { additive of torture, extrajudicial killings, political } \\
\text { imprisonments, and disappearance, ranging from 0-8 }\end{array}$ & $\begin{array}{l}\text { Cingranelli and } \\
\text { Richards (2011) }\end{array}$ \\
\hline Bureaucracy quality & 4(very low risk), 0 (very high risk) & ICRG (2012) \\
\hline Corruption & 6 (very low risk), 0 (very high risk) & “ \\
\hline Democratic accountab. & 6 (very low risk), 0 (very high risk) & “ \\
\hline External conflict & 12(very low risk), 4(very high risk); 3 components & “ \\
\hline Internal conflict & 12(very low risk), 4(very high risk); 3 components & “ \\
\hline Government stability & 12(very low risk), 4(very high risk); 3 components & “ \\
\hline Socio econ. conditions & 12(very low risk), 4(very high risk); 3 components & “ \\
\hline Law and order & 6 (very low risk), 0 (very high risk) & “ \\
\hline
\end{tabular}


Table A5.4: Countries included in the study

\begin{tabular}{|c|c|c|c|}
\hline Albania & Cyprus & Korea, Rep. & Sao Tome \& Principe \\
\hline Algeria & Czech Republic & Kuwait & Saudi Arabia \\
\hline Angola & Denmark & Kyrgyz Republic & Senegal \\
\hline Antigua \& Barbuda & Dom Republic & Latvia & Singapore \\
\hline Argentina & Ecuador & Lebanon & Slovak Republic \\
\hline Armenia & Egypt, Arab Rep. & Lesotho & Slovenia \\
\hline Australia & El Salvador & Libya & South Africa \\
\hline Austria & Equatorial Guinea & Lithuania & Spain \\
\hline Azerbaijan & Eritrea & Luxembourg & Sri Lanka \\
\hline Bahamas, The & Estonia & Macedonia, FYR & St. Lucia \\
\hline Bahrain & Ethiopia & Malaysia & St. Vincent \& the Grenadines \\
\hline Bangladesh & Fiji & Maldives & Sudan \\
\hline Barbados & Finland & Malta & Sweden \\
\hline Belarus & France & Mauritius & Switzerland \\
\hline Belgium & Gambia, The & Mexico & Syrian Arab Republic \\
\hline Belize & Germany & Moldova & Tajikistan \\
\hline Benin & Ghana & Mongolia & Tanzania \\
\hline Bhutan & Greece & Morocco & Thailand \\
\hline Bolivia & Grenada & Mozambique & Togo \\
\hline Bosnia \& Herzegovina & Guatemala & Namibia & Tonga \\
\hline Botswana & Guinea-Bissau & Nepal & Trinidad \& Tobago \\
\hline Brazil & Guyana & Netherlands & Tunisia \\
\hline Brunei Darussalam & Haiti & New Zealand & Turkey \\
\hline Bulgaria & Honduras & Nicaragua & Turkmenistan \\
\hline Cabo Verde & Hungary & Nigeria & Ukraine \\
\hline Cambodia & India & Norway & United Arab Emirates \\
\hline Cameroon & Indonesia & Pakistan & United Kingdom \\
\hline Canada & Iran, Islamic Rep. & Panama & United States \\
\hline Chile & Iraq & Paraguay & Uruguay \\
\hline China & Ireland & Peru & Uzbekistan \\
\hline Colombia & Israel & Philippines & Venezuela, RB \\
\hline Comoros & Italy & Poland & Vietnam \\
\hline Congo, Dem. Rep. & Jamaica & Portugal & Yemen, Rep. \\
\hline Congo, Rep. & Japan & Qatar & Zambia \\
\hline Costa Rica & Jordan & Romania & \\
\hline Cote d'Ivoire & Kazakhstan & Russia & \\
\hline Croatia & Kenya & Samoa & \\
\hline
\end{tabular}




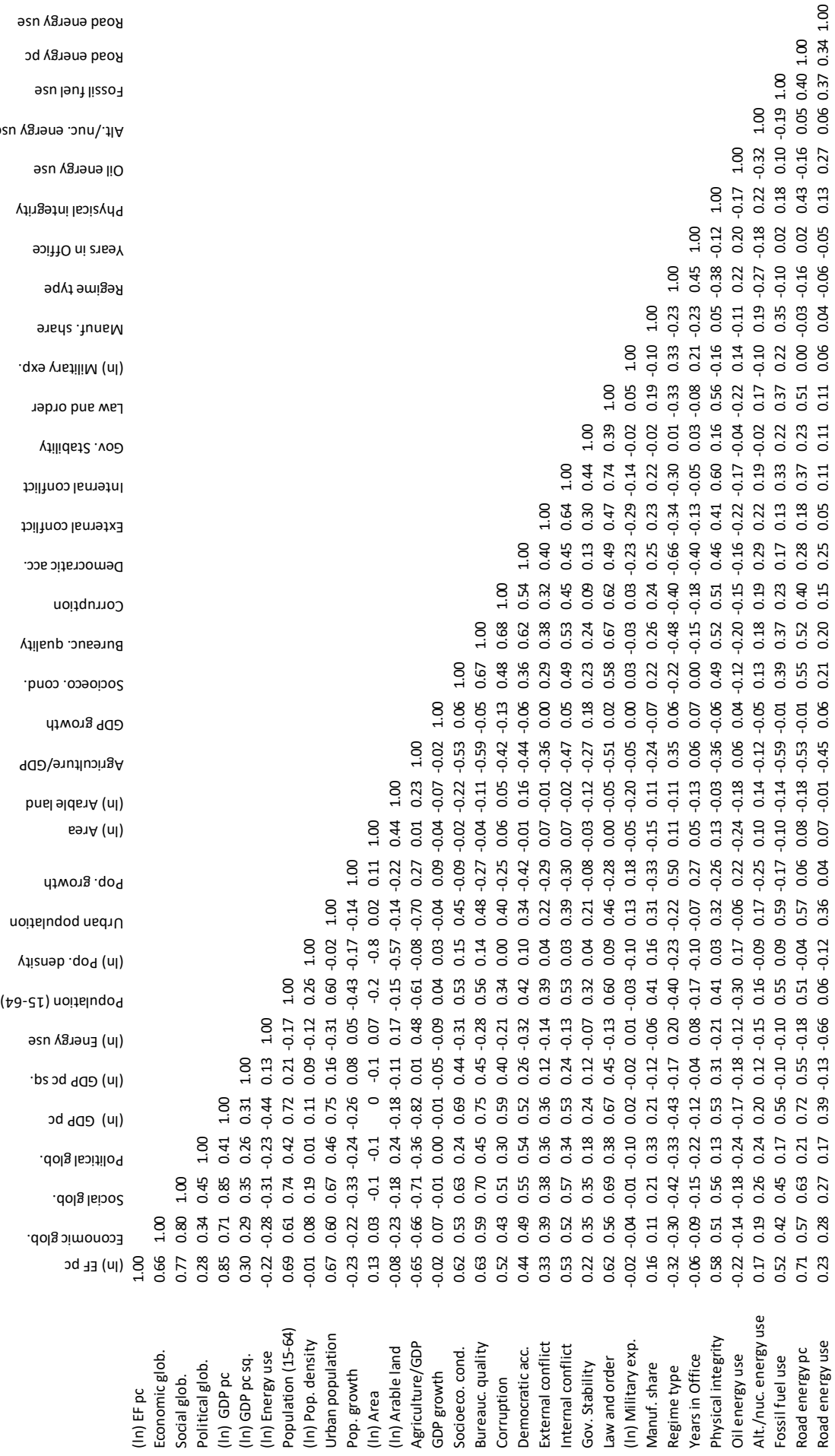




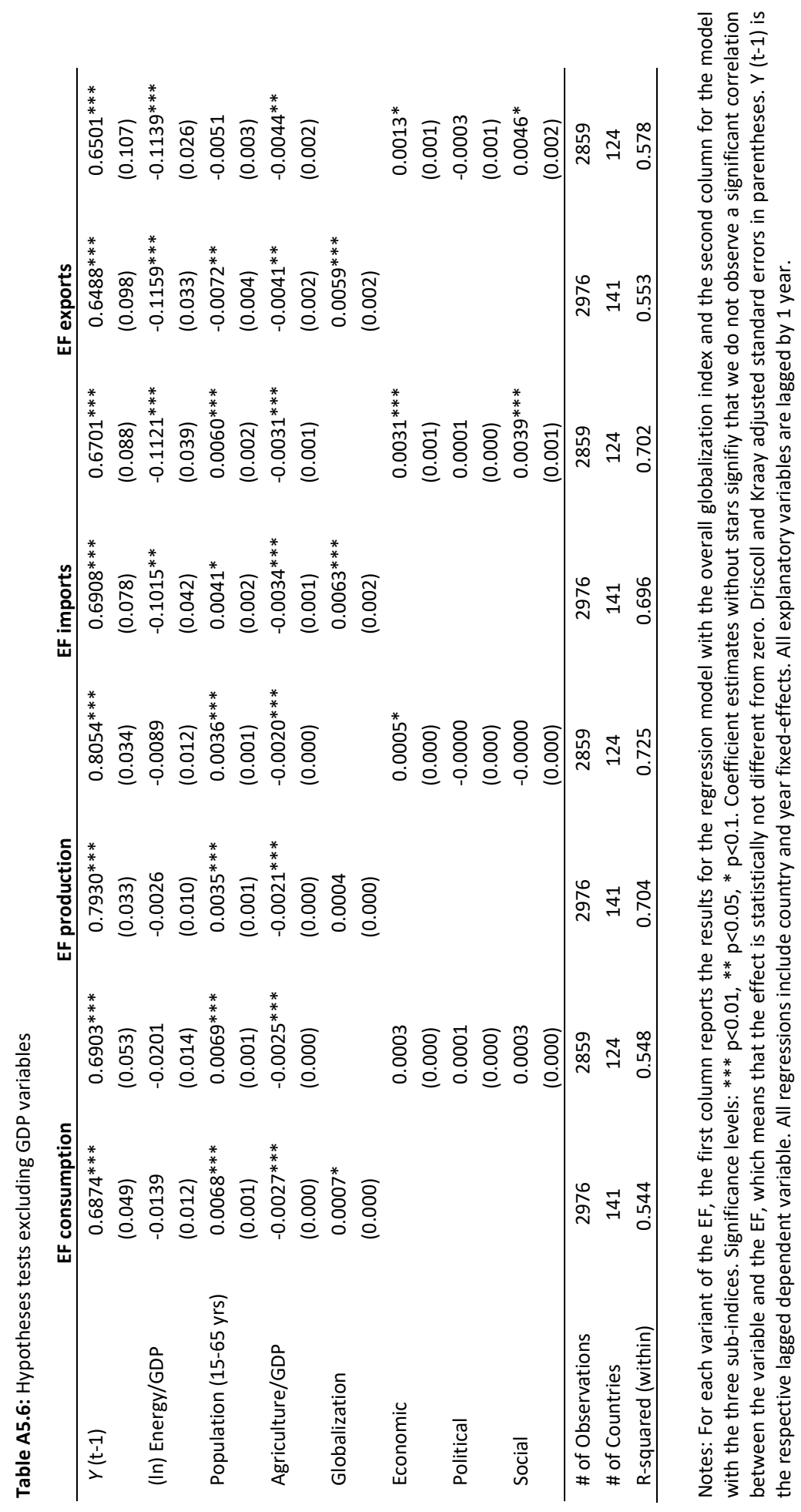


CHAPTER 6

The sustainability of globalization: including the 'social robustness criterion' 
"Capitalism is the astounding belief that the most wickedest of men will do the most wickedest of things for the greatest good of everyone."

John Keynes, economist

"At town meetings, you can see the shy folks, the ones who have trouble sounding off in public, leaning against the back wall or bending over their knitting. On talk radio, those people are invisible, but they're there. It's a mistake to think that the blowhards who call in speak for the nation."

Donella Meadows, environmental scientist

\begin{abstract}
Many scholars, commentators and activists have been involved in debates about the desirability of globalization. Judgements as well as evidence on the positive and negative impacts of globalization on the economy, society and ecology can be seen as statements on the sustainability of globalization: is globalization leading to a world in which people now and in the future can have a good quality of life? This chapter explores the sustainability of globalization by analyzing its 'social robustness'. It argues that in order to be sustainable, a policy, trend or process should be acceptable to a broad range of people in society. A text-based discourse analysis, derived from Cultural Theory, demonstrates the overall dominance of the 'individualist' perspective. With the results of this analysis we contribute towards the discussion on global issues that matter in the context of a sustainable future. We believe that a more socially robust form of globalization is possible, but only if marginalized perspectives are included in the policy debates and thereby allowed to contribute to solving humanity's most pressing issues.
\end{abstract}

The extended Abstract Figge, L., Elliott, J., \& Beumer, C. The sustainability of globalization: including the 'social robustness criterion' has been accepted for the Journal of Cleaner Production special issue on 'Rethinking Sustainability: Questioning old perspectives and developing new ones and is currently under revision'. 


\section{Introduction: sustainable globalization?}

The sustainability of globalization is a complex, contested and ambiguous issue that remains difficult to measure and quantify. Sustainable development is often seen as encompassing three 'pillars': the economic, social and ecological. If globalization has positive impacts on each of the three dimensions of sustainable development then it could be considered sustainable, while if it has negative consequences for one or more dimensions it may be considered unsustainable. This three pillar approach can be thought of as one criterion for judging the sustainability of globalization (Giddings et al., 2002).

Several empirical studies have investigated the sustainability of globalization from the three pillar approach (Chapters 4 and 5; Borghesi \& Vercelli, 2003; Martens \& Raza, 2010; Tisdell, 2001). The results of these empirical studies suggest that the trends and processes towards sustainable globalization are not uniform and the quantitative assessment of the sustainability of globalization, even when composite indices are applied for analysis, is fraught with difficulties due the lack of suitable data and methods, and the political nature of the subject matter (Borghesi \& Vercelli, 2003; Chapters 2 and 3 ). The resulting empirical uncertainty means it is possible for people to argue for conflicting views whilst backing those views up with sound evidence.

We argue that conflicting perspectives over the sustainability of globalization will continue to exist and shape the future of the process, despite more empirical evidence and greater perceived certainty about the impacts of globalization. As Sarewitz (2004) argues, sustainability controversies exist not because of a lack of knowledge but rather because of conflict over values and interests. Sustainability remains inherently subjective and political (Banerjee, 2003; Castro, 2004; Robinson, 2004). Thus, in any sustainability issue, and even more so for globalization, people's perceptions of the positive or negative nature of observed trends will differ (Martens \& Rotmans, 2002). Antiglobalists, for instance, will portray globalization as the root of unsustainability, whereas others see increased global integration as the solution to sustainability challenges. Reformists propose to transform globalization towards becoming more democratic and less based upon corporate economic interests (Rennen \& Martens, 2003). None of these perspectives is inherently right or wrong. Indeed it has been argued that our basic values and assumptions about the world and our idea about what a good world should look like affects the value we attribute to scientific knowledge itself (Bacchi, 2009; Kahan, Braman, Slovic, Gastil, \& Cohen, 2007). For a more insightful and fruitful debate in the globalization arena it is therefore imperative to gain a better understanding of underlying cultural perspectives. 
More concretely and following evolutionary theory of socio-ecological resilience and adaptation (Anton, 1995; Gunderson \& Holling, 2002), we argue, that a balance of cultural perspectives is crucial for sustainable globalization in two ways: first, it increases societal support for policies; second, it diversifies and enriches the policy options to deal with global environmental, economic and societal changes and other anticipated and unanticipated events.

This chapter explores the sustainability of globalization by analyzing its 'social robustness'. We argue that social robustness implies that the respective (global) policy discourses should balance the various cultural perspectives in order to be acceptable to a broad range of people in society. We pose the main research question 'how balanced and therefore socially robust is the policy discourse on globalization?' In order to answer this question we put forward a discourse analysis, based on Cultural Theory and analyze eleven reports published by significant organizations in the field of global governance which cover themes reflected by the three pillars of sustainability: economy (read: economic globalization), climate change (read: ecological globalization), and human well-being (read: social globalization). We believe that documents produced by major global organizations deliver suitable text material for analyzing the current perspectives in globalization. With the results of this analysis, we contribute to the discussion of global issues that matter for a sustainable future in a globalizing world.

\subsection{The social robustness criterion and Cultural Theory}

\subsubsection{Social Robustness}

Social robustness is achieved if a "strategy and its consequences on the fulfilment of needs are considered acceptable from different present and future points of view (perspectives)" (Offermans, 2012, p. 4). It must be acceptable not only now, but also under different possible future conditions. Changing strategies too often - for example due to changing political regimes - is costly, less effective and not always possible (Offermans, 2012). Indeed, it has been argued that policies or technological solutions to sustainability problems that do not enjoy widespread acceptance can lead to negative rather than positive sustainability impacts (Vallance, Perkins, \& Dixon, 2011). This can be seen as an instrumental conception of social robustness, where social acceptability is important as far as it affects the efficacy of a policy or solution to a sustainability problem. To illustrate this point, we put forward a cyclical model (figure 6.1) of how globalization processes are shaped by, and in return shape, cultural values and assumptions. The point is that if the policy discourse on globalization is not acceptable to a wide spectrum of society (which is illustrated by a balanced representation of six different cultural per- 
spectives in the inner circle) it will be opposed and ultimately abandoned or fall apart in fragmentation and will therefore not be able to 'sustain' itself over time.

Figure 6.1. 'The cultural wheel of globalization' integrates the three pillar criterion of sustainable development with the social robustness criterion based on a balance of cultural perspectives.

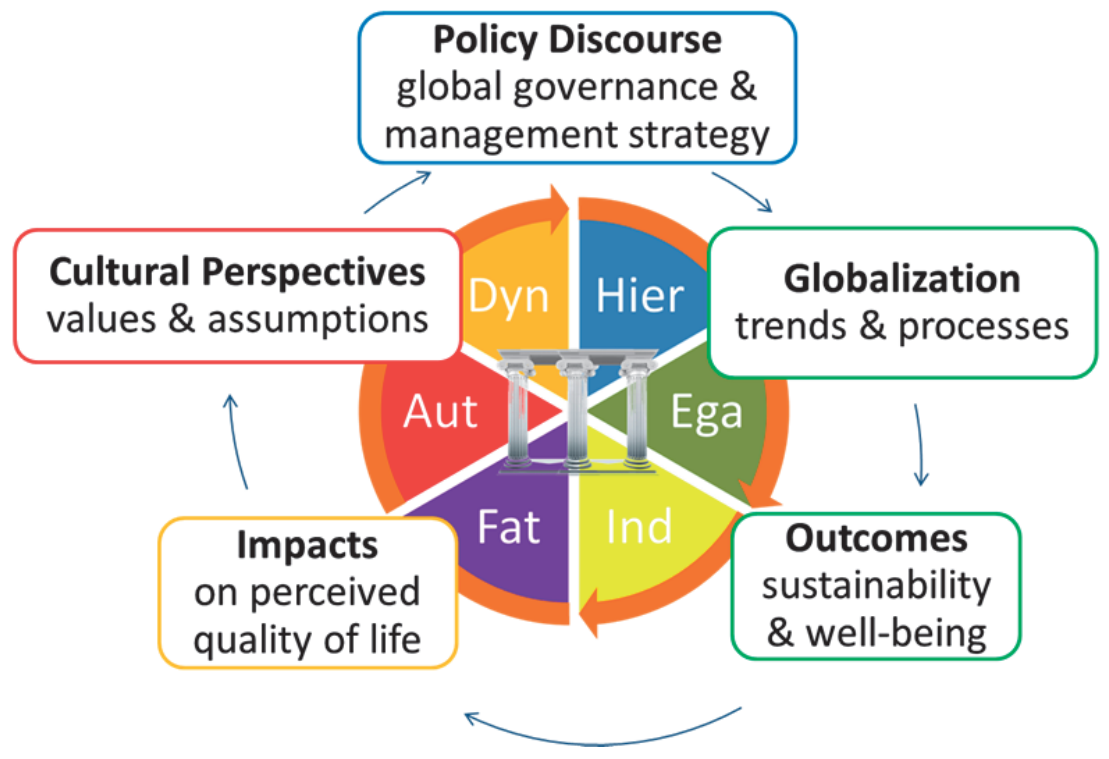

\subsubsection{Cultural Theory as a Heuristic Framework for Discourse Analysis}

In order to gain insights into the assumptions and values underlying globalization, it is helpful to have a tested framework or typology that structures the diversity of existing worldviews and management styles into some archetypical general patterns. With billions of individual people on Earth, each with their own background and interests, the range of possible viewpoints on globalization could seem overwhelming. Typologies classify people into groups in order to spot patterns and gain understanding of their preferences and behaviour in a structured way (Offermans, 2012). The Cultural Theory (CT) typology provides a framework for structuring and understanding a debate where there are different interpretations on the nature of a trend as well as its sustainability consequences (Beumer \& Martens, 2013; Pan et al., 2015). Offermans (2012) has compared the CT typology to six other typologies and found that it satisfies criteria for a typology as well as incorporates the perspectives found in other typologies and is therefore a suitable tool for analysing perspectives in sustainability issues. Furthermore, Kahan et al. (2007) find that the perspectives embodied in the CT typology much more closely explain people's views and preferences on issues than any other individual characteristic such as political ideology or gender. CT has already been applied in 
many contexts, including water management (Offermans, 2012; Valkering, Tabara, Wallman, \& Offermans, 2009), climate change (Verweij et al., 2006), multi-criteria optimization (Tošić, Marinković, Dašić, \& Stanić, 2015), life-cycle assessments (Blankendaal, Schuur, \& Voordijk, 2014), transition management (Tukker \& Butter, 2007), biodiversity conservation (Beumer \& Martens, 2010, 2013), and environmental risks (Asselt, Rotmans, Elzen, \& Hilderink, 1995).

An amended version of CT gives rise to six possible 'ways of life', each with a particular pattern of social relations and a distinctive set of 'cultural biases' (convictions about how the world is and how people are) that justify and reinforce each other: the Hierarchist, Egalitarian, Individualist, Fatalist, Autonomous and Dynamic Integrator ${ }^{10}$ (see table 6.1).

Table 6.1: Key characteristics of the six CT perspectives.

\begin{tabular}{|c|c|c|c|c|c|c|}
\hline & Hierarchist & Egalitarian & Individualist & Fatalist & Autonomous & Dyn. Int. \\
\hline Social relations & $\begin{array}{l}\text { Hierarchically } \\
\text { nested groups, } \\
\text { power rela- } \\
\text { tions }\end{array}$ & $\begin{array}{l}\text { Egalitarian- } \\
\text { bounded } \\
\text { groups }\end{array}$ & $\begin{array}{l}\text { Ego-focused } \\
\text { networks, } \\
\text { competitive } \\
\text { relations }\end{array}$ & $\begin{array}{l}\text { Involuntary } \\
\text { exclusion, } \\
\text { relations } \\
\text { determined by } \\
\text { others }\end{array}$ & \begin{tabular}{|l} 
Deliberate \\
withdrawal, no \\
involvement in \\
coercive \\
relations
\end{tabular} & $\begin{array}{l}\text { Deliberate } \\
\text { combination, } \\
\text { pluralistic } \\
\text { relations }\end{array}$ \\
\hline Myth of nature & $\begin{array}{l}\text { Perverse/ } \\
\text { tolerant: } \\
\text { Nature is } \\
\text { robust within } \\
\text { limits }\end{array}$ & $\begin{array}{l}\text { Ephemeral: } \\
\text { Nature is } \\
\text { fragile }\end{array}$ & $\begin{array}{l}\text { Resourceful: } \\
\text { Nature is a } \\
\text { resource } \\
\text { without limits. }\end{array}$ & $\begin{array}{l}\text { Capricious: } \\
\text { No rhyme or } \\
\text { reason }\end{array}$ & $\begin{array}{l}\text { Benign: } \\
\text { Nature is a } \\
\text { pure, giving, } \\
\text { living entity }\end{array}$ & $\begin{array}{l}\text { Resilient: } \\
\text { Nature is } \\
\text { dynamic \& } \\
\text { complex } \\
\text { system }\end{array}$ \\
\hline $\begin{array}{l}\text { Idea of Human } \\
\text { Nature }\end{array}$ & $\begin{array}{l}\text { Sinful but } \\
\text { redeemable by } \\
\text { good institu- } \\
\text { tions }\end{array}$ & $\begin{array}{l}\text { Good but } \\
\text { corruptible by } \\
\text { evil institu- } \\
\text { tions, } \\
\text { malleable }\end{array}$ & $\begin{array}{l}\text { Self-seeking } \\
\text { and very } \\
\text { stable, } \\
\text { unmalleable }\end{array}$ & $\begin{array}{l}\text { Unpredictable } \\
\text { - some are } \\
\text { benevolent, } \\
\text { more are } \\
\text { hostile }\end{array}$ & $\begin{array}{l}\text { Good but } \\
\text { ignorant }\end{array}$ & $\begin{array}{l}\text { Human nature } \\
\text { is complex and } \\
\text { dynamic }\end{array}$ \\
\hline $\begin{array}{l}\text { Directing } \\
\text { Principle }\end{array}$ & $\begin{array}{l}\text { Law and } \\
\text { Legislation }\end{array}$ & $\begin{array}{l}\text { Fairness \& } \\
\text { Justice }\end{array}$ & $\begin{array}{l}\text { Needs, wants } \\
\text { \& preferences }\end{array}$ & Providence & Love, Dignity & Integrity \\
\hline Activity & Policy & $\begin{array}{l}\text { Civil Disobedi- } \\
\text { ence }\end{array}$ & $\begin{array}{l}\text { Technological } \\
\text { Innovation }\end{array}$ & Passivity & Self Realization & $\begin{array}{l}\text { Integrated } \\
\text { Assessment }\end{array}$ \\
\hline $\begin{array}{l}\text { Knowledge } \\
\text { Epistemology }\end{array}$ & $\begin{array}{l}\text { Empiricism \& } \\
\text { Expertise }\end{array}$ & $\begin{array}{l}\text { Art \& Poetry \& } \\
\text { Lay/Indigenous } \\
\text { Knowledge }\end{array}$ & $\begin{array}{l}\text { Experimenta- } \\
\text { tion \& Explora- } \\
\text { tion \& Innova- } \\
\text { tion }\end{array}$ & $\begin{array}{l}\text { Agnos- } \\
\text { tic/Opinion }\end{array}$ & $\begin{array}{l}\text { Meditation \& } \\
\text { Prayer \& } \\
\text { Intuition \& } \\
\text { 'Verstehen' }\end{array}$ & $\begin{array}{l}\text { Integrated } \\
\text { Assessment }\end{array}$ \\
\hline $\begin{array}{l}\text { Sustainability } \\
\text { model }\end{array}$ & $\begin{array}{l}\text { Regulating } \\
\text { people, planet } \\
\text { and profit }\end{array}$ & $\begin{array}{l}\text { Planet \& } \\
\text { People first }\end{array}$ & $\begin{array}{l}\text { Profit is pre- } \\
\text { requisite for } \\
\text { people and } \\
\text { planet }\end{array}$ & $\begin{array}{l}\text { Survival of the } \\
\text { fittest }\end{array}$ & Planet first & $\begin{array}{l}\text { Integrating } \\
\text { people, planet } \\
\text { and profit }\end{array}$ \\
\hline
\end{tabular}

${ }^{10}$ We need to point out here that the Dynamic Integrator does not result from Cultural Theory as originally developed by Douglas (1970) and Thompson et al (1990), but rather from an extended version, as applied in Beumer (2014). The most significant difference is the addition of the Dynamic Integrator, who is not included in the original CT typology. 


\begin{tabular}{|c|c|c|c|c|c|c|}
\hline & Hierarchist & Egalitarian & Individualist & Fatalist & Autonomous & Dyn. Int. \\
\hline Risk Approach & $\begin{array}{l}\text { Risk averse - } \\
\text { involuntary } \\
\text { dangers im- } \\
\text { posed on } \\
\text { people not } \\
\text { acceptable. }\end{array}$ & $\begin{array}{l}\text { Acceptable } \\
\text { risks dealt with } \\
\text { in community }\end{array}$ & $\begin{array}{l}\text { Opportunity } \\
\text { for personal } \\
\text { reward }\end{array}$ & $\begin{array}{l}\text { Avoid personal } \\
\text { risk and cope } \\
\text { with imposed } \\
\text { risks }\end{array}$ & $\begin{array}{l}\text { Acceptance of } \\
\text { perceived risks } \\
\text { for personal } \\
\text { learning }\end{array}$ & $\begin{array}{l}\text { Risk anticipat- } \\
\text { ing }\end{array}$ \\
\hline $\begin{array}{l}\text { Management } \\
\text { attitude }\end{array}$ & $\begin{array}{l}\text { Monitoring \& } \\
\text { controlling }\end{array}$ & $\begin{array}{l}\text { Support \& } \\
\text { guidance }\end{array}$ & $\begin{array}{l}\text { Leadership \& } \\
\text { Innovation }\end{array}$ & Coping & $\begin{array}{l}\text { Personal } \\
\text { enlightenment }\end{array}$ & $\begin{array}{l}\text { Co-evolution \& } \\
\text { engaging }\end{array}$ \\
\hline $\begin{array}{l}\text { Management } \\
\text { style }\end{array}$ & Control & $\begin{array}{l}\text { Preventio \& } \\
\text { Precaution }\end{array}$ & $\begin{array}{l}\text { Engagement\& } \\
\text { Lobbying }\end{array}$ & Coping & Retreat & Adaptation \\
\hline $\begin{array}{l}\text { Management } \\
\text { priority }\end{array}$ & $\begin{array}{l}\text { Political and } \\
\text { social stability }\end{array}$ & $\begin{array}{l}\text { Protection of } \\
\text { the weaker }\end{array}$ & Prosperity & Why bother? & Harmony & $\begin{array}{l}\text { Dynamic } \\
\text { Balance } \\
\end{array}$ \\
\hline $\begin{array}{l}\text { Resource } \\
\text { management } \\
\text { strategy }\end{array}$ & $\begin{array}{l}\text { Differential } \\
\text { maintenance: } \\
\text { Needs are } \\
\text { prescribed. } \\
\text { Collective } \\
\text { resources can } \\
\text { be increased } \\
\text { by certified } \\
\text { experts. }\end{array}$ & $\begin{array}{l}\text { Sharing: Needs } \\
\text { are managed } \\
\text { by sharing and } \\
\text { fair distribu- } \\
\text { tion. }\end{array}$ & $\begin{array}{l}\text { The winner } \\
\text { takes it all: } \\
\text { Increase both } \\
\text { needs and } \\
\text { resources as } \\
\text { far as entre- } \\
\text { preneurial skill } \\
\text { will allow. }\end{array}$ & $\begin{array}{l}\text { Survival by } \\
\text { coping: Cannot } \\
\text { manage needs } \\
\text { or resources } \\
\text { therefore must } \\
\text { simply cope. }\end{array}$ & $\begin{array}{l}\text { Simplicity and } \\
\text { abstemious- } \\
\text { ness: Re- } \\
\text { sources are } \\
\text { fixed so one } \\
\text { person's gain is } \\
\text { another per- } \\
\text { son's loss. }\end{array}$ & $\begin{array}{l}\text { Needs and } \\
\text { resources } \\
\text { determined on } \\
\text { principles of } \\
\text { integrated } \\
\text { assessment. }\end{array}$ \\
\hline $\begin{array}{l}\text { Climate } \\
\text { Change Risk } \\
\text { perception }\end{array}$ & $\begin{array}{l}\text { Medium, less } \\
\text { urgent }\end{array}$ & High, urgent & Low & $\begin{array}{l}\text { Low/ why does } \\
\text { it matter? }\end{array}$ & High, urgent & Medium/ high \\
\hline $\begin{array}{l}\text { Climate } \\
\text { change causes }\end{array}$ & $\begin{array}{l}\text { Lack of global } \\
\text { governance } \\
\text { and planning }\end{array}$ & $\begin{array}{l}\text { Profligate } \\
\text { production } \\
\text { and consump- } \\
\text { tion }\end{array}$ & $\begin{array}{l}\text { Sceptical } \\
\text { towards scien- } \\
\text { tific consensus }\end{array}$ & $\begin{array}{l}\text { Inevitable } \\
\text { human/ natu- } \\
\text { ral processes }\end{array}$ & $\begin{array}{l}\text { Lack of one- } \\
\text { ness with } \\
\text { nature }\end{array}$ & Mix of causes \\
\hline $\begin{array}{l}\text { Climate } \\
\text { Change } \\
\text { Management }\end{array}$ & $\begin{array}{l}\text { International } \\
\text { agreements, } \\
\text { imposed by } \\
\text { states on } \\
\text { consumers and } \\
\text { producers. }\end{array}$ & $\begin{array}{l}\text { Strict precau- } \\
\text { tionary princi- } \\
\text { ple. Rapid } \\
\text { reduction in } \\
\text { emissions. } \\
\text { Decentraliza- } \\
\text { tion of deci- } \\
\text { sion making. }\end{array}$ & $\begin{array}{l}\text { Innovative } \\
\text { business as } \\
\text { usual. Perhaps } \\
\text { internalisation } \\
\text { of environ- } \\
\text { mental costs. }\end{array}$ & $\begin{array}{l}\text { Life goes on. } \\
\text { Take ad- } \\
\text { vantage of } \\
\text { windfalls in } \\
\text { resources. }\end{array}$ & $\begin{array}{l}\text { Individual } \\
\text { voluntary } \\
\text { simplicity. }\end{array}$ & $\begin{array}{l}\text { Integrated } \\
\text { solutions. }\end{array}$ \\
\hline $\begin{array}{l}\text { Cost distribu- } \\
\text { tion }\end{array}$ & $\begin{array}{l}\text { Common } \\
\text { responsibility } \\
\text { for costs, } \\
\text { distributed } \\
\text { across global } \\
\text { society. }\end{array}$ & $\begin{array}{l}\text { Costs should } \\
\text { be borne by } \\
\text { the richest. } \\
\text { Strict polluter } \\
\text { pays principle. }\end{array}$ & $\begin{array}{l}\text { Costs distrib- } \\
\text { uted by free } \\
\text { market }\end{array}$ & $\begin{array}{l}\text { Costs of adap- } \\
\text { tation borne } \\
\text { by those who } \\
\text { need to adapt. } \\
\text { It is just bad } \\
\text { luck. }\end{array}$ & $\begin{array}{l}\text { Low individual } \\
\text { costs when } \\
\text { going off the } \\
\text { grid. }\end{array}$ & $\begin{array}{l}\text { Collective } \\
\text { agreement } \\
\text { based on } \\
\text { cooperative } \\
\text { stakeholder } \\
\text { dialogue. } \\
\end{array}$ \\
\hline $\begin{array}{l}\text { Economy as a } \\
\text { driver } \\
\text { of/response to } \\
\text { CC }\end{array}$ & $\begin{array}{l}\text { Contributing } \\
\text { driver, con- } \\
\text { tributing } \\
\text { response }\end{array}$ & $\begin{array}{l}\text { Main driver of } \\
\text { climate } \\
\text { change, innap- } \\
\text { propriate } \\
\text { response }\end{array}$ & $\begin{array}{l}\text { Not a driver, } \\
\text { main response }\end{array}$ & $\begin{array}{l}\text { Globalization } \\
\text { and climate } \\
\text { change seen as } \\
\text { inevitable } \\
\text { processes }\end{array}$ & $\begin{array}{l}\text { Driver, retreat } \\
\text { from global } \\
\text { economic } \\
\text { system \& } \\
\text { consumption } \\
\text { as response }\end{array}$ & $\begin{array}{l}\text { Contributor } \\
\text { and part of } \\
\text { possible re- } \\
\text { sponse }\end{array}$ \\
\hline
\end{tabular}

Note: Adapted from: Beumer (2014); Offermans (2012); Thompson et al. (1990); Verweij et al. (2006) 
These biases are built around a framework of stronger and weaker incorporation into social groups and stronger and weaker confinements to normative prescriptions of a given society (Douglas, 1970; Thompson, Ellis, \& Wildavsky, 1990). Cultural Theorists also link the different perspectives to particular social constructions of environmental and human nature, corresponding management strategies, and preferences on the issues of risk, growth, scarcity and apathy (Beumer, 2014; Offermans, 2012; Verweij et al., 2006). As these attributes are described elaborately by different authors already (Asselt et al., 1995; Thompson et al., 1990; Verweij et al., 2006), we refrain from explaining the perspectives or strategies here in more detail, but provide an overview of the key characteristics in table 6.1.

We claim that a certain level of balance between the different perspectives is required for a sustainable and well-functioning society, as defined by the robustness criterion. Marco Verweij and his colleagues (2006) support this claim by arguing:

"[e]ach way of organizing and perceiving: (1) distils certain elements of experience and wisdom that are missed by the others; (2) provides a clear expression of the way in which a significant portion of the populace feels we should live with one another and with nature; and (3) needs all the others in order to be sustainable." (Verweij et al., 2006, p 821)

People will always argue about the 'best' strategies and they are usually based on their beliefs about the world. Management strategies do what is most important for people: they uphold their own way of life (Thompson et al., 1990, p 48). This will often lead to conflict and disagreement (Verweij et al., 2006). Awareness of the value of plurality of perspective and its need for adaptive capacity is imperative to channel disagreements into constructive dialogues for a sustainable future (Hirst, 1997; Robinson, 2011; Verweij et al., 2006).

\subsection{Methods}

\subsubsection{Content analysis \& data choice}

Following Beumer (2014); Beumer and Martens (2010, 2013); De Kraker, Kuijs, Cörvers, and Offermans (2014); Offermans and Cörvers (2012) we conduct a CT based content analysis on eleven reports published by organizations in the field of global governance. We believe documents by major global organizations allow to analyze the current distribution of perspectives in globalization. The reports have all been published within the last ten years (2007-2016), and represent a recent milestone, future vision, or outlook delineating a sustainable future. The focus in each report is on one of the follow- 
ing themes: the economy, climate change and human well-being (see table 6.2). The three themes allow for a potential balance of environmental, economic, and social concerns (three pillars of sustainability). Thereby, we make explicit the underlying values and assumptions that shape global policy and globalization processes. We are then able to judge the social robustness of globalization-shaping policies as represented in these documents. We now elaborate on the three themes and on the selection of reports, which provide the text data for the analysis.

\subsubsection{Theme Economy}

Economy and globalization are historically intertwined terms and the economy is often defined as the main driver of globalization (Rennen \& Martens, 2003; Scholte, 2002; Stiglitz, 2007). This is especially reflected in global trade liberalization advocated by the World Trade Organization, and the power of the economic development programmes of the World Bank and the OECD. These organizations shape and constitute financial, political and even cultural structures and interrelations between most of the world's countries through increasing the exchange of goods, services and people. The current global economy is largely based on capitalist ideals to foster socio-economic development through growth in production and consumption. The concept of sustainable development arrived in the global policy arena in 1987 with the publication of the Brundtland report (Brundtland-Commission, 1987), which was the beginning of the acknowledgment of the necessity of sustainable forms of economic development which later evolved into notions of Green Growth, or a Green Economy (UNEP, 2011). In policy circles, all eyes remain focused on continuing economic growth as the solution to crises and as the way to reduce inequality (Martens, 2013). This has also been recently reaffirmed by the eighth SDG (UNGA, 2015), which calls for sustained economic growth in all countries. The chosen reports for analysis of this theme are: The History and Future of the World Trade Organization, by the WTO (2013), which represents a future vision for the WTO; Strengthening Global Trade Investment System 21st Century by the World Economic Forum (2016), which provides a future vision on trade and investment; the OECD Environmental Outlook to 2050: the Consequences of Inaction (2012); and Towards a Green Economy: Pathways to Sustainable Development and Poverty Eradication by UNEP (2011).

\subsubsection{Theme Climate Change}

It is useful here to clarify how the case of climate change is considered in this research since it is related to globalization processes and could be considered as a consequence of globalization (e.g. due to the global use of fossil fuels); a form of globalization in itself (e.g. ecological globalization); or even a driver of globalization (e.g. through the movement of climate refugees) (Borghesi \& Vercelli, 2003; Gallagher, 2009; Rennen \& Martens, 2003; Scholte, 2005). Here climate change is conceptualised as a sustainability issue with social and economic aspects as well as environmental ones, which can be 
evaluated from all possible perspectives of CT. The significant recent reports we chose are: Climate Change 2014: Synthesis Report by the IPCC (2014a), which is a report on the progress of climate change based on latest scientific insights; the COP 21 Paris Agreement by the UNFCCC (2015); Better Growth, Better Climate: The New Climate Economy Report by the World Resources Institute (Global Commission on the Economy and Climate, 2014) and the World Development Report on Development and Climate Change by the World Bank (2010).

\subsubsection{Theme Well-being}

Human well-being and health are intertwined with the two previous themes. Both health and well-being are connected to micro and macro-economic patterns (Pickett \& Wilkinson, 2015), global environmental change such as climate change (Huynen, 2008; Huynen, Martens, \& Akin, 2013) and biodiversity (Beumer, Huynen, \& Martens, 2008; Chivian, 2002; IUCN, 2009; Martens et al., 2010b; Martens \& Beumer, 2015; MEA, 2005). We define health not as the absence of illness in individuals, but place it in a global context where it becomes constituted by the interplay of economic, social and environmental factors (Huynen, 2008; Labonte, 2009; Labonte \& Torgerson, 2003; Martens, Akin, Huynen, \& Raza, 2010a). Therefore, when we use well-being, we refer to inclusive health which takes into account social and environmental determinants. The WHO (2007) report Towards Health-Equitable Globalization: Rights, Regulation and Redistribution explicitly discusses the health topic. We also chose a on labour conditions, which are discussed by the ILO (2015) in the World Employment Social Outlook. Next to this we selected a recent report discussing the foundations of human health and wellbeing by the WHO, UNEP and the CBD (2015) called Connecting Global Priorities: Biodiversity and Health.

The three themes form the basis for a categorization of the selected reports into five subcategories which we refer to as 'document-families'. Family 1 has an economic focus, whereas family 2 concerns the idea of a green economy. Family 3 is concerned with climate change and family 4 puts climate change in relation to globalization processes. Family 5 relates to human well-being, including labour conditions and an environmental perspective on well-being and health (table 6.2).

Table 6.2 Themes and document families

\begin{tabular}{|l|l|}
\hline Theme & Family \\
\hline Economy & $\begin{array}{l}\text { Family 1: Economy (WEF 2016 \& WTO 2013) } \\
\text { Family 2: Green Economy (UNEP 2011 \& OECD 2012) }\end{array}$ \\
\hline Climate Change & $\begin{array}{l}\text { Family 3: Climate Change (COP21 } 2015 \text { \& IPCC 2014) } \\
\text { Family 4: Globalization \& Climate Change (WRI 2014 \& WB 2010) }\end{array}$ \\
\hline Well-being & $\begin{array}{l}\text { Family 5: Human Well-being \& Health } \\
\text { (WHO 2007 \& ILO 2015 \& CBD/WHO/ UNEP 2015) }\end{array}$ \\
\hline
\end{tabular}




\subsubsection{Coding}

The content analysis of the selected documents was performed with Atlas.ti 7, a software programme for text and content analysis. Six equally long search strings based on key words representing general characteristics of the CT perspectives were used to code the texts. The words in the search strings (see table A6.1 in the Appendix) were chosen based on literature research conducted in earlier studies and the perspectives map (table 6.1) as applied in (Beumer, 2014; Beumer \& Martens, 2010, 2013; De Kraker et al., 2014; Offermans \& Cörvers, 2012; Offermans, Haasnoot, \& Valkering, 2011). Applying the search strings to the text, we count how often a perspective shows up in the documents. Based on this we calculate percentages of perspective occurrence within the set of texts as a whole, within each of the five text families, and within each individual report. The assumption we make is that the occurrence of the key words indicates how prevalent the respective cultural perspective is in the discourse. For globalization to be socially robust, we would expect a balanced representation of perspectives with no single perspective being either particularly dominant or marginalized.

Content analysis by means of strings and a software programme implies that the context of the words has not been taken into account. This could be a particular problem in this case if a perspective or discourse is being criticised or discussed from a 'negative' point of view. For example, an egalitarian author criticizing market-based (individualist) approaches to the protection of nature would necessarily describe these market-based approaches using many of the same words as an individualist would. To check the robustness (not social robustness!) of our results, we manually coded three random pages per document in order to take the context of the words into account. Removing coded segments which were completely unfitting did not significantly change the percentage results of the analysis for the samples. According to our robustness checks, none of the document results seemed to be fundamentally flawed. Another limitation to this assessment is that the documents differ in size. Therefore, in the total count of the perspectives for all documents, large documents contributed most to the perspectives. This limitation is addressed by focusing the reporting and discussion of results on the Family level and on the Individual document level.

\subsubsection{Calculations}

As we assume a certain balance of perspectives to contribute to the social robustness of globalization, we introduce balance benchmarks. In a perfectly balanced world, each cultural perspective would make up $16.7 \%$ of the total count. Being less strict, we consider a discourse to be balanced if the perspectives are between 8 and $25 \%$. Hence, we consider a perspective to be dominant, when it scores more than $25 \%$ and marginalized if it scores below $8 \%$ (which is $16.7 \pm[16.7 * 0.5]$ ). Then, we can also determine the "de- 
gree of balance" (counting how many perspectives are within the range, this is between 0 and 6).

Further, we employ a Shannon Entropy measure (Lin, 1991). On a data set of $n$ instances, with $k$ perspectives of size $p$, Shannon Entropy is calculated

$$
H=-\sum_{i=1}^{k} \frac{p_{i}}{n} \ln \frac{p_{i}}{n}
$$

which is equal to zero if there is one single perspective (unbalanced) and $\ln (k)$ when all the perspectives are equally balanced. We divide by $\ln (k)$, in order to get a measure of balance

$$
\text { Balance }=\frac{H}{\ln k}=\frac{-\sum_{i=1}^{k} \frac{p_{i}}{n} \ln \frac{p_{i}}{n}}{\ln k}
$$

which is zero for an unbalanced data set and one for a perfectly balanced data set. Based on those scores we further calculate normalized (or relative) balance scores

$$
\text { relative Balance }=100\left(1-\frac{B_{\max }-B_{i}}{B_{\max }-B_{\min }}\right)
$$

with $B$ being the maximum and minimum Balance score, as found in the individual reports. The relative balance is then a value between 0 for the least balanced and 100 for the most balanced report. This implies that these need to be interpreted as relative scores (relative meaning relative to the minimum and maximum score of the reports that are included in the analysis). The reports and families have been ranked accordingly, from least balanced (i.e. 11 for the reports and 5 for the families) to most balanced (1) (see table 6.3). 


\subsection{Results}

Table 6.3 presents the counts for the separate documents, families and total level, as well as the degree of balance and the relative balance score (Shannon Balance in brackets) and rank. The overall results of the content analysis show that all perspectives are included in the policy discourse. In table 6.4 we report the correlations between the perspectives and the Balance score, and also how often the perspectives show up marginalized, balanced and dominant (out of the eleven reports). The individualist is the most dominant perspective (eight out of eleven reports), followed by the dynamic integrator, who is dominant in five instances. The egalitarian is dominant in four instances and balanced in the other seven. The hierarchist shows up balanced ten times, and is never dominant, while the autonomous and fatalist perspective are the most marginalized.

Table 6.3: Counting perspectives and calculated Balance scores

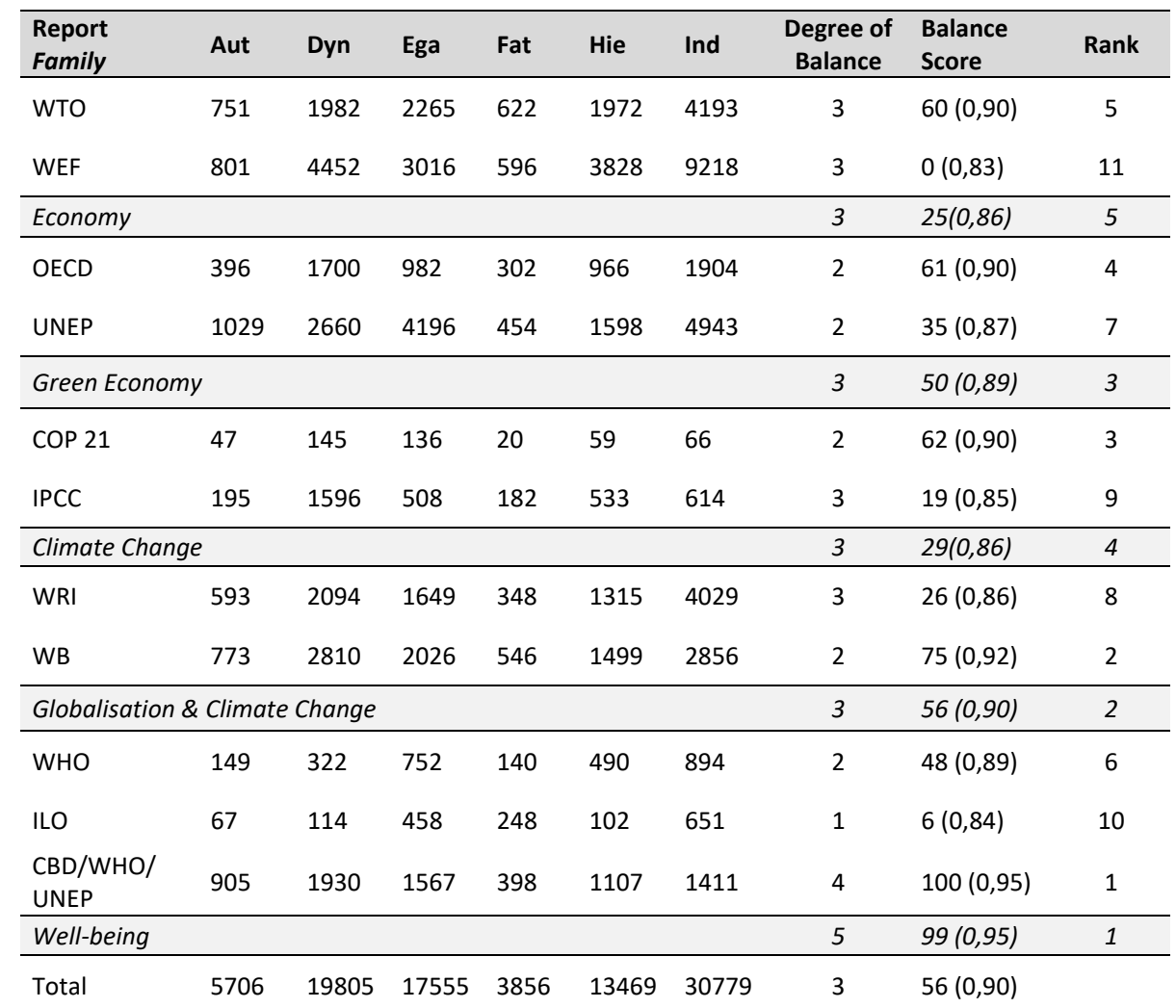

Note: we report the actual counts for the perspectives which are used to calculate the \%s in Figure 6.2. In the Balance column we report the relative Balance first and in brackets the Balance Score. Degree of balance is a score between 1 ( $\min$ balance) and 6 ( $\max )$. 
When adding up all the counts of the reports and calculating the percentages (see first row in Fig 6.2), we again find the individualist perspective as the single dominant one, with the hierarchist, egalitarian and dynamic integrator being balanced, and the autonomous and fatalist being marginalized. The correlations in table 6.5 confirm that the individualist has negative relationships with most of the other perspectives (except the fatalist), meaning that his strength comes at the cost of other perspectives. The dynamic and egalitarian, while at times dominant, have a moderate positive relation with balance. However, the dynamic integrator has negative relations (moderate to strong) with the egalitarian, fatalist and individualist. His presence seems to come at the cost of others. Results are further presented in more detail on two more levels: the family and the document level (figure 6.2).

Table 6.4: Correlation tables and distribution of balance

\begin{tabular}{|c|c|c|c|c|c|c|c|c|c|c|}
\hline & Balance & Aut & Dyn & Ega & Fat & Hie & Ind & Marg & Bala & Dom \\
\hline Balance & 1,00 & & & & & & & & & \\
\hline Aut & 0,88 & 1,00 & & & & & & 9 & 2 & 0 \\
\hline Dyn & 0,45 & 0,53 & 1,00 & & & & & 1 & 5 & 5 \\
\hline Ega & 0,26 & 0,34 & $-0,49$ & 1,00 & & & & 0 & 7 & 4 \\
\hline Fat & $-0,11$ & $-0,18$ & $-0,69$ & 0,37 & 1,00 & & & 10 & 1 & 0 \\
\hline Hie & 0,35 & 0,14 & 0,57 & $-0,50$ & $-0,69$ & 1,00 & & 1 & 10 & 0 \\
\hline Ind & $-0,29$ & $-0,58$ & $-0,53$ & $-0,07$ & 0,08 & $-0,05$ & 1,00 & 0 & 3 & 8 \\
\hline
\end{tabular}

Note: correlations range between 1 and -1 . Values between 0 and $\pm 0,33$ are considered weak, values greater (or smaller) than $\pm 0,67$ are considered strong, and moderate in between.

\subsubsection{Economy family}

The Economy family ranks as the least balanced of all families (rank 5). We find a strong dominance of the individualist perspective, which also comes through in the individual reports. In particular the World Economic Forum (2016), which proclaims to be "committed to improving the state of the world" and being the "International Organization for Public-Private Cooperation" exhibits very high individualist scores. The WEF claims to represent many perspectives and covers many topics. Indeed, all the perspectives are represented, but the report comes out as the least balanced of all the documents (rank 11 out of 11). For the WTO (2013) it is in the realm of expectations for the individualist perspective to be dominant. Surprisingly, the individualist perspective in the WTO document is weaker than in the WEF. In both reports the dynamic, egalitarian and hierarchist are rather equally balanced. An economy that operates on the primary objective to produce prosperity and economic growth and is under the assumption that the global environment is robust may run into problems, and be un-sustainable, if this assumption turns out not to be true. 
Figure 6.2: Perspective composition of the families and reports

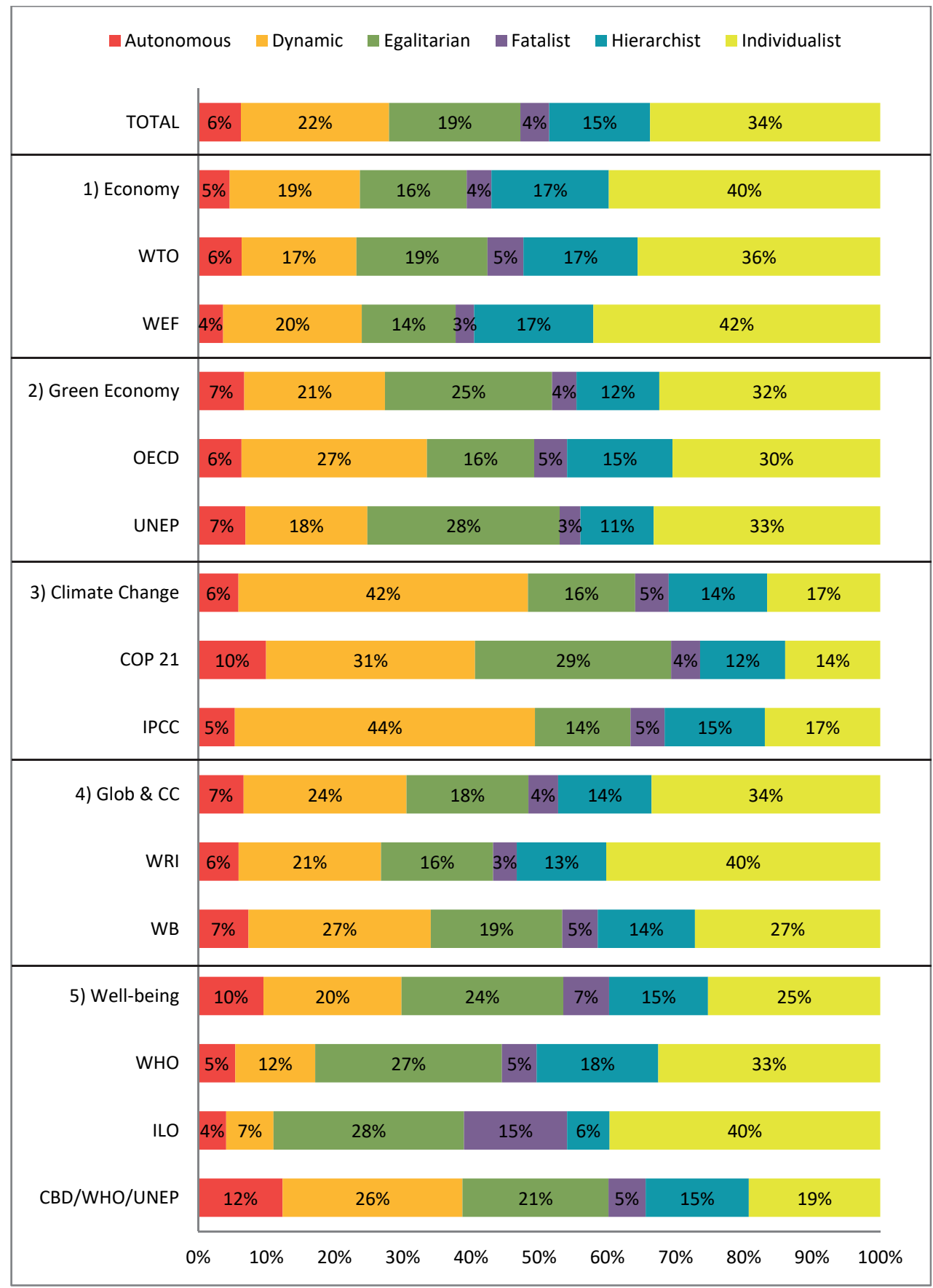

Note: percentages of perspectives were calculated based on the counts of key words as reported in table 6.3. For the families and total level they were simply added up. 


\subsubsection{Green Economy family}

A way to enhance robustness is to more strongly incorporate the autonomous and fatalist perspective. The question is whether this is done in the reports of the green economy family? Here we analyzed documents that explicitly integrate economic and environmental objectives. Both documents envision a sustainable future based on 'green growth'. The individualist is still the dominant perspective, but its dominance is weaker than in the Economy family. The egalitarian perspective is represented more strongly than in the Economy family, while the hierarchist is significantly weaker. In terms of overall balance this family comes out as the median, with rank three. At the document level, the OECD (2012) exhibits a strengthened dynamic integrator as second strongest perspective, with the hierarchist and egalitarian being on the same level. The UNEP (2011) has a slightly stronger individualist discourse, with a strengthened and complementing egalitarian perspective. Especially the hierarchist is considerably weaker in the UNEP report compared to those previously discussed. We clearly find more balance, and less individualist dominance in the Green Economy than in the Economy family. This illustrates that the green economy is a more balanced way forward, compared to the economy family, and hence indeed a little more socially robust and sustainable.

\subsubsection{Climate Change family}

The document family dedicated to the issue of Climate Change is the second least balanced (rank 4), but stands out as it is dominated by the dynamic integrator and not by the individualist. The hierarchist, egalitarian and individualist are equally balanced, while the fatalist and autonomous remain marginalized. The COP 21 (UNFCCC, 2015) document exhibits a second dominating perspective, the egalitarian; and the autonomous qualifies as balanced. The IPCC report (2014a), assembled by the global community of climate scientists, is strongly dominated by the dynamic perspective, while the individualist, hierarchist and egalitarian are balanced.

\subsubsection{Globalization \& Climate Change family}

In this Family we included documents that address climate change in the context of (economic) globalization. This reframing brings the individualist perspective back to dominance and the dynamic integrator, egalitarian and hierarchist are in balanced positions. Overall, this family has a similar pattern as the green economy family and comes out as second most balanced. The World Bank (2010) report exhibits two dominating perspectives, the individualist and dynamic integrator, three balanced perspectives, the fatalist, egalitarian and hierarchist; the autonomous remains marginalized. The WRI document (Global Commission on the Economy and Climate, 2014) has a dom- 
inant individualist perspective, with a complementary balance between the dynamic, egalitarian and hierarchist perspective.

\subsubsection{Human well-being family}

This family is the most balanced (rank 1, with 5 degrees of balance), and hence the most socially robust. On the overall theme level, the individualist, egalitarian, dynamic hierarchist and autonomous perspectives qualify as balanced. It is particularly noticeable that the autonomous perspective is surprisingly balanced. This balance can be largely attributed to the WHO/UNEP/CBD report (2015) and may be partly caused by the organizational collaboration or the focus on health and biodiversity. While the WHO report aims to advance equitable health in its title, the individualist discourse comes out stronger than the egalitarian and the other perspectives. In the ILO report (2015) the fatalist perspective is well balanced, with the autonomous, hierarchist and dynamic perspectives marginalized, and the individualist and egalitarian being dominant. Hence, this report stands out, with a degree of balance of 1 , which is in contract to all other documents. This can be attributed to the attention given to the 'crisis' narrative, which is causing a global employment gap, reduced trust in governments, uncertainty in employment conditions and increased labour market turnover. The hierarchist perspective with its focus on regulation is significantly marginalized in the ILO document.

\subsection{Discussion and conclusions}

We have counted and measured diversity and balance of cultural perspectives in policy discourses on globalization. We started with the research question "how balanced and therefore socially robust is the global policy discourse on globalization?' We assessed this over three major themes in globalization: the economy, climate change and human well-being.

We found variation and plurality in the composition of the different policy discourses. This is encouraging; perspectives are combined and drawn upon in different ways in different policy areas. However, there are a few arguments to be made that globalization, as it is currently shaped, is not socially robust: overall and in most families and reports we find the dominance of the individualist perspective and a marginalization of the autonomous and fatalist worldviews. The latter finding is not surprising as the fatalist and autonomous perspectives are considered to be perspectives which - even though important in the debate - do not play an active role in policy processes (e.g. Offermans 2012). The correlation tables give some first indications of how the perspectives (cor-)relate with balance and each other - for this analysis especially it is strongly 
suggested to extend the scope and number of reports in order to be able to get more conclusive and reliable statistics.

The findings for the dynamic integrator, have to be enjoyed with some consideration. As stated before, the DI is not part of the original CT typology. Hence, we also calculated the percentages excluding the DI and report those in table A6.2. Some nuances of the findings change, however the overall findings and conclusions remain the same. The dominance of the individualist can be intepreted as a reflection of the predominant capitalistic and neo-liberal values and worldviews, which are recently put forward in approaches such as green growth, ecological modernization and ecoinnovation (UNEP, 2011).

At the same time, however, the world is becoming more uncertain and politically polarized while ecological pressures continue to increase. Given these global trends, it is questionable whether the current policy discourse will be able to shape responses to the sustainability challenges of the present and future. As stated before, we believe that a balanced and inclusive approach is an important factor for socio-economic resilience, which will also translate into environmental resilience (Gunderson \& Holling, 2002). The plurality of the perspectives can only be effective in addressing current and future challenges in all three pillars of sustainable development if there is a healthy balance of the different strategies and worldviews.

What could be the consequences for globalization and sustainability of this global course? Unbalanced policy approaches inhibit the risk of leading to fragmentation and disintegration, rather than greater discussion and mutual understanding, which are crucial conditions for sustainability. Rather the opposite is needed to address current economic, political, social and ecological challenges: strong democratic but visionary leadership, cooperation based on inclusive deliberation in an open public sphere (Edwards, 2014). We conclude, that it is important to acknowledge and recognize the current imbalance as a first step towards making globalization socially robust. 


\section{Appendix 6}

Table A6.1: Word strings for the six CT perspectives

\begin{tabular}{|c|c|c|c|c|c|}
\hline Hierarchist & Egalitarian & Individualist & Fatalist & Autonomous & Dynanmic I \\
\hline Regul & Particip & Challeng & Survive & Beauty & Transit \\
\hline Control & Equal & Chance & Cope & Love & Tip \\
\hline Manag & Equit & Opportun & Uncertain & Fragile & Transform \\
\hline Know & Fair & Progress & Deal & Touch & Dynamic \\
\hline Ration & Emancip & Consum & Accept & Conscious & Change \\
\hline Stable & Precaution & Market & Unpredictable & Guide & Flow \\
\hline Monitor & Protect & Technol & Adapt & Ecol & Complex \\
\hline Safe/Save & Revolut & Innova & Grasp & Learn & Improvise \\
\hline Law & Protest & Capital & Wonder & Empath & Evolut \\
\hline Polic & Public & Econ & Bother & Ethic & Evolve \\
\hline Improve & Empower & Win & Faith & Harmon & System \\
\hline State & Help & Achiev & Trust & Earth & Anticipate \\
\hline Govern & Social & Privat & Adjust & Give/Giving & Equilibrium \\
\hline Limit & Share/Shar & Value & Fail & Provid & Planet \\
\hline Boundary & People & Finan & Fall & Mind & Context \\
\hline Secur & Subsid & Trade & Loss & Heart & Integrat \\
\hline Predict & Collaborat & Invest & Lack & Soul & Scenario \\
\hline Legal & Green & Free & Releas & Wholeness & Open \\
\hline Order & Well-being & Growth & Crisis & Enough & Co-existence \\
\hline Mainstream & Serv & Goods & Fun & Suffic & Divers \\
\hline Risk & Nature & Resource & Fear & Good & Cooperat \\
\hline Legislation & Friend & Partner & Playball & Holistic & Time \\
\hline Nation & Group & Speed & Coincidence & Creat & Horizon \\
\hline Marker & Solidari & Fast & Surprise & Less & Perception \\
\hline Strateg & Common & Potential & Fate & Footprint & Perspective \\
\hline Norm & Unite/Union & Commerc & Destin & Simple & Integrit \\
\hline Object & Subject & Extract & Depend & Peace & Pattern \\
\hline Steer & Support & Lead & Luck & Sacred & Emerge \\
\hline Standard & Alternative & Option & Impuls & Religion & Synthesis \\
\hline Comply & Resist & Fight & Instinct & Heal & Links \\
\hline Rule & Help & Use/Util & Collaps & Life/Live & Process \\
\hline End & Minority & Benefit & Enjoy & Retreat & Actor \\
\hline Measure & Weak & Business & Force & Indigenous & Future \\
\hline Past & Future & Now & Never & Eternal & Multi \\
\hline Strict & Vulnerable & Want & Chaos & Wonderful & Various \\
\hline Logic & Kind & Smart & Happy & Bright & Non-linear \\
\hline Roadmap & Effective & Efficient & Conflict & Spirit & Pathway \\
\hline Discipline & Need & Build & Pray & Meditate & Explor \\
\hline Regime & Together & Sell & Destin & Inspir & Reflect/Reflex \\
\hline Behav & Aware & Act & React & Feel & Think \\
\hline
\end{tabular}


Table A6.2: Results excluding the Dynamic Integrator

\begin{tabular}{|c|c|c|c|c|c|c|c|c|}
\hline $\begin{array}{l}\text { Report } \\
\text { Family }\end{array}$ & Aut & Ega & Fat & Hie & Ind & $\begin{array}{c}\text { Degree of } \\
\text { Balance }\end{array}$ & $\begin{array}{l}\text { Balance } \\
\text { Score }\end{array}$ & Rank \\
\hline WTO & $8 \%$ & $23 \%$ & $6 \%$ & $20 \%$ & $43 \%$ & 2 & $56(0,87)$ & 6 \\
\hline WEF & $5 \%$ & $17 \%$ & $3 \%$ & $22 \%$ & $53 \%$ & 2 & $0(0,76)$ & 11 \\
\hline Economy & $6 \%$ & $19 \%$ & $4 \%$ & $21 \%$ & $49 \%$ & 2 & $23(0,81)$ & 5 \\
\hline OECD & $9 \%$ & $22 \%$ & $7 \%$ & $21 \%$ & $42 \%$ & 2 & $63(0,88)$ & 5 \\
\hline UNEP & $8 \%$ & $34 \%$ & $4 \%$ & $13 \%$ & $40 \%$ & 1 & $34(0,83)$ & 9 \\
\hline $\begin{array}{l}\text { Green Econ- } \\
\text { omy }\end{array}$ & $8 \%$ & $31 \%$ & $5 \%$ & $15 \%$ & $41 \%$ & 1 & $45(0,85)$ & 4 \\
\hline COP 21 & $14 \%$ & $41 \%$ & $6 \%$ & $18 \%$ & $20 \%$ & 3 & $72(0,90)$ & 4 \\
\hline IPCC & $10 \%$ & $25 \%$ & $9 \%$ & $26 \%$ & $30 \%$ & 4 & $91(0,93)$ & 2 \\
\hline $\begin{array}{l}\text { Climate } \\
\text { Change }\end{array}$ & $10 \%$ & $27 \%$ & $9 \%$ & $25 \%$ & $29 \%$ & 4 & $92(0,93)$ & 1 \\
\hline WRI & $7 \%$ & $21 \%$ & $4 \%$ & $17 \%$ & $51 \%$ & 2 & $23(0,81)$ & 10 \\
\hline WB & $10 \%$ & $26 \%$ & $7 \%$ & $19 \%$ & $37 \%$ & 3 & $76(0,90)$ & 3 \\
\hline $\begin{array}{l}\text { Globalisation } \\
\& C C\end{array}$ & $9 \%$ & $24 \%$ & $6 \%$ & $18 \%$ & $44 \%$ & 2 & $53(0,86)$ & 3 \\
\hline WHO & $6 \%$ & $31 \%$ & $6 \%$ & $20 \%$ & $37 \%$ & 1 & $54(0,86)$ & 7 \\
\hline ILO & $4 \%$ & $30 \%$ & $16 \%$ & $7 \%$ & $43 \%$ & 2 & $36(0,83)$ & 8 \\
\hline $\begin{array}{l}\text { CBD/WHO/ } \\
\text { UNEP }\end{array}$ & $17 \%$ & $29 \%$ & $7 \%$ & $21 \%$ & $26 \%$ & 4 & $100(0,95)$ & 1 \\
\hline Well-being & $12 \%$ & $30 \%$ & $8 \%$ & $18 \%$ & $32 \%$ & 4 & $90(0,93)$ & 2 \\
\hline Total & $8 \%$ & $25 \%$ & $5 \%$ & $19 \%$ & $43 \%$ & 2 & $51(0,86)$ & \\
\hline
\end{tabular}


CHAPTER 7

\section{Conclusion, Discussion and Epilogue}


"Learn from yesterday, live for today, hope for tomorrow. The important thing is not to stop questioning."

Albert Einstein, theoretical physicist 


\subsection{Conclusion: What have we learned?}

This thesis set out on a research journey to quantitatively assess the sustainability of globalization and gain insights into the main research question 'to what extent is globalization as a process and policy discourse sustainable?' We put forward an interdisciplinary quantitative assessment of globalization that looked at four main issues: definition and measurement, recent state and trends, its consequences on ecological sustainability and the social robustness of globalization as a policy discourse (Fig 1.2 p.14). This concluding chapter will first recap and integrate the answers to the sub-questions and the main research question. A second section presents a discussion before we conclude with a personal epilogue.

\subsubsection{To what extent can globalization be better understood by measuring it and what are the limitations of existing indices?}

We defined contemporary globalization as "the intensification of cross-national interactions that promote the establishment of trans-national structures and the global integration of cultural, economic, ecological, political, technological and social processes on global, supra-national, national, regional and local levels" (Rennen \& Martens, 2003). It has two key characteristics: trans-dimensionality and trans-scalarity, meaning that globalization is a process that operates across, beyond and through many domains and scale levels. Chapter 2 and 3 have shown that globalization cannot be directly measured; however, existing indicators can be employed as proxies for globalization and put together into composite (globalization) indices, which allow us to detect and understand patterns of the phenomenon. Existing indices by themselves are at best multi-dimensional: indicators for the different dimensions of globalization (i.e. economic, political, social, technological, environmental) are put together into one final index. This says little about processes that operate across, beyond and through the domains. Chapter 2 has further clarified that those statistical proxies rather measure internationalization, liberalization and westernization. Supra-territorial indicators, which would capture trans-scalarity, are currently not available. Another limitation is that (most) data is only available at the national level.

Most globalization indices that have been recently updated and published (except for the MGI and KOF index of globalization) have two key limitations: the indices and reports do not undergo peer-review processes, and only some of them make their methodology publicly available and thereby transparent. In addition to transparency and validity concerns comes the observation that many are constructed by consulting firms and more recently by businesses themselves. It is questionable how independent those tools are. Consulting firms (McKinsey, A.T.Kearney and EY) and businesses (DHL and Huawei) produce and disseminate knowledge about globalization that promotes their 
business and economic interests. In the DHL Globalization report, for instance, Frank Appel, the CEO of Deutsche Post DHL Group, promotes specifically e-commerce and global supply chain solutions, arguing that $\mathrm{DHL}$ is "proud of the role it plays in enabling e-commerce and global supply chain solutions. By connecting merchants and consumers across virtually all geographies, we improve lives. Globalization is simply part of the fabric of our organization, and we are passionate advocates for the progress it has achieved and for the potential it still holds" (Ghemawat \& Altman, 2016, p. 2). In a similar fashion, HUAWEI, a leading ICT company, states that "Technology needs to be available or governments, industry, and people can't use it; it needs to deliver a good experience or people won't use it; it needs to sow the seeds for a better future or its potential is wasted." (HUAWEI, 2016, p. 5). Based on their data analysis, they make policy recommendations regarding ICT to increase investments and subsidies, reduce tariffs, and open markets to telecommunication companies (pp. 54-57).

Being aware that the current policy discourse on globalization needs to become more socially robust (chapter six), we raise the concern, that the business driven Gls and their reports mostly push a one-sided perspective and agenda, and thereby rather reinforce the current pre-dominant worldviews in policy discourses. We do not mean to discredit these efforts, and also need to point out that even 'independent' academic indices have their own normative biases and agenda. One objective of the initial MGI and of this thesis, for instance, is to present another perspective. With this work we hope to make the available set of Globalization indices more socially robust and balanced. What academia could learn and adopt from the business driven Gls is to better market and promote the knowledge, for instance by producing reports and inter-active webpages, rather than just publishing the results in journal articles. We conclude, that the political nature of knowledge construction needs to be taken seriously in the quantitative globalization debate.

The academic and independent measurement of globalization remains important to deliver sound knowledge and understanding of the phenomenon and its consequences. The measurement, as illustrated in chapter three, allows us to calculate globalization scores and ranks, thereby making the abstract notion of globalization graspable and understandable. Further, Gls allow us to assess its consequences, and thanks to over 160 studies with the KOF index and MGI, we have now extensive scientific empirical evidence on the consequences of globalization. Chapters 4 and 5 make a significant contribution to this literature, by assessing globalization's effects on human demands on the environment. Hence, we gain trans-dimensional insights, in this case into how economic, social, political and technological aspects of globalization affect ecological ones. This further deepens our understanding of how the different dimensions of globalization are interrelated. 
Chapter 6 took a different approach to measuring globalization. Here we looked at the relevant global policy discourse on globalization in a trans-dimensional way (covering the economic, social and ecological domain) to reveal the underlying cultural values and assumptions that underpin globalization-relevant policy. This approach was supraterritorial, as global policy discourses certainly transcend and move beyond territorial borders. To conclude, all approaches have strengths and weaknesses; we believe that interdisciplinary approaches that combine the best of quantitative and qualitative methods to understand globalization and how it relates to sustainable development are the way forward.

\subsubsection{What are the recent states and trends in globalization between 2000 and 2012 ?}

Measuring globalization allows us to map and analyze recent states and trends. For this, we need continuous development, revisions, updates and extensions of Gls. Chapters 4 and 5 updated and extended the MGI for the year 2012, and from 117 to 183 countries. Globalization continues and increased on average by $26.2 \%$ in the period 2000 - 2012 (chapter 3), with a slow down after the economic crisis in 2008 . The top 10 remain dominated by European countries, with Belgium, the Netherlands, Switzerland, the UK, Austria and Germany being the top six. Globalization does not currently represent an equal playing field for all nations of this world; those at the lower end are currently not globalizing faster than the countries at the top and therefore the globalizing world is not yet becoming a more balanced arena. Chapter 3 further makes clear that globalization is changing over time, which influences the way it needs to be measured as well: for instance, the indicator Cell Phone replaced Phone, which had been defined as 'incoming and outgoing international telephone traffic in minutes per capita'. Trends and changes inherent to the globalization process highlight the importance for continuous updates, extensions and revisions of GIs, which we have done here.

\subsubsection{To what extent do globalization and its different domains intensify Ecological Footprints and/or contribute to ecologically sustainable development? What are robust determinants of Ecological Footprints?}

We dedicated two chapters to this question. Chapter 4 employed the extended MGI 2012 edition to establish upper boundaries of globalization's effect on ecological footprints. Chapter 5 employed the KOF index and tested 28 control variables to establish lower limits. Overall, we found that globalization intensifies ecological footprints, but mostly through the economic dimension. We found that a 10-point increase in economic globalization corresponds to an increase in the EF of consumption in the range of $0.7 \%$ (KOF index) to $10 \%$ (MGI). The findings with the KOF index are smaller, since we included the lagged dependent variable, more control variables, and fixed country and time effects. What can we learn from this? It depends very much how (economic) 
globalization is framed and positioned in an explanatory model or framework. In other words, it matters which other factors are taken into consideration when discussing and assessing its (ecological) consequences. The difference between the upper and lower limit of our finding may be frustrating - what now are the exact impacts of globalization? Our best guess is that it is something in between those two numbers, and the exact parameters will differ between localities and nations. We provide the big picture about general trends and a potential range for the magnitude. Certainly, more research into this topic is in order.

We further found that a 10-point increase in social globalization is decreasing the EF of consumption by $0.9 \%$ and the EF of production by $0.6 \%$. Hence, we conclude that economic globalization does not contribute to ecologically sustainable development while social globalization does. We do not find any effects for political globalization. For overall globalization, we have no definite results. Chapter 5 highlights that the overall KOF index captures diverging effects of sub-indices, economic globalization has an increasing effect of $0.7 \%$ while social globalization has a decreasing effect of $0.9 \%$ on the EF of consumption. Overall, however, we conclude that in its recent form, globalization has not contributed to a reduction in Ecological Footprints. This would, however, be necessary in order to steer humanity out of ecological overshoot.

In addition to the role of globalization, we identified robust determinants of the EF of consumption. We found affluence, energy intensity and the share of economically active population to have increasing effects; and the share of agricultural value added to national income (as a proxy for the composition of the economy) to have decreasing effects $^{11}$. These seem to be the most powerful leverage points for policy makers to steer humanity out of ecological overshoot. Most promising would be an integrated policy approach, which targets all of the (robust) determinants: reduce (and redistribute) affluence, enhance energy efficiency, decrease the share of the economically active population (for instance by reducing working hours) and re-structure the economy. Further, policy should look into how to mitigate the negative effects of economic globalization on human demands, while harnessing the positive effects of social globalization. These are only first ideas, for how these findings could be translated into policy recommendations. More research and knowledge transfer is needed, in order to translate these findings into realistic and sensible policy recommendations. We conclude, however, that our findings question the dominant approach to sustainable development (UNGA, 2015) and green growth to further grow GDP while pursuing enhanced energy and resource efficiency.

\footnotetext{
${ }^{11}$ Note that we look at and discuss per capita ecological footprints. Hence another important determinant of the EF of consumption not discussed here is population.
} 


\subsubsection{How balanced and therefore socially robust is the policy discourse on globalization?}

We left the composite indices behind and approached the sustainability of globalization from a semi quantitative-qualitative angle in chapter 6 . We applied the cultural perspectives method to conduct a discourse analysis of policy discourses. We can conclude that to some degree, there is variation and plurality in the composition of the different policy discourses. Perspectives are combined and drawn upon in different ways in different policy areas. However, there are also a few arguments to be made that the current policy discourse regarding globalization is not socially robust: overall and in most reports we find the dominance of the individualist perspective and a marginalization of the autonomous and fatalist worldviews. Potential risks of this imbalance are ineffectiveness in addressing current and future global challenges, such as migration and climate change. We conclude, that it is important to acknowledge and recognize the current imbalance as a first step towards making globalization socially robust.

\subsubsection{Main research question: to what extent is globalization as a process and policy discourse sustainable?}

We defined sustainable globalization as a form of globalization that is socially robust and contributes (positively) to the three pillars of sustainable development: the economic, social and ecological domains. To what extent is globalization as a process and policy discourse sustainable? "a world out of balance" is the emerging qualification that this thesis detects for all four issues of globalization: definition and measurement, recent trends, its consequences on (ecological) sustainability and the social robustness of globalization as a policy discourse. We will discuss these four in turn.

For the academic discourse on the definition and measurement, we detect that it continues on the national scale, and indicators fall short to capture supra-territorial features of globalization. For recent trends, we find that globalization continues in a rather diverging way, leading to a greater imbalance in levels of globalization. Regarding globalizations' consequences, previous research had shown, that globalization contributes to social and economic aspects of sustainable development. We have complemented the evidence to find that overall globalization has certainly no positive effect on the ecological pillar of sustainable development. In addition, the different dimensions of globalization have different effects on EFs. Social globalization has decreasing effects, economic globalization has increasing effects and for political globalization, we find no effects. Finally, we concluded that the policy discourse on globalization is unbalanced, not socially robust - in general, and we found different levels of imbalance for the different dimensions (economic, ecological and social). Hence we conclude, that globalization, as a process and policy discourse, is not sustainable in its current form. 


\subsection{Discussion}

\subsubsection{Reflection}

It is the $22^{\text {nd }}$ of April 2017 - Earth Day - interestingly enough, this year, the organizers put forward a march for science, rather than a march for earth. This highlights the importance of (sustainability) science for the integrity and survival of our planet earth. It is on this day that I write my final reflection on this thesis.

The ontological reflection question, is whether there is single truth or reality of globalization to be discovered? I have learned and found that this is not the case. Globalization is not just an object out there to be known and measured objectively. Rather, it is a social phenomenon and construct, which is subject to human agency. Researchers themselves construct multiple empirical and conceptual realities; the truth and reality about globalization is co-created by the scholars who set out to understand, define and measure its trends and consequences. The act of inquiry in itself becomes an act of intervention in the process; the maker of knowledge about globalization becomes an active agent, by the simple act of observing, defining, and measuring. Yet, I employed and worked with rather positivist statistical and econometric methods. Proxies can be used to better measure and understand globalization. Approaches as put forward here allow us to detect "ceteris paribus" patterns and effects of globalization and its ecological consequences through the construction of knowledge.

The nature, quality and quantity of human connectedness and relatedness (read: globalization), however, has always and will continue to change. Hence, there will never be an endpoint, a finite or maximum. Dynamic change processes will continue to coevolve across the different scales and dimensions. Some will further intensify, some will be reversed, some will be replaced. Hence, the ceteris paribus nature of econometric analysis, which assumes "other things equal" is a gross over-simplification of a much more complex and dynamic reality.

What does this imply for ecological sustainability? We have found that globalization and its policy discourse seem to be inherently un-sustainable. On a positive note, this is only one perspective and much more a historical study, of what has been in the past. We looked at historical trends in globalization and ecological overshoot. This leaves hope and optimism that globalization and development in general may have the potential to develop into more sustainable ways. However, at the same time there is also the risk of reversal of the positive trends of globalization. Nationalist movements, leading to re-territorialization, as recently observed in the US and UK, amongst others, could enhance the global tragedy of the commons, not only in the ecological dimension. 


\subsubsection{A (new) way forward?}

What lies ahead of us? What is the future of globalization and its measurement? The title of this thesis reads "connectedness in times of ecological overshoot". Ecological overshoot implies that humanity is using up more resources than the ecological systems of the planet can provide in a sustainable way. Hence, there are some crucial questions that policy makers, businesses, civil society and researchers who work on the front of creating the future of sustainable globalization need to take into consideration. In a recent discussion paper we have presented a young scientists' perspectives on 'Reshaping Sustainability Science for the $21^{\text {st }}$ Century' (Schinko, Borgomeo, Dufva, Figge, \& Schipfer, 2017) ${ }^{12}$. We will present here some of the key questions and discuss how they are relevant for future (quantitative) globalization research.

First: planetary boundaries and resource constraints: (How) will we manage to further globalize within planetary boundaries and resource constraints? Recent research on planetary boundaries (Steffen, Richardson, et al., 2015) and environmental footprints (Hoekstra \& Wiedmann, 2014) has shown that the rate at which we simultaneously consume resources and harm the environment is simply not sustainable. Underlying these concepts is the idea of an inter-connected 'humanity' as a whole, whose activities within the Earth system have become a planetary transformative force and therefore a common global concern. This raises the question: what kind of globalization is required for us to live within 'a safe and just operating space'? And what kind of research is needed for this?

Second: adapting to changing environments: Who will be affected by globalization and its consequences and to what degree? The impacts of global environmental change and globalization will be distributed unevenly across societies and economies. The IPCC (IPCC, 2014c) argues that poor communities in high-risk areas are those most likely to be negatively affected. However, given the nature of our inter-connected and globalized world, these global transformations and adaptations have the potential to produce unforeseen 'butterfly effects' across the world, for better or worse (Goldin \& Mariathasan, 2014). Globalization research and policy is thus being called upon to devise mitigation and adaptation strategies which take into account both the ecological and human responses to environmental change, and to consider equity issues and other challenges such as energy, ecosystem services etc.

Third: dealing with conflict: What are likely to be the causes of future conflicts and how can they be overcome? Inequality is increasing globally with respect to the distribution of connectedness, wealth, resources and capabilities and current and expected future

\footnotetext{
${ }^{12}$ note that the following text on the four questions has been adapted from the article by Schinko et. al
} 
impacts of ecological overshoot, such as climate change will only aggravate this. This is expected to lead to new, as well as intensify existing, conflicts in many different forms across the world. Working towards distributional justice globally by addressing the roots of the problems is key to avoid and mitigate future conflict within the context of continuing globalization (Scheffran, Brzoska, Kominek, Link, \& Schilling, 2012).

Fourth: Re-defining quality of life: (How) can humanity globalize without economic growth? Conventional economic theory, which is used as a blueprint for today's economic praxis, is based on the paradigm of economic growth; this is no longer feasible if humanity wants to thrive on what is a finite planet (Farley et al., 2013). The concept of green growth, which demands and promises an absolute de-coupling of economic growth from natural throughput and emissions, needs to be questioned and reassessed. The current challenges call for a globalizing economic system that promotes well-being and prosperity, compatible with the planet's carrying capacity.

We strongly believe that academic research should continue to measure globalization and assess its consequences in order to further explore answers to questions raised. This thesis was a first important step in that direction. We have re-confirmed that GIs give the globalization debate a solid scientific footing. We believe that it is important to continue the independent academic measurement of globalization in order to balance the neoliberal / individualistic bias of the Gls that promote business and economic interests of companies and consulting firms. Academia needs to stay involved to guarantee a socially robust discourse on the globalization that is transparent and scientifically validated. Further, globalization is here to stay, and most certainly, it will continue to change its course and dynamics in increasingly complex and ambiguous ways. Hence, continuous updates, new developments, revisions and critical discussions of the definition and measurement of globalization are in demand. We believe this to be important for a sustainable globalization to become possible.

Future research with GIs should work towards a set of complementary approaches, integrating qualitative and quantitative approaches, spanning various social scale levels and units, from the individual to the global. Further, supra-territorial indicators should be explored to develop proxies that are closer to the 'true nature' of globalization. This thesis has relied mostly on old fashioned statistics, provided by World Development Indicators and other similar databases. The last few years has seen the advent of Big Data, which is a phenomenon of technological globalization itself. This seems to be a promising direction forward to capture connectedness in new ways that go beyond and below the national level.

We have put forward a solid method to decompose the underlying cultural values and assumptions of current global policy discourses. In addition to counting the perspective 
percentages, we have calculated a balance measure to indicate the social robustness of the current discourse. A question is how these quantifications can help policymakers to make globalization more inclusive, accepted and therefore socially robust. The quantification of perspectives reveals misbalances and potential gaps in the discourse and worldviews that would need extra attention and inclusion. In a way, this would enhance the self-awareness of a policy discourse as a first step to making policy more balanced. Furthermore, it could reveal which marginalized perspectives may (unexpectedly!?) rise up to "revolt". Think of recent fatalist reactions in the UK and US, and also other populist, nationalist and protectionist movements across the world. This basic assessment could be a solid starting point to determine whether and how one could and should make policy processes more socially robust. By realizing which perspectives are marginalized, or at the risk of marginalization, one could take deliberate actions to include respective stakeholders (e.g. from civil society) more in the policymaking processes, and thereby design more robust strategies for a sustainable globalization.

A deeper understanding of any policy discourse also reveals the underlying discussion on what 'the good society' (e.g. a socially robust and sustainable society) is or means in a given context (Edwards, 2014). Therefore, further research could apply this method to further policy themes, but also on different (policy) levels (e.g. national, subnational, etc.). Furthermore, it would be interesting to assess whether more balanced policy discourses, as measured here, actually lead to more sustainable outcomes, which is one of our basic assumptions. Additionally, the perspective composition could be measured for national policy discourses and then be linked to measures of globalization and connectedness, to assess the relationship between cultural values on a nationstate level and actual globalization processes.

It will not be easy for globalization and global policy processes to become socially robust and/or sustainable. In a way, however, the post-modern human civilization does not really have a choice if it is to survive and continue. Not having a choice can either lead to resignation or unleash the greatest potentials - it is our choice. 


\subsection{Epilogue}

Following the scientific research, the analytical analysis and the intellectual reflections on science, we now arrive at the more personal part of this thesis, comprised of more intuitive knowledge that goes beyond the mind. I shortly present some insights that I personally see to be true but cannot prove empirically - in the pre-dominant materialistic-scientific sense.

What is needed is a definition of sustainability that is valid irrespective of time and place. I therefore define sustainability as the context that provides the conditions for all life on earth to thrive. Such a context provides peace, harmony, acceptance, nondiscrimination, abundance, courage, compassion, health, empowerment and social justice. Every human life is mediated through a set of relationships - to ourselves, other humans, all animal species, nature, the cosmos and the transcendent (there are many different labels, e.g. god, tao, consciousness, spirit to name just a few). And it is the quality of those relationships that creates the experience of human beings.

The driver of un-sustainability, in this context is ignorance about the interconnectedness or inter-being of all life on Earth. Everything is ONE - fully interconnected already, in the physical just as in the meta-physical realm. This (spiritual) wisdom has been around for a very long time, and is available to anyone who goes out to search for it, or rather, opens up to the possibility. All that which is characterized as un-sustainable can be boiled down to actions, behavior, policies, strategies and interactions that stem from the ignorance about this interconnectedness. It is separation that creates the possibility to engage in relationships that exhibit violence, harm, degradation or dis-empowerment in their many forms.

Now, how does globalization fit into this context? The key question becomes what is the effect of globalization on the quality of human relations? Does it create a more true interconnectedness - in the spiritual sense rather than as measured 'objectively' in this thesis? Or does it lead to separation? Part of the problem is that globalization increases the complexity of human relationships by increasing the spatial and temporal spread of our relations and interactions. If this is not accompanied by the spiritual realization that everything is ONE, this will inevitably lead to un-sustainable relations and outcomes. I believe that the single most important determinant of the future of humanity will be the evolution or development of its consciousness. The multi-dimensional framework of globalization as presented and researched in this thesis needs to be complemented by the spiritual dimension. So, to conclude this thesis, what is ultimately needed to get humanity out of our current mess is nothing less than a global awakening to the fundamental truth of the inter-being of all life, so that we can live fully connected to ourselves, all humans, animals, nature, the cosmos and the transcendent. 


\section{References}

A.T. Kearney/Foreign Policy. (2001). Measuring globalization. Foreign Policy, 122, 56-65.

Alamuti, M. M. (2011). Critical Rationalism and Macrosociology of Globalisation. University of Newcastle upon Tyne, UK.

Albrow, M. (1996). The golden age: state and society beyond modernity. Cambridge: Polity.

Andersen, T. M., \& Herbertsson, T. T. (2005). Quantifying globalization. Applied Economics, 37(10), 10891098.

Ansón, J., \& Helble, M. (2013). A gravity model of international postal exchanges. In M. A. Crew \& P. R. Kleindorfer (Eds.), Reforming the postal sector in the face of electronic competition (pp. 36-47). Cheltenham: Edward Elger.

Anton, D. J. (1995). Diversity, Globalization, and the Ways of Nature. Ottawa $\bullet$ Cairo • Dakar • Johannesburg - Montevideo • Nairobi New Delhi • Singapore: International Development Research Centre.

Antweiler, W., Copeland, B. R., \& Taylor, M. S. (2001). Is Free Trade Good for the Environment? American Economic Review, 91(4), 877 - 908. doi: 10.1257/aer.91.4.877

Asselt, M. v., Rotmans, J., Elzen, M. d., \& Hilderink, H. (1995). Uncertainty in integrated assessment modeling: a cultural perspective approach. Bilthoven: National Institute of Public Health and the Environment (RIVM).

Axford, B. (2007). Editorial. Globalizations, 4(3), 321-326.

Bacchi, C. (2009). Analysing policy: what is the problem represented to be? Australia: Pearson.

Banerjee, S. B. (2003). Who sustains Whose Development? Sustainable Development and the Reinvention of Nature. Organization Studies, 24(1), 143-180.

Bauman, Z. (1998). Globalization: The human consequences. Cambridge: Polity.

Beck, T., Clarke, G., Groff, A., Keefer, P., \& Walsh, P. (2001). New tools in comparative political economy: The Database of Political Institutions. the world bank economic review, 15(1), 165-176.

Beck, U. (2004). Der kosmopolitische Blick oder: Krieg ist Frieden. Frankfurt a. M.: Suhrkamp.

Beumer, C. (2014). Stepping Stone Cities.Exploring Urban Greening and Gardening as a Viable Contribution to Global Biodoversity Conservation. (PhD), Maastricht University, Maastricht.

Beumer, C., Huynen, M., \& Martens, P. (2008). Finding Paradise in a Complex Web: The Inter-relation of Biodiversity, Ecosystems and Human Health. In L. Westra (Ed.), Reconciling human existence with ecological integrity. London: Earthscan.

Beumer, C., \& Martens, P. (2010). Noah's Ark or World Wild Web? Cultural Perspectives in Global Scenario Studies and Their Function for Biodiversity Conservation in a Changing World. Sustainability(Special Issue Futures).

Beumer, C., \& Martens, P. (2013). IUCN and Perspectives on Biodiversity Conservation in a Changing World. Biodiversity and Conservation. doi: 10. 1007/s10531-013-0573-6

Blankendaal, T., Schuur, P., \& Voordijk, H. (2014). Reducing the environmental impact of concrete and asphalt: a scenario approach. Journal of Cleaner Production, 66, 27-36.

Borghesi, S., \& Vercelli, A. (2003). Sustainable globalisation. Ecological Economics, 44(1), 77-89. doi: 10.1016/s0921-8009(02)00222-7

Borucke, M., Moore, D., Cranston, G., Gracey, K., Iha, K., Larson, J., . . . Galli, A. (2013). Accounting for demand and supply of the biosphere's regenerative capacity: The National Footprint Accounts' underlying methodology and framework. Ecological Indicators, 24, 518-533.

Brundtland-Commission. (1987). Our Common Future.

Buchan, N. R., Grimalda, G., Wilson, R., Brewer, M., Fatas, E., \& Foddy, M. (2009). Globalization and human cooperation. Proceedings of the National Academy of Sciences, 106(11), 4138-4142.

Caro, D., LoPresti, A., Davis, S. J., Bastianoni, S., \& Caldeira, K. (2014). CH4 and N2O emissions embodied in international trade of meat. Environmental Research Letters, 9(11), 114005.

Caselli, M. (2008). Measuring... What? Notes on Some Globalization Indices. Globalizations, 5(3), 383-404. doi: $10.1080 / 14747730802252529$

Caselli, M. (2012). Trying to Measure Globalization: Experiences, Critical Issues and Perspectives. Dordrecht: Springer. 
Castro, C. J. (2004). Sustainable Development: Mainstream and Critical Perspectives. Organization \& Environment, 17(195), 195-225.

Chase-Dunn, C., \& Jorgenson, A. (2007). Trajectories of trade and investment globalization. In I. Rossi (Ed.), Frontiers of globalization research (pp. 165-184). New York: Springer.

Chen, G., \& Han, M. (2015). Global supply chain of arable land use: Production-based and consumption-based trade imbalance. Land Use Policy, 49, 118-130.

Chivian, E. (2002). Biodiversity: It's Importance to Human Health. In E. Chivian (Ed.). Harvard: Center for Health and the Global Environment \& Harvard Medical School.

Cole, M. A. (2004). Trade, the pollution haven hypothesis and the environmental Kuznets curve: examining the linkages. Ecological Economics, 48(1), 71-81.

Copeland, B. R., \& Taylor, M. S. (2004). Trade, Growth, and the Environment. Journal of Economic Literature, 42, 7-71.

Cörvers, R., de Kraker, J., Kemp, R., Martens, P., \& van Lente, H. (Eds.). (2016). Sustainable Development Research at ICIS. Maastricht: ICIS.

De Kraker, J., Kuijs, S., Cörvers, R., \& Offermans, A. (2014). Internet public opinion on climate change: a world views analysis of online reader comments. International Journal of Climate Change Strategies and Management, 6(1), 19-33.

De Lombaerde, P., Flores, R., lapadre, L., \& Schulz, M. (Eds.). (2012). The regional integration manual: quantitative and qualitative methods. London: Routledge.

De Lombaerde, P., \& lapadre, L. (2007). International integration and societal progress: A critical review of globalisation indicators. In OECD (Ed.), Statistics, knowledge and policy: Measuring and fostering the progress of societies. Paris: OECD.

De Lombaerde, P., \& lapadre, P. L. (2008). The World is not Flat: Implications for the construction of globalisation indices. World Economics, 9(4), 159-180.

Den Elzen, M. G., \& De Moor, A. P. (2002). Analyzing the Kyoto Protocol under the Marrakesh Accords: economic efficiency and environmental effectiveness. Ecological Economics, 43(2), 141-158.

Dicken, P. (2011). Global Shift: Mapping the Changing Contours of the World Economy (6 ed.). New York: The Guilford Press.

Dietz, T., Rosa, E. A., \& York, R. (2007). Driving the human ecological footprint. Frontiers in Ecology and the Environment, 5(1), 13-18.

Dietz, T., Rosa, E. A., \& York, R. (2012). Environmentally efficient well-being: Is there a Kuznets curve? Applied Geography, 32(1), 21-28.

Dinda, S. (2004). Environmental Kuznets Curve Hypothesis: A Survey. Ecological Economics, 49(4), 431-455. doi: 10.1016/j.ecolecon.2004.02.011

Douglas, M. (1970). Natural symbols: Explorations in cosmology. London: Routledge.

Dreher, A. (2006). Does globalization affect growth? Evidence from a new index of globalization. Applied Economics, 38(10), 1091-1110.

Dreher, A., Gassebner, M., \& Siemers, L. H. R. (2012). Globalization, Economic Freedom, and Human Rights. Journal of Conflict Resolution, 56(3), 516-546.

Dreher, A., Gaston, N., \& Martens, P. (2008). Measuring globalisation: Gauging its consequences. New York: Springer.

Dreher, A., Gaston, N., Martens, P., \& Van Boxem, L. (2010). Measuring globalisation-opening the black box: a critical analysis of globalisation indices. Journal of Globalization Studies, 1(1), 166-185.

Ebenthal, S. (2007). Messung von Globalisierung in Entwicklungsländern: Zur Analyse der Globalisierung mit Globalisierungsindizes Berichte uas dem Weltwirtschaftlichem Colloquium der Universität Bremen (pp. 1-36): IWIM.

Edwards, M. (2014). Civil Society. Cambridge: Polity Press.

Erez, M., \& Gati, E. (2004). A dynamic, multi-level model of culture: from the micro level of the individual to the macro level of a global culture. Applied Psychology: An International Review, 53(4), 583-598.

Ewing, B., Moore, D., Goldfinger, S., Oursler, A., Reed, A., \& Wackernagel, M. (2010). Ecological Footprint Atlas 2010. Retrieved from http://www.footprintnetwork.org/images/uploads/Ecological_ Footprint_Atlas_2010.pdf

EY. (2012). Looking Beyond the obvious: globalization and new opportunities for growth. Retrieved 15.01.2017, 2017, from http://www.ey.com/gl/en/issues/driving-growth/globalization---lookingbeyond-the-obvious 
Farley, J., Burke, M., Flomenhoft, G., Kelly, B., Murray, D. F., Posner, S., . . Witham, A. (2013). Monetary and fiscal policies for a finite planet. Sustainability, 5(6), 2802-2826.

Field, C., Barros, V., Dokken, D., Mach, K., Mastrandrea, M., Bilir, T., . . . Genova, R. (2014). IPCC, 2014 : Climate Change 2014: Impacts, Adaptation, and Vulnerability. Part A: Global and Sectoral Aspects. Contribution of Working Group II to the Fifth Assessment Report of the Intergovernmental Panel on Climate Change: Cambridge University Press, Cambridge, United Kingdom and New York, NY, USA.

Figge, L., \& Martens, P. (2014). Globalisation continues: The Maastricht Globalisation Index revisited and updated. Globalizations, 11(6), 875-893. doi: 10.1080/14747731.2014.887389

Friedman, T. (1999). The lexus and the olive tree: understanding globalisation. New York: Farrar, Straus and Giroux.

Gallagher, K. P. (2009). Economic globalization and the environment. Annual Review of Environment and Resources, 34, 279-304.

Galli, A. (2015). On the rationale and policy usefulness of Ecological Footprint Accounting: The case of Morocco. Environmental Science \& Policy, 48, 210-224.

Gassebner, M., Lamla, M. J., \& Sturm, J.-E. (2011). Determinants of pollution: what do we really know? Oxford Economic Papers, 63(3), 568-595. doi: 10.1093/oep/gpq029

Ghemawat, P., \& Altman, S. A. (2016). DHL Global Connectedness Index 2016: The state of Globalization in an age of Ambiguity Retrieved from http://www.dhl.com/content/dam/flash/g0/gci/download/ DHL_GlobalConnectednessIndex.pdf

Giddings, B., Hopwood, B., \& O'brien, G. (2002). Environment, economy and society: fitting them together into sustainable development. Sustainable development, 10(4), 187-196.

Global Commission on the Economy and Climate. (2014). Better Growth Better Climate: The new climate economy report. Washington D.C.: World Resources Institute.

Global Footprint Network. (2012a, 10.12.2012). Defintion Ecological Footprint. Retrieved 10.01.2013, from http://www.footprintnetwork.org/en/index.php/GFN/page/glossary/\#Ecologicalfootprint

Global Footprint Network. (2012c). The National Footprint Accounts, 2011 edition. Retrieved from: http://www.footprintnetwork.org

Goldin, I., \& Mariathasan, M. (2014). The butterfly defect: How globalization creates systemic risks, and what to do about it: Princeton University Press.

Granger, C. W. (1969). Investigating causal relations by econometric models and cross-spectral methods. Econometrica: Journal of the Econometric Society, 424-438.

Grant, R. W., \& Keohane, R. O. (2005). Accountability and abuses of power in world politics. American political science review, 99(01), 29-43.

Griggs, D., Stafford-Smith, M., Gaffney, O., Rockström, J., Öhman, M. C., Shyamsundar, P., . . Noble, I. (2013). Policy: Sustainable development goals for people and planet. Nature, 495, 305-307. doi: 10.1038/495305a

Gunderson, L. H., \& Holling, C. S. (Eds.). (2002). Panarchy. Understanding Transformations in Human and Natural Systems. Washington: Island Press.

Guo, Y., \& Schwarz, T. (2016). Measuring Connectivity. In S. Lee (Ed.), Connectivity: Facts and Perspectives (Vol. 2, pp. 15-53). Singapore: Asia-Europe Foundation (ASEF).

Gwartney, J., Lawson, R., \& Hall, J. (2013). Economic Freedom of the World: 2013 Annual Report: Fraser Institute.

Hales, M., \& Pena, A. M. (2012). 2012 Global Cities Index and Emerging Cities Index Retrieved from http://www.atkearney.com/documents/10192/dfedfc4c-8a62-4162-90e5-2a3f14f0da3a

Hales, M., Peterson, E., Pena, A. M., \& Dessibourg-Freer, N. (2016). Global cities 2016. Retrieved from: https://www.atkearney.com/documents/10192/8178456/Global+Cities+2016.pdf/8139cd44c760-4a93-ad7d-11c5d347451a

Held, D., McGrew, A., Goldblatt, D., \& Perraton, J. (1999). Global transformations: Politics, economics and culture. Stanford: Stanford University Press.

Hirst, P. (1997). From Statism to Pluralism: Democracy, Civil Society and Global Politics. London/New Tork: Routledge.

Hirst, P., \& Thompson, G. (2002). The future of globalization. Cooperation and Conflict, 37(3), 247-265.

Hoekstra, A. Y., \& Wiedmann, T. O. (2014). Humanity's unsustainable environmental footprint. Science, 344(6188), 1114-1117.

Holton, R. J. (2005). Making globalization. New York: Palgrave Macmillan. 
HUAWEI. (2016). Global Connectivity Index 2016: Connect where it counts Mapping your transformation into a digital economy qwith $\mathrm{GCl} 2016$ (pp. 94). Retrieved from http://www.huawei.com/minisite/gci/ pdfs/Global_Connectivity_Index_2016_whitepaper.0614.pdf

Huynen, M. (2008). Future Health in a Globalising World. Maastricht: Maastricht University Press.

Huynen, M., Martens, P., \& Akin, S. (2013). Climate change: an amplifier of existing health risks in developing countries. Environment, Development and Sustainability, 15(6), 1425-1442.

ILO. (2015). World Employment Social Outlook. Geneva: International Labour Organization.

IPCC. (2014a). Climate Change 2014 Synthesis Report. In Core Writing Team, R. K. Pachauri, \& L. A. Meyer (Eds.). Geneva: IPCC.

IPCC. (2014c). Climate Change 2014: Synthesis Report.

IUCN. (2009). Life Support. Human Health and the Environment. Gland, Switzwerland.

Jessop, B. (2000). The crisis of the national spatio-temporal fix and the tendential ecological dominance of globalizing capitalism. International Journal of Urban and Regional Research, 24(2), 323-360. doi: 10.1111/1468-2427.00251

Jones, A. (2010). Globalization: Key Thinkers. Hoboken: John Wiley \& Sons.

Jorgenson, A. K. (2003). Consumption and environmental degradation: A cross-national analysis of the ecological footprint. Social Problems, 50(3), 374-394.

Jorgenson, A. K., \& Burns, T. J. (2007). The political-economic causes of change in the ecological footprints of nations, 1991-2001: a quantitative investigation. Social Science Research, 36(2), 834-853.

Jorgenson, A. K., \& Clark, B. (2009). The Economy, Military, and Ecologically Unequal Exchange Relationships in Comparative Perspective: A Panel Study of the Ecological Footprints of Nations, 1975-2000. Social Problems, 56(4), 621-646.

Jorgenson, A. K., \& Clark, B. (2011). Societies consuming nature: a panel study of the ecological footprints of nations, 1960-2003. Social Science Research, 40(1), 226-244.

Jorgenson, A. K., Clark, B., \& Kentor, J. (2010). Militarization and the environment: A panel study of carbon dioxide emissions and the ecological footprints of nations, 1970-2000. Global Environmental Politics, 10(1), 7-29.

Kahan, D. M., Braman, D., Slovic, P., Gastil, J., \& Cohen, G. L. (2007). The second national risk and culture study: Making sense of-and making progress in-the american culture war of fact. GWU Legal Studies Research Paper(370), 08-26.

Keesing, R. M. (1974). Theories of Culture. Annual Review of Anthropology, 3, 73-97.

Kemp, R., \& Martens, P. (2007). Sustainable development: how to manage something that is subjective and never can be achieved. Sustainability: Science, Practice, \& Policy, 3(2), 5-14.

Kennedy, P. (2009). Local lives and global transformations: Towards world society. Basingstoke: Palgrave Macmillan.

Kluver, R., \& Fu, W. (2004a, 10.02.2004). The Cultural Globalization Index. from foreignpolicy.com/2004/ $02 / 10 /$ the-cultural-globalization-index/

Kluver, R., \& Fu, W. (2004c). The cultural globalization index. Foreign Policy online Web Exclusive. Online available: http://www.foreignpolicy.com/story/cms.php?story_id=2494.

Labonte, R. (2009). Introduction: globalization challenges to people's health. In R. Labonte, S. T, C. Packer, \& V. Runnels (Eds.), Globalization and health: pathways, evidence and policy. New York: Routledge.

Labonte, R., \& Torgerson, R. (2003). Frameworks for analyzing the links between globalization and health. Geneva: World Health Organization.

Lambin, E. F., \& Meyfroidt, P. (2011). Global land use change, economic globalization, and the looming land scarcity. Proceedings of the National Academy of Sciences, 108(9), 3465-3472.

Lamla, M. J. (2009). Long-run determinants of pollution: A robustness analysis. Ecological Economics, 69(1), 135-144.

Leamer, E. E. (1983). Let's take the con out of econometrics. The American Economic Review, 31-43.

Lemos, M. C., \& Agrawal, A. (2006). Environmental governance. Annu. Rev. Environ. Resour., 31, $297-325$.

Levine, R., \& Renelt, D. (1992). A sensitivity analysis of cross-country growth regressions. The American Economic Review, 942-963.

Lianos, T. P. (2013). The world budget constraint. Environment, Development and Sustainability, 15(6), 15431553.

Lin, J. (1991). Divergence measures based on the Shannon entropy. IEEE Transactions on Information theory, $37(1), 145-151$. 
Lockwood, B., \& Redoano, M. (2005). CSGR Globalization Index: An Introductory Guide, Centre for Study of Globalization and Regionalization Working Paper 155/04.

Maddala, G. S., \& Wu, S. (1999). A comparative study of unit root tests with panel data and a new simple test. Oxford Bulletin of Economics and statistics, 61(S1), 631-652.

Martens, P. (2006). Sustainability: science or fiction? Sustainability: Science Practice and Policy, 2(1), 36-41.

Martens, P. (2013). Grey, green or blue economy? It's sustainability, stupid! Pim Martens (Vol. 10 June 2013). Brunssum.

Martens, P., Akin, S., Huynen, M., \& Raza, M. (2010a). Is globalization healthy: a statistical indicator analysis of the impacts of globalization on health. Globalization and Health, 6(1), 1-14. doi: 10.1186/17448603-6-16

Martens, P., Akin, S. M., Huynen, M., \& Raza, M. (2010b). Is globalization healthy: a statistical indicator analysis of the impacts of globalization on health. Globalization and health, 6(1), 16.

Martens, P., \& Beumer, C. (2015). Biodiversity Keeps People Healthy. In C. D. Butler, J. Dixon, \& A. G. Capon (Eds.), Health of People, Places and Planet. Reflections based on Tony McMichael's four decades of contribution to epidemiological understanding (pp. 477-491): ANU Press.

Martens, P., \& Raza, M. (2009). Globalisation in the 21st century: measuring regional changes in multiple domains. Integrated Assessment, 9(1), 1-19.

Martens, P., \& Raza, M. (2010). Is Globalisation Sustainable? Sustainability, 2(1), 280-293.

Martens, P., \& Rotmans, J. (2005). Transitions in a globalising world. Futures, 37(10), 1133-1144.

Martens, P., \& Rotmans, J. (Eds.). (2002). Transitions in a globalising world. Lisse: Swets \& Zeitlinger Publishers.

Martens, P., \& Zywietz, D. (2006a). Rethinking globalisation: a modified globalisation index. Journal of International Development, 18, 331-350.

Martens, P., \& Zywietz, D. (2006c). Rethinking globalization: a modified globalization index. Journal of International Development, 18(3), 331-350.

McKinsey Global Institute. (2016). Digital Globalization: the new era of global flows R. Dobbs, J. Manyika, \& J. Woetzel (Eds.), Retrieved from http://www.mckinsey.com/ /media/McKinsey/Business\%20 Functions/McKinsey\%20Digital/Our\%20Insights/Digital\%20globalization\%20The\%20new\%20era\% 20of\%20global\%20flows/MGI-Digital-globalization-Full-report.ashx

MEA. (2005). Ecosystems and human well-being: synthesis. Island, Washington, DC.

Melendez-Ortiz, R., \& Samans, R. (Eds.). (2016). The E15 Initiative: Strengthening the Global Trade and Investment System in the 21st Century. Geneva: ICTSD \& World Economic Forum.

Mittelman, J. H. (2000). The globalization syndrome: transformation and resistance. Princeton: Princeton University Press.

Moses, J., \& Knutsen, T. (2012). Ways of knowing: Competing methodologies in social and political research: Palgrave Macmillan.

Motoshita, M., Sakagami, M., Kudoh, Y., Tahara, K., \& Inaba, A. (2015). Potential impacts of information disclosure designed to motivate Japanese consumers to reduce carbon dioxide emissions on choice of shopping method for daily foods and drinks. Journal of Cleaner Production, 101, 205214.

Najam, A., Runnalls, D., \& Halle, M. (2007). Environment and globalization: five propositions.

Nederveen-Pieterse, J. (2004). Globalization and Culture. Lanham: Rowman and Littlefield Publishers Inc.

Norgaard, K. M. (2011). Living in denial: Climate change, emotions, and everyday life. Cambridge: MIT Press.

OECD. (2008). Handbook on Constructing Composite Indicators: Methodology and User Guide. Paris: OECD Publishing.

OECD. (2012). OECD Environmental Outlook to 2050: The Consequences of Inaction. Paris: OECD Publishing.

Offermans, A., \& Cörvers, R. (2012). Learning from the past; changing perspectives on river management in the Netherlands. Environmental Science \& Policy, 15(1), 13-22.

Offermans, A., Haasnoot, M., \& Valkering, P. (2011). A method to explore social response for sustainable water management strategies under changing conditions. Sustainable development, 19(5), 312324.

Offermans, A. G. E. (2012). The Perspectives Method: Towards socially robust river management. Maastricht: Universitaire Pers.

Pan, S.-Y., Du, M. A., Huang, I.-T., Liu, I.-H., Chang, E., \& Chiang, P.-C. (2015). Strategies on implementation of waste-to-energy (WTE) supply chain for circular economy system: a review. Journal of Cleaner Production, 108, 409-421. 
Peters, G. P., \& Hertwich, E. G. (2008). CO2 embodied in international trade with implications for global climate policy. Environmental science \& technology, 42(5), 1401-1407.

Pickett, K. E., \& Wilkinson, R. G. (2015). Income inequality and health: A causal review. Social Science \& Medicine, 128, 316-326.

Pillarisetti, J. R., \& van den Bergh, J. C. (2010). Sustainable nations: what do aggregate indexes tell us? Environment, Development and Sustainability, 12(1), 49-62.

Potrafke, N. (2014). The Evidence on Globalisation. The World Economy. doi: 10.1111/twec.12174

PRS Group. (2012). International Country Risk Guide (ICRG). Retrieved from: https://www.prsgroup.com/ about-us/our-two-methodologies/icrg

Ray, L. (2007). Globalization and everyday life. Abingdon: Routledge.

Rennen, W., \& Martens, P. (2003). The globalisation timeline. Integrated Assessment, 4(3), 137-144.

Ritzer, G., \& Stillman, T. (2003). Assessing McDonaldization, americanization and globalizatin. In U. Beck, N. Sznaider, \& R. Winter (Eds.), Global America? the Cultural Consequences of Globalization (pp. 3048).

Robertson, R. (1992). Globalization: Social theory and global culture. London: Sage.

Robinson, J. (2004). Squaring the circle? Some thoughts on the idea of sustainable development. Ecological Economics, 48(4), 369-384.

Robinson, J. (2011). Ethical Pluralism, pragmatism, and sustainability in conservation practice. Biological Conservation, 144, 958-965.

Rosa, E. A., York, R., \& Dietz, T. (2004). Tracking the anthropogenic drivers of ecological impacts. AMBIO: $A$ Journal of the Human Environment, 33(8), 509-512.

Rosenau, J. N. (2007). Three steps toward a viable theory of globalization. In I. Rossi (Ed.), Frontiers of globalization research (pp. 307-315). New York: Springer.

Rosenberg, J. (2005). Globalization theory: A post mortem. International politics, 42(1), 2-74.

Rossi, I. (2008). Frontiers of globalization research: theoretical and methodological approaches. New York: Springer.

Sala-i-Martin, X. X. (1997). I just ran two million regressions. The American Economic Review, 178-183.

Sarewitz, D. (2004). How science makes environmental controversies worse. Environmental Science \& Policy, 7, 385-403. Retrieved from: http://ac.els-cdn.com/S1462901104000620/1-s2.0S1462901104000620-main.pdf?_tid=c305ec0c-7087-11e5-84da-

00000aab0f01\&acdnat=1444616590_51d4051540ffead1e7435dd2e7cd644b

doi:10.1016/j.envsci.2004.06.001

Sassen, S. (2000). New frontiers facing urban sociology at the Millennium. The British journal of sociology, 51(1), 143-159.

Sassen, S. (2007). Theoretical and empirical elements in the study of globalization. In I. Rossi (Ed.), Frontiers of globalization research (pp. 287-305). New York: Springer.

Scheffran, J., Brzoska, M., Kominek, J., Link, P., \& Schilling, J. (2012). Climate change and violent conflict. Science, 336(6083), 869-871.

Schinko, T., Borgomeo, E., Dufva, M., Figge, L., \& Schipfer, F. (2017). Re-shaping Sustainability Science for the 21st Century: Young Scientists' Perspectives. IIASA working Paper. Retrieved from: http://pure.iiasa.ac.at/14375/

Scholte, J. A. (2002). Globalization: a critical introduction. New York: Palgrave.

Scholte, J. A. (2005). Globalization: A Critical Introduction (2 ed.). New York: Palgrave Macmillan.

Scholte, J. A. (2008). Defining Globalisation. World Economy, 31(11), 1471-1502.

Scholte, J. A. (2010). Governing a more global world. Corporate Governance, 10(4), 459-474.

Schuerkens, U. (2003). The Sociological and Anthropological Study of Globalization and Localization. Current Sociology, 51(3/4), 209-222.

Sen, A. (2002). Globalizzazione e libertà (Vol. 3). Milano: Mondadori.

Shaw, M. (1994). Global society and international relations. Cambridge: Polity Press.

Sklair, L. (1991). Sociology of the global system. London: Harvester Wheatsheaf.

Spangenberg, J. H. (2011). Sustainability science: a review, an analysis and some empirical lessons. Environmental Conservation, 38(03), 275-287.

Steffen, W., Broadgate, W., Deutsch, L., Gaffney, O., \& Ludwig, C. (2015). The trajectory of the Anthropocene: The Great Acceleration. The Anthropocene Review, 1-18. doi: 10.1177/2053019614564785 
Steffen, W., Richardson, K., Rockström, J., Cornell, S. E., Fetzer, I., Bennett, E. M., . . Sörline, S. (2015). Planetary Boundaries: Guiding human development on a changing planet. Science. doi: 10.1126/science. 1259855

Steffen, W., Sanderson, A., Tyson, P., Jäger, J., Matson, P. A., Moore III, B., . . Turner II, B. L. (2005). Global change and the earth system: a planet under pressure. Berlin: Springer.

Stern, D. I. (2004). The rise and fall of the environmental Kuznets curve. World Development, 32(8), 14191439.

Stiglitz, J. (2007). Making globalization work. New York: W.W. Norton.

Sturm, J.-E., \& De Haan, J. (2005). Determinants of long-term growth: New results applying robust estimation and extreme bounds analysis. Empirical Economics, 30(3), 597-617.

Tamazian, A., Chousa, J. P., \& Vadlamannati, K. C. (2009). Does higher economic and financial development lead to environmental degradation: evidence from BRIC countries. Energy policy, 37(1), 246-253.

Tamazian, A., \& Rao, B. B. (2010). Do economic, financial and institutional developments matter for environmental degradation? Evidence from transitional economies. Energy Economics, 32(1), 137145.

Taylor, P. (2004). World city network: a global urban analysis. London: Routledge.

Taylor, P., Catalano, G., \& Walker, D. R. (2002). Exploratory analysis of the world city network. Urban Studies, 39(13), 2377-2394.

Thompson, M., Ellis, R., \& Wildavsky, a. (1990). Cultural Theory. Boulder: Westview Press.

Tošić, N., Marinković, S., Dašić, T., \& Stanić, M. (2015). Multicriteria optimization of natural and recycled aggregate concrete for structural use. Journal of Cleaner Production, 87, 766-776.

Tukker, A., \& Butter, M. (2007). Governance of sustainable transitions: about the $4(0)$ ways to change the world. Journal of Cleaner Production, 15(1), 94-103.

UNEP. (2011). Towards a Green Economy. Pathways to Sustainable Development and Poverty Eradication. Nairobi, Kenya: UNEP.

UNEP. (2012a). Global Environment Outlook 5. Nairobi: United Nations Environment Programme (UNEP).

UNEP. (2012e). Measuring Progress: Environmental Goals \& Gaps. Nairobi: United Nations Environment Programme (UNEP).

COP Paris Agreement (2015).

Transforming our world: the 2030 Agenda for Sustainable Development (2015).

UNIDO. (2011). Networks for Prosperity: Achieving Development Goals through Knowledge Sharing Retrieved from https://www.unido.org/fileadmin/user_media/News/2011/UN\%20Report\%20LowRes.pdf

Urry, J. (2005). The complexities of the global. Theory, Culture \& Society, 22(5), 235-254.

Valkering, P., Tabara, J. D., Wallman, P., \& Offermans, A. (2009). Modelling cultural and behavioural change in water management: An integrated, agent based, gaming approach. The Integrated Assessment Journal, 9(1), 19-46. Retrieved from

Vallance, S., Perkins, H. C., \& Dixon, J. E. (2011). What is social sustainability? A clarification of concepts. Geoforum, 42, 342-348. Retrieved from: http://ac.els-cdn.com/S0016718511000042/1-s2.0S0016718511000042-main.pdf?_tid=45dfae7e-7088-11e5-942a00000aabOf01\&acdnat=1444616809_094046ac043b677ad7a3e19bda873311 doi:10.1016/j.geoforum.2011.01.002

VanGrasstek, C. (2013). The History and Future of the World Trade Organization Retrieved from https://www.wto.org/english/res_e/booksp_e/historywto_e.pdf

Verweij, M., Douglas, M., Ellis, R., Engel, C., Hendriks, F., Lohmann, S., . . . Thompson, M. (2006). Clumsy solutions for a complex world: the case of climate change. Public Administration, 84(4), 817-843.

Vujakovic, P. (2010). How to Measure Globalization? A New Globalization Index (NGI). Atlantic Economic Journal, 38(2), 237-237.

Wackernagel, M., \& Rees, W. (1996). Our Ecological Footprint: Reducing Human Impact on the Earth. Gabriola Island, BC: New Society Publishers.

Waters, M. (1995). Globalization: Key Ideas. London and New York: Routledge.

WEF. (2013). The global competitiveness report 2013-2014. Geneva: World Economic Forum.

Weinzettel, J., Hertwich, E. G., Peters, G. P., Steen-Olsen, K., \& Galli, A. (2013). Affluence drives the global displacement of land use. Global Environmental Change, 23(2), 433-438.

WHO. (2007). Towards Health-Equitable Globalisation: Rights, Regulation and Redistribution Geneva: World Health Organisation.

WHO, UNEP, \& CBD. (2015). Connecting Global Priorities: Biodiversity and Human Health. Geneva: WHO. 
World Bank. (2010). World Development Report 2010: Development and Climate Change. Washington DC: World Bank.

World Bank. (2014). World Development Indicators 2014. Retrieved from: http://data.worldbank.org/ products/wdi

WWF. (2014). Living Planet Report 2014: Species and Spaces, People and Places. published online.

Yang, H., He, J., \& Chen, S. (2015). The fragility of the Environmental Kuznets Curve: Revisiting the hypothesis with Chinese data via an "Extreme Bound Analysis". Ecological Economics, 109, 41-58.

York, R., Rosa, E. A., \& Dietz, T. (2003a). Footprints on the earth: The environmental consequences of modernity. American Sociological Review, 68(2), 279-300.

York, R., Rosa, E. A., \& Dietz, T. (2003h). STIRPAT, IPAT and ImPACT: analytic tools for unpacking the driving forces of environmental impacts. Ecological Economics, 46(3), 351-365.

Yu, Y., Feng, K., \& Hubacek, K. (2013). Tele-connecting local consumption to global land use. Global Environmental Change, 23(5), 1178-1186.

Zeng, K., \& Eastin, J. (2012). Do developing countries invest up? The environmental effects of foreign direct investment from less-developed countries. World Development, 40(11), 2221-2233. 


\section{Summary}

This thesis sets out on a research journey to quantitatively assess the sustainability of globalization and to gain insights into the main research question 'to what extent is globalization as a process and policy discourse sustainable?'

Chapter one introduces the concept of sustainable development (SD), which encompasses the social, economic and ecological pillars. The social pillar considers health, justice, equity, equality, and education; the economic pillar includes affluence, income and wealth; and the ecological one demands that socio-economic development does not threaten the integrity of ecological systems. This thesis follows Griggs et al. (2013) definition of SD as "development that meets the needs of the present while safeguarding Earth's life support system, on which the welfare of current and future generations depends". Hence, we define sustainable globalization as a form of globalization that is socially robust and contributes (positively) to the three pillars of sustainable development: the economic, the social and ecological. We put forward an interdisciplinary quantitative assessment of globalization that looked at four main issues: definition and measurement, recent trends, its consequences on (ecological) sustainability and the social robustness of globalization as a policy discourse.

Chapter two discusses the measurement of globalization with a view to advancing the construction of globalization indices. It critically analyzes the types of indices that can contribute to knowledge and policy on globalization. Three issues are particularly highlighted: (a) the focus of measurement (i.e. on activities or policies); (b) the dimensions of measurement (i.e. cultural, ecological, economic, political and/or social); and (c) the units of measurement (i.e. local, national, regional and/or global). The chapter argues that a workable forward strategy should not seek to identify a single best composite globalization index, but should rather work in an interdisciplinary mode towards a set of complementary approaches. These quantitative analyses can then be productively integrated with qualitative approaches in a fuller assessment of globalization's extent and impact.

Chapter three introduces the Maastricht Globalization Index (MGI) in detail, elaborating on its indicators and revised calculation method, and presents the results of the updated 2012 edition. This provides an assessment of the state and trends of globalization between 2000 and 2012 for 117 countries. The evidence shows that in this period, globalization slowed down but nevertheless continued to increase. The MGI makes clear that countries differ greatly in their degrees of globalization. Moreover, the evi- 
dence also indicates that the least globalized countries are not catching up to the more globalized ones.

Chapter four builds on chapter three and extends the data coverage of the MGI to 181 countries by employing imputation methods. We further review the evidence regarding the consequences of globalization. Previous literature has shown that globalization has contributed to the social and economic dimensions of sustainable development - enhancing economic growth, health, human development, integrity rights and gender equality. However, evidence about the effects of globalization on the ecological environment has not provided clear patterns; for instance, different dimensions of globalization have differnt effects on various pollutants. This chapter finds that ecological indicators, in particular Ecological Footprints, have been absent from the existing literature. Hence, this chapter analyzes the statistical relationship between the most recent MGI (2012 edition) and four variants of the Ecological Footprint. The relation between globalization and sustainable development is controlled for by GDP per capita as a proxy for affluence. We report the results for Pearson correlations and multivariate regressions for up to 171 countries. We conclude that the overall index of globalization significantly increases the Ecological Footprint of consumption, exports and imports. The decomposition of globalization into different domains reveals that apart from the political dimension, all dimensions drive human pressures and demands on the environment.

Chapter five goes further and employs the KOF-index of globalization, to develop an unbalanced data set covering 146 countries for the period 1981-2009. We are thus able to address the influence of countries' development over time, by controlling for country and time-fixed effects. After empirically showing that globalization is an explanatory factor of Ecological Footprints, rather than the other way around, we employ an Extreme Bounds Analysis (EBA) to identify a robust set of determinants, out of 29 potential drivers. Subsequently, we consider specifically the multiple dimensions of globalization and test specific hypotheses on economic, political, social and overall globalization. We find that economic globalization drives the EF of consumption, production, imports and exports. Social globalization correlates negatively with the EF of consumption and production, while increasing the EF of imports and exports. The findings show that globalization may have different effects on EFs, depending on the dimension (consumption, production, exports and imports) one refers to.

Chapter six explores the sustainability of globalization by analyzing its 'social robustness'. It argues that to be considered sustainable, a policy, trend or process should be acceptable to a broad range of people in society. A text and discourse analysis, based on Cultural Theory, demonstrates a general imbalance of perspectives across various policy reports and documents on three core themes of global governance: climate 
change, the economy and well-being. With the results of this analysis we contribute towards a more inclusive discussion on global issues that matter in the context of a sustainable future for all. We believe that a more socially robust form of globalization is possible, but only if marginalized perspectives are included in the policy debates and thereby able to contribute to solving humanity's most pressing issues.

Chapter seven answers the research questions and finds "a world out of balance" as the emerging qualification for all four issues of globalization: definition and measurement, recent trends, its consequences on (ecological) sustainability and the social robustness of globalization as a policy discourse. Hence, the thesis concludes that globalization, as a process and policy discourse is not sustainable in its recent form and that it needs to go into new directions if it is to contribute towards all aspects of sustainable development. 


\section{Valorization addendum}

\section{Introduction}

The aim of such a PhD thesis is to ask relevant questions about important problems and then find, develop and use the right tools and methods to find answers, build knowledge and gain insights. This is inherently a very philosophical endeavor since a $\mathrm{PhD}$ thesis explores ontological and epistemological questions about Reality and Truth. What is it? How can we know, experience and explain this Reality? The assumption or belief that Reality is knowable, whether in a positivist or constructivist manner is the fundamental premise of science. Of course, science and research in practice deal with more "applied" problems and questions about the physical-natural and/or socialcultural world. Yet, it is placed within this greater philosophical discourse which makes science intrinsically valuable.

According to Wikipedia, science is the systematic enterprise that builds and organizes knowledge in the form of testable explanations and predictions about the universe. So by doing science we connect and become a part of a scientific community that is bigger than our Selves, the first is the scientific community, which in itself is part of society and beyond this, we become an integral part of the universe. If you manage to overcome the dualistic way of thinking, which divides the world into subjects and objects, you come to the conclusion that we are the universe experiencing, knowing and understanding itself. So science to me is also inherently a transcendental activity and therefore places the individual scientist and a PhD thesis in a much larger scheme of things.

Further, the researcher can be defined as a knowledge builder fighting ignorance. And yes, we believe that enlightened knowledge has the power to reduce ignorance and to make vital contributions to well-being and happiness. Specifically Sustainability Science aims to do so, by addressing some of the most difficult, universal and complex problems facing humanity and the planet. This is our calling, our purpose, our service.

Dealing with the most pressing global and universal issues humanity is facing, such as climate change, biodiversity loss, water scarcity, resource degradation, overfishing, desertification, deforestation and of course also inequality and poverty which are inherently related to environmental issues can be quite depressing at times. Those problems operate at scales much bigger than us and under governance regimes, which seem incapable to address those effectively - future prospects often seem bleak. And we know that solving our problems today will only create a new set of problems in the future that needs further problem-solving. This poses psychological and emotional 
challenges which are not to be neglected, however, hardly ever openly discussed. Each of us has to find his or her ways of dealing with them.

Yet, we hold a very privileged position in this world. Not only do we have fascinating and fulfilling jobs, but we hold great intellectual capacity and knowledge. Knowledge is power; and "with great power comes great responsibility". We are not doing this for us, we are doing this for society, especially those who are the most deprived and vulnerable, who are less fortunate and knowledgeable than us.

Hence, the need for a valorization chapter, which more specifically lays out how the knowledge of this thesis may trickle down into and benefit society. Knowledge valorization is defined as the "process of creating value from knowledge by making knowledge suitable and/or available for social (and/or economic) use and by making knowledge suitable for translation into competitive products, services, processes and new commercial activities" (as defined in the regulation governing the attainment of doctoral degrees at Maastricht University).

\section{What is the social relevance of the research results?}

This thesis was driven by curiosity to grasp what is going on with our (global) civilization. Hence, I took at broad and systemic perspective on global change, trying to understand the interrelations of drivers and pressures that are affecting this planet and humanity. I believe that that this understanding is relevant for decision making processes.

This thesis employed macro level compounded indicators of globalization and human demands that include and capture many issues at once. The advantage is that one gets a good understanding of macro trends, but a shortcoming is that the findings are not directly relevant for actual policy development, implementation and monitoring at regional and national scales. Globalization as operationalized in this thesis is a nonpolicy issue that spans multiple policy scales, actors and domains and is as such not really governable. I argue however, that the results are crucial and relevant for the early stages of a policy cycle: problem definition, agenda setting and issue framing. At this stage, policy makers and decision makers need to grasp the context (or landscape) in which they operate and build political will around issues. Further, causes and potential solutions are identified (Galli, 2015).

The results have shown that globalization in its recent form has not been sustainable and socially robust. We have identified the effects of globalization on human demands and further identified the statistically robust determinants of the Ecological Footprint 
(and hence Ecological Overshoot). The results suggest that those are potential leverage points for intervention, and looking deeper into how those could be affected by policy seems worthwhile. However, the results on globalization, drivers and social robustness need to be consolidated, extended and integrated with other findings and should not be considered in isolation. I will now turn to discussing some first ideas for potential products and services, which could function as channels for knowledge dissemination.

\section{Potential products and services}

The results have been published in four international and peer-reviewed journal articles with one more in the making. This means that this traditional channel has already been exploited to the fullest.

Other globalization indices have a webpage, where data, reports, summaries and press releases are made available (e.g. DHL Connectedness Index and KOF index). This is one possibility that we have not made use of. Another update of the MGI would be in order, which could then be published online. One aspect that would be innovative is a "build your own index" feature, as has been available for the Human Development Index, for instance. Users and researchers could create their own Globalization index, by choosing indicators and weights themselves, which they could then compare to the original MGI. A further idea is to create a meta-webpage for globalization indices that brings together and integrates information and data from various indices. Respective pages on Wikipedia could be updated with the knowledge of this thesis, in order to make it available to the public.

The consequences of globalization have been reported in a book in 2008 (Dreher et al., 2008). Clearly, the quantitative literature has much advanced since then, and a new (and cheaper!) edition of this book would certainly be worthwhile for academics, decision makers and students. Such a book would put the results into a larger context of social, economic, political and ecological consequences. Such an effort should specifically aim to reveal the (numerical) trade-offs of globalization, as it certainly has positive and negative consequences. The review by Potrafke (2014) would be a good starting point for this.

Further, the results on the ecological consequences of globalization and the determinants of the Ecological Footprint would benefit from being further processed into realistic and practical policy recommendations. Here I see two possibilities. First, these findings could be integrated into reports by several think tanks. For instance, the findings could be relevant for the chapter on drivers of global change of the forthcoming World Environment Outlook 6 by UNEP. Another relevant report is the Living Planet 
Report, which is published every other year by the World Wide Fund for nature (WWF). Second, scenario workshops on 'the future of globalization' could be organized with policy think tanks, such as the OECD, WEF or the WorldBank. A new narrative vision and practical policy agenda to advance a sustainable (and socially-robust) form of globalization could be developed and published as policy briefs or in the form of a white paper.

Regarding the work on social robustness, I envision an extension of the empirical analysis that spans more policy documents (50-100), organizations, policy domains and years. The results could be reported online, including a report with profiles for each individual document, executive summaries, policy briefs, etc. Extending the analysis to more years would allow tracking cultural trends and shifts over time. Another option could be to develop an automated web-based platform which allows users to upload documents. The platform would then do the analysis and produce a standardized report. This could also be commercialized by offering further analytic and consulting services on socially robust policy. Such a service would ideally be co-developed with a relevant policy think tank that has the relevant expertise and clients. Potential candidates could be IIASA, the New Economics Foundation, Adelphi and Heinrich Böll Foundation.

The topics and knowledge of this thesis are quite complex and as such inaccessible for non-experts. One of the greatest challenges in science communication is to simplify complex and complicated matters in such a way that they are easily understandable to the wider public. Here I see two possibilities, the first one is a popular science book, the second is a novel. For instance, with Animal Farm, George Orwell brought across the wicked story of the rise and fall of socialism in Russia. Cultural Theory could be used, for instance, to construct the main characters for an 'Animal Farm of the $21^{\text {st }}$ century', which tells the wicked rise (and fall!?) of globalization.

In addition to the scientific results, I have learned a lot about personal development and empowerment throughout my PhD trajectory. I had my fair share of personal and professional challenges, which most PhD candidates have to go through. Further, I had to find my way to master the psychological challenge of facing the sustainability problems of our times on a daily basis. In the process, I have explored tools and methods of personal development and empowerment (coaching, mindfulness etc.) to deal with and overcome those challenges. I have kept track of my journey in the form of journals which I may develop into an autobiographic book. Further, I have already developed and implemented two Erasmus+ trainings to empower young change makers to be the change they want to see in this world and started coaching PhD candidates. This I will further pursue in the future. 


\section{Acknowledgements}

What a journey this has been. Doing a PhD is not a walk in the park; it's rather a crazy road trip into the unknown, with all kinds of challenges, difficulties, breakdowns, but also breakthroughs, moments of success and progress. What doesn't kill you makes you stronger. Fortunately, this has not been a solitary adventure.

First, I want to express my gratitude and appreciation for my promoter, Pim Martens. Thank you for the trust, support and freedom that characterize your supervision. And while challenging at times, I see now how this has contributed to my development as an independent academic. Your guidance was wise and crucial to the success of this project. Astrid Offermans, my second supervisor, thank you for your honest, critical and in-depth feedback and guidance - this is why I chose to get you on board. You really challenged me up to the last draft, keeping me on my toes. Both of you, thank you for your patience and unconditional approachability.

Second, my gratitude goes to all my (other) co-authors, whose fingerprints are all over this thesis: Marco Caselli, Philippe de Lombaerde, Jan-Aart Scholte, Kay Oebels, Alexandra Rudolph, James Elliott and Carijn Beumer. It was an honor to collaborate with you on the articles, which form the basis for this thesis. Thanks also to the journal editors, reviewers, the assessment committee and the opponents.

What would an individual be without the nurturing environment? I have experienced ICIS as a very kind and warm environment. Special thanks to Ron, Su-Mia and Carijn, our conversations were crucial for getting me into ICIS in the first place. Thanks also to my (former) PhD colleagues for sharing the struggles: Julia, Sjouke, Ceren, Alex, Laura, Bram, Martina, Jing, Bingtao, Joana, Ibnu, Esther, Nia and Atika. Annet, Anja and Saskia, thanks for the administrative support. Further thanks for support go to Joop, Marc and Pieter (Valkering).

I also had the privilege of making very valuable experiences away from my home base. Thanks to Axel Dreher and Alexandra Rudolph for your collaboration and hosting me at Heidelberg University, which made the KOF chapter possible. Thanks to everyone at IIASA and the 2014 YSSP: Matthias and Oskar for the supervision; Brian, Joanne, Aleks and Tanja for running the program and making this an incredible experience; thanks also to Mike, the ASA group, and all the participants for the engaging presentations and discussions. Special thanks to Thomas, Edoardo, Mikko and Fabian for our little side project on the big five challenges. 
This research would not have been possible without the generous data contribution and training opportunity by the Global Footprint Network. Thanks to Mathis Wackernagel and his team for the inspiring work and partnership.

In addition to the professional, there is also the personal context that makes a great PhD experience. Thanks to my dear friends and roomies Philipp, Alex, Tobi and Joscha for enriching my life, especially in the beginning years. Thanks to Dominique and rootAbility, especially to Felix and Tim, for the companionship and giving me the opportunity to develop myself as a trainer and social entrepreneur. Our training projects gave me a much needed feeling to have a more immediate impact on this world, than my PhD has had.

What would a PhD be without multiple existential crises? Thanks for nurture, healing and support go to: Saint James, all my fellow pilgrims and hospitaleros of the various Caminos; the Pietersberg - you are my sanctuary in Maastricht; Plum Village and the Wake Up Sangha Maastricht, especially Jendrik, Susan, Andreas and Lilli for getting it started; and the trainers and fellow trainees at Creative Consciousness.

Thanks to my parents and family for the unconditional love and support throughout my life. You never told me what and how to do, thanks for the freedom, generosity, kindness and support that made me who I am today. I know I can always count on you.

Last, but not least, thanks to my partner, Carolin Muschalik, for the companionship and love throughout the last three years. Your love gives me comfort, support and confidence. Your companionship gives me stability, joy and trust.

Thanks also to the Universe, Gaia and God for guidance and inspiration. 


\section{About the author}

Lukas Figge was born on 12 May 1986 in Heppenheim, Germany. He came to Maastricht University in 2007 to start a Bachelor in International Economic Studies. He spent one semester as an exchange student at the Universidad del Pacifico in Lima, Peru and graduated thereafter in the summer of 2010. Lukas then entered the Master in Public Policy and Human Development at the Maastricht Graduate School of Governance and pursued a specialization in Sustainable Development. During this time, he was also the president of Demos, the study association of the program, and represented the student body in the education committee. He completed the Master in November 2011 with a thesis on 'Who is responsible and accountable for the environmental degradation and human misery in the Niger Delta, Nigeria?'.

Thereafter, Lukas started working as a PhD researcher at the International Centre for Integrated assessment and Sustainable development (ICIS) in December 2011 under the supervision of Pim Martens and Astrid Offermans. The PhD research was conducted in cooperation with the Global Footprint Network (Oakland, CA) and the Chair of International and Development Politics at Heidelberg University, where he spent a total of six weeks. He was awarded a scholarship for the Young Scientists Summer Program (YSSP) and spent three months at the International Institute for Applied Systems Analysis (IIASA, Laxenburg, Austria) in 2014. Lukas lectured and tutored in the undergraduate courses on 'Globalization, Environmental Change and Society' at the University College Maastricht and the Master courses on Global Dynamics, 'Basic Modeling' and 'Academic Writing and Presenting' at ICIS in the years 2012-2015.

In addition to the PhD, Lukas joined rootAbility as a trainer beginning of 2015 to empower students to make universities sustainable with the GreenOffice model. Later that year, rootAbility was awared the UNESCO-Japan price on Education for Sustainable Development for its outstanding work. In 2016, Lukas successfully co-developed and implemented two editions of the Inner Leadership Training, a 5 day transformative journey for change makers as Erasmus+ projects. In June 2017, he graduated from the Creative Consciousness Academy Master Curriculum and qualified as a Professional Consciousness Coach.

As of September 2017, Lukas works as Lecturer at the Department of Organization and Strategy at the Maastricht School of Business and Economics, while continuing coaching and training PhD candidates and young change makers under his own Business ResponseAbility. 